Cochrane Database of Systematic Reviews

\title{
Surgical hand antisepsis to reduce surgical site infection (Review)
}

Tanner J, Dumville JC, Norman G, Fortnam M

Tanner J, Dumville JC, Norman G, Fortnam M.

Surgical hand antisepsis to reduce surgical site infection.

Cochrane Database of Systematic Reviews 2016, Issue 1. Art. No.: CD004288.

DOI: 10.1002/14651858.CD004288.pub3.

www.cochranelibrary.com 
TABLE OF CONTENTS

HEADER 1

ABSTRACT

PLAIN LANGUAGE SUMMARY

BACKGROUND

OBJECTIVES

METHODS

RESULTS

Figure 1.

Figure 2.

DISCUSSION

AUTHORS' CONCLUSIONS

ACKNOWLEDGEMENTS

REFERENCES

CHARACTERISTICS OF STUDIES

DATA AND ANALYSES

Analysis 1.1. Comparison 1 basic hand hygiene versus alcohol rub, Outcome $1 \mathrm{SSI}$.

Analysis 2.1. Comparison 2 chlorhexidine versus iodine, Outcome 1 CFUs.

Analysis 3.1. Comparison 3 chlorhexidine versus iodine plus triclosan, Outcome 1 CFUs.

Analysis 4.1. Comparison 4 alcohol rub versus other alcohol rub, Outcome 1 CFUs.

Analysis 5.1. Comparison 5 scrub versus alcohol-only rub, Outcome $1 \mathrm{SSI}$.

Analysis 6.1. Comparison 6 scrub versus alcohol rub, Outcome $1 \mathrm{SSI}$.

Analysis 7.1. Comparison 7 scrub (chlorhexidine) versus alcohol rub + additional ingredient, Outcome 1 CFUs. ......................

Analysis 8.1. Comparison 8 scrub (povidone iodine) versus alcohol rub + additional ingredient, Outcome 1 CFUs.

Analysis 9.1. Comparison 9 scrub (chlorhexidine) versus rub + additional ingredient, Outcome 1 CFUs.

Analysis 10.1. Comparison 10 scrub (chlorhexidine) versus alcohol rub + additional ingredient, Outcome 1 CFUs.

Analysis 11.1. Comparison 11 duration - Kappstein (5 minutes versus 3 minutes), Outcome 1 CFUs immediately after antisepsis.

Analysis 12.1. Comparison 12 duration $-5+3$ min versus $3+0.5$ min with chlorhexidine), Outcome 1 CFUs.

Analysis 13.1. Comparison 13 duration $-5+3$ min versus $3+0.5$ minutes with iodine), Outcome 1 CFUs.

Analysis 14.1. Comparison 14 duration $-5+3.5$ min versus $3+2.5$ min chlorhexidine), Outcome 1 CFUs.

Analysis 15.1. Comparison 15 scrub versus scrub plus brush, Outcome 1 CFUS.

Analysis 16.1. Comparison 16 scrub versus scrub plus nail pick, Outcome 1 CFUs.

Analysis 17.1. Comparison 17 scrub plus brush versus scrub plus nail pick, Outcome 1 CFUs.

ADDITIONAL TABLES

APPENDICES

FEEDBACK

WHAT'S NEW

HISTORY

CONTRIBUTIONS OF AUTHORS

DECLARATIONS OF INTEREST

SOURCES OF SUPPORT

DIFFERENCES BETWEEN PROTOCOL AND REVIEW

INDEX TERMS 
[Intervention Review]

\section{Surgical hand antisepsis to reduce surgical site infection}

Judith Tanner ${ }^{1}$, Jo C Dumville², Gill Norman², Mathew Fortnam³

1School of Health Sciences, University of Nottingham, Nottingham, UK. 2 School of Nursing, Midwifery and Social Work, University of Manchester, Manchester, UK. ${ }^{3}$ Cochrane Wounds Group, University of York, York, UK

Contact address: Judith Tanner, School of Health Sciences, University of Nottingham, Queens Medical Centre, Nottingham, NG7 2HA, UK.judith.tanner@nottingham.ac.uk.

Editorial group: Cochrane Wounds Group.

Publication status and date: New search for studies and content updated (no change to conclusions), published in Issue 1, 2016.

Citation: Tanner J, Dumville JC, Norman G, Fortnam M. Surgical hand antisepsis to reduce surgical site infection. Cochrane Database of Systematic Reviews 2016, Issue 1. Art. No.: CD004288. DOI: 10.1002/14651858.CD004288.pub3.

Copyright @ 2016 The Cochrane Collaboration. Published by John Wiley \& Sons, Ltd.

\section{A B S T R A C T}

\section{Background}

Medical professionals routinely carry out surgical hand antisepsis before undertaking invasive procedures to destroy transient microorganisms and inhibit the growth of resident micro-organisms. Antisepsis may reduce the risk of surgical site infections (SSIs) in patients.

\section{Objectives}

To assess the effects of surgical hand antisepsis on preventing surgical site infections (SSIs) in patients treated in any setting. The secondary objective is to determine the effects of surgical hand antisepsis on the numbers of colony-forming units (CFUs) of bacteria on the hands of the surgical team.

\section{Search methods}

In June 2015 for this update, we searched: The Cochrane Wounds Group Specialized Register; The Cochrane Central Register of Controlled Trials (CENTRAL) (The Cochrane Library); Ovid MEDLINE; Ovid MEDLINE (In-Process \& Other Non-Indexed Citations) and EBSCO CINAHL. There were no restrictions with respect to language, date of publication or study setting.

\section{Selection criteria}

Randomised controlled trials comparing surgical hand antisepsis of varying duration, methods and antiseptic solutions.

\section{Data collection and analysis}

Three authors independently assessed studies for inclusion and trial quality and extracted data.

\section{Main results}

Fourteen trials were included in the updated review. Four trials reported the primary outcome, rates of SSIs, while 10 trials reported number of CFUs but not SSI rates. In general studies were small, and some did not present data or analyses that could be easily interpreted or related to clinical outcomes. These factors reduced the quality of the evidence.

\section{SSIs}

One study randomised 3317 participants to basic hand hygiene (soap and water) versus an alcohol rub plus additional hydrogen peroxide. There was no clear evidence of a difference in the risk of SSI (risk ratio (RR) $0.97,95 \% \mathrm{Cl} 0.77$ to 1.23 , moderate quality evidence downgraded for imprecision). 
One study (500 participants) compared alcohol-only rub versus an aqueous scrub and found no clear evidence of a difference in the risk of $\mathrm{SSI}$ (RR $0.56,95 \% \mathrm{Cl} 0.23$ to 1.34 , very low quality evidence downgraded for imprecision and risk of bias).

One study (4387 participants) compared alcohol rubs with additional active ingredients versus aqueous scrubs and found no clear evidence of a difference in SSI (RR 1.02, $95 \% \mathrm{Cl} 0.70$ to 1.48 , low quality evidence downgraded for imprecision and risk of bias).

One study (100 participants) compared an alcohol rub with an additional ingredient versus an aqueous scrub with a brush and found no evidence of a difference in SSI (RR $0.50,95 \% \mathrm{Cl} 0.05$ to 5.34, low quality evidence downgraded for imprecision).

\section{CFUs}

The review presents results for a number of comparisons; key findings include the following.

Four studies compared different aqueous scrubs in reducing CFUs on hands.Three studies found chlorhexidine gluconate scrubs resulted in fewer CFUs than povidone iodine scrubs immediately after scrubbing, 2 hours after the initial scrub and 2 hours after subsequent scrubbing. All evidence was low or very low quality, with downgrading typically for imprecision and indirectness of outcome. One trial comparing a chlorhexidine gluconate scrub versus a povidone iodine plus triclosan scrub found no clear evidence of a difference-this was very low quality evidence (downgraded for risk of bias, imprecision and indirectness of outcome).

Four studies compared aqueous scrubs versus alcohol rubs containing additional active ingredients and reported CFUs. In three comparisons there was evidence of fewer CFUs after using alcohol rubs with additional active ingredients (moderate or very low quality evidence downgraded for imprecision and indirectness of outcome). Evidence from one study suggested that an aqueous scrub was more effective in reducing CFUs than an alcohol rub containing additional ingredients, but this was very low quality evidence downgraded for imprecision and indirectness of outcome.

Evidence for the effectiveness of different scrub durations varied. Four studies compared the effect of different durations of scrubs and rubs on the number of CFUs on hands. There was evidence that a 3 minute scrub reduced the number of CFUs compared with a 2 minute scrub (very low quality evidence downgraded for imprecision and indirectness of outcome). Data on other comparisons were not consistent, and interpretation was difficult. All further evidence was low or very low quality (typically downgraded for imprecision and indirectness).

One study compared the effectiveness of using nail brushes and nail picks under running water prior to a chlorhexidine scrub on the number of CFUs on hands. It was unclear whether there was a difference in the effectiveness of these different techniques in terms of the number of CFUs remaining on hands (very low quality evidence downgraded due to imprecision and indirectness).

\section{Authors' conclusions}

There is no firm evidence that one type of hand antisepsis is better than another in reducing SSIs. Chlorhexidine gluconate scrubs may reduce the number of CFUs on hands compared with povidone iodine scrubs; however, the clinical relevance of this surrogate outcome is unclear. Alcohol rubs with additional antiseptic ingredients may reduce CFUs compared with aqueous scrubs. With regard to duration of hand antisepsis, a 3 minute initial scrub reduced CFUs on the hand compared with a 2 minute scrub, but this was very low quality evidence, and findings about a longer initial scrub and subsequent scrub durations are not consistent. It is unclear whether nail picks and brushes have a differential impact on the number of CFUs remaining on the hand. Generally, almost all evidence available to inform decisions about hand antisepsis approaches that were explored here were informed by low or very low quality evidence.

\section{PLAIN LANGUAGE SUMMARY}

\section{Surgical hand antisepsis to reduce surgical site infection}

\section{What are surgical site infections and who is at risk?}

The inadvertent transfer of micro-organisms such as bacteria to a patient's wound site during surgery can result in a wound infection that is commonly called a surgical site infection (SSI). SSIs are one of the most common forms of health care-associated infections for surgical patients. Around 1 in 20 surgical patients develop an SSI in hospital, and this proportion rises when people go home. SSIs result in delayed wound healing, increased hospital stays, increased use of antibiotics, unnecessary pain and, in extreme cases, the death of the patient, so their prevention is a key aim for health services.

\section{Why use hand antisepsis prior to surgery?}

There are many different points in the care pathway where prevention of SSIs can take place. This includes antiseptic cleansing of the hands for those who are operating on the patient. Surgical hand antisepsis is the focus of this review. The two most common forms of hand antisepsis involve aqueous scrubs and alcohol rubs. Aqueous scrubs are water-based solutions containing antiseptic ingredients such as chlorhexidine gluconate or povidone iodine. Scrubbing involves wetting the hands and forearms with water, systematically applying an aqueous scrub solution using either hands or sponges, rinsing under running water and then repeating this process. Alcohol solutions containing additional active ingredients are used to perform an 'alcohol rub'. Surgical teams systematically apply the alcohol rub solutions to their hands and allow it to evaporate. Alcohol is effective against a wide range of bacteria and other micro-organisms. Following hand 
antisepsis, operating staff then put on gloves, which provide an important barrier between operating staff and the patient; however, because gloves can become perforated during surgery, it is necessary to have hands as germ-free as possible.

\section{What we found}

In June 2015 we searched for as many relevant studies that had a robust design (randomised controlled trials) as we could find and compared different types of hand antisepsis before surgery. We included 14 studies that compared a range of methods for performing surgical hand antisepsis. The two measures used to assess the effectiveness of treatments were the number of cases of SSIs in patients (presented in four included studies) and the number of viable bacteria or fungal cells (known as colony-forming units, or CFUs) on the hand of the person operating before surgery and after surgery (which is a way of counting the bacteria present on the skin surface). It is not clear whether the method of hand antisepsis influences the risk of SSI, as most of the studies were too small and had flaws. There was some evidence that hand antisepsis with chlorhexidine may reduce the number of bacteria on the hands of health professionals compared with povidone iodine. Importantly, we do not know what the number of CFUs on the hands tells us about the likelihood of patients developing SSIs. There was also some evidence that alcohol rubs with additional antiseptic ingredients may reduce CFUs compared with aqueous scrubs.

Up-to-date June 2015 


\section{B A C K G R O U N D}

The inadvertent transfer of micro-organisms to patients' wound sites during surgery can result in postoperative surgical site infections (SSIs). SSIs are one of the most common forms of healthcare-associated infections for surgical patients (NICE 2008). Around $5 \%$ of surgical patients develop an SSI (NICE 2008), though this incidence can double when surveillance includes active postdischarge follow-up (Leaper 2015). SSIs result in delayed wound healing, increased hospital stays, increased use of antibiotics, unnecessary pain and, in extreme cases, the death of the patient (Plowman 2000).

Micro-organisms that cause SSIs come from a variety of sources within the operating room, including the hands of the surgical team. Members of the surgical team wear sterile gloves to prevent transferring bacteria from their hands to patients. However, gloves can become perforated during surgery, so it is necessary to have hands as germ-free as possible. This is achieved by conducting surgical hand antisepsis immediately before donning sterile gloves prior to commencing surgical or invasive procedures. While handwashing removes transient micro-organisms, surgical hand antisepsis goes a step further to inhibit the growth of resident microorganisms, thereby minimising the risk of a patient developing an SSI (WHO 2009).This is achieved using antiseptic agents that kill and inhibit bacteria, fungi, protozoa and bacterial spores. An ideal antiseptic agent would be fast-acting, persistent (effective for a number of hours), cumulative (repeated exposure inhibits bacterial growth for a number of days), have a broad spectrum of activity and be safe to use.There are several individual components of surgical hand antisepsis, including the pre-wash; the application technique; the use of sponges, brushes or nail picks; the choice of antiseptic solution and the duration of the antisepsis.

\section{Defining terms - scrub and rubs}

Several different terms are used when describing surgical hand antisepsis. Antisepsis with running water and an aqueous solution is referred to as a surgical or a traditional scrub. Antisepsis with an alcohol solution is referred to as an alcohol rub or a waterless scrub. In this review, we understand surgical hand antisepsis to encompass both methods of surgical antisepsis: scrubbing and rubbing. The very first antisepsis of the day is referred to as the initial antisepsis. Scrubs or rubs performed thereafter but on the same day are referred to as subsequent antisepses.

\section{Surgical hand antisepsis - current practice}

The Association for Perioperative Practice (AfPP) recommends a pre-wash prior to the first antisepsis of the day, when hands are washed with soap or an antimicrobial solution under running water (AfPP 2011). The function of the pre-wash is to remove dirt (organic material). AfPP 2011 then recommends cleaning nails using a pick under running water. Clinicians can then perform antisepsis using either an antimicrobial solution with running water, referred to as a traditional scrub, or an alcoholic rub without water. AfPP 2011 suggests alcohol rubs are more effective in reducing bacteria on the skin but should not be used if there is visible dirt present. The AfPP does not cite any specific antimicrobial solution as being the most effective, but, like many other organisations, recommends that the solution chosen meets the ideal properties for an antimicrobial solution (ACORN 2012; AORN 2010; WHO 2009). These properties are identified by the Centers for Disease Control and Prevention (CDC) as the solution being:

- fast-acting.

- persistent (effective for a number of hours);

- cumulative (repeated exposure inhibits bacterial growth for a number of days);

- having a broad spectrum of activity; and

- safe to use (CDC 2002).

AfPP 2011 recommends a duration of 2 to 5 minutes (depending on manufacturers instructions) for a traditional scrub, but does not provide details on the recommended duration of an alcoholic rub. There is some discrepancy regarding aspects of hand antisepsis between different organisations. For example, the World Health Organization (WHO) and the Australian College of Operating Room Nurses (ACORN) only recommend a pre-wash if hands are visibly dirty (ACORN 2012; WHO 2009), and ACORN 2012 recommends that the first scrub of the day last 5 minutes while subsequent scrubs last 3 minutes. Nail brushes no longer appear to be recommended as these can damage skin (ACORN 2012; AfPP 2011; AORN 2010; WHO 2009).

Guidelines for surgical antisepsis also cover topics such as rings, artificial nails and nail polish (AORN 2010; ACORN 2012; AfPP 2011; HIS 2001; Mangram 1999). The impact of these factors on SSI is the focus of another Cochrane review (Arrowsmith 2014). There are concerns that hand antisepsis causes skin damage to staff hands and that some products are more abrasive than others (Larson 1986b). This topic is outside the remit of this review.

\section{Surgical hand antisepsis solutions}

Solutions for hand antisepsis are either aqueous (water) based or alcohol based.

\section{Aqueous scrubs}

Aqueous scrubs are water based solutions containing active ingredients that are used during traditional handscrubs. The most common solutions contain chlorhexidine gluconate or povidone iodine (see below). Scrubbing involves wetting the hands and forearms with water, systematically applying an aqueous scrub solution using either hands or sponges, rinsing under running water and then repeating the process.

\section{Alcohol rubs}

Alcohol-based solutions are used to perform an 'alcohol rub'. Health professionals apply the solution to dry hands and then rub them together systematically before allowing the solution to evaporate. Alcohol rubs do not require water for their application. Some alcohol rub solutions contain additional active antiseptic agents.

\section{Antiseptic agents}

\section{Alcohol}

Alcohols have little or no residual effect, and the concentration rather than the type of alcohol is thought to be most important in determining its effectiveness (Larson 1995). Alcohol rubs are usually available in preparations of $60 \%$ to $90 \%$ strength and are effective against a wide range of gram-positive and gram negative bacteria, mycobacterium tuberculosis, and many fungi and viruses. The three main alcohols used are ethanol, isopropanol 
and $\mathrm{n}$-propanol, and some rubs may contain a mixture of these. Compared with other common antiseptic products, alcohol is associated with the most rapid and greatest reduction in microbial counts (Lowbury 1974a), but it does not remove surface dirt as it does not contain surfactants or have a foaming action (Hobson 1998). Alcohol-based solutions usually (but not always) contain additional active ingredients to combine the rapid bacteriocidal effect of alcohol with more persistent chemical activity.

\section{lodine and iodophors}

lodine has mostly been replaced by iodophors, as iodine often causes irritation and discolouring of skin. lodophors are composed of elemental iodine, iodide or triiodide, and a polymer carrier of high molecular weight (WHO 2009). Combining iodine with various polymers increases the solubility of iodine, promotes sustained release of iodine and reduces skin irritation. lodophors are effective against a wide range of gram-positive and gram negative bacteria, mycobacterium tuberculosis, fungi and viruses (Joress 1962). lodophors contain iodine with a carrier such as polyvinylpyrrolidone (PVP). PVP, also known as povidone, is a polymer that detoxifies and prolongs the activities of drugs. PVP prolongs the activity of iodine by releasing it slowly. A combination of PVP and iodine, known as povidone iodine (PI), is less irritating than earlier solutions of iodine tincture (Joress 1962). lodophors rapidly reduce transient and colonising bacteria but have little or no residual effect (Larson 1990).

\section{Chlorhexidine}

Chlorhexidine is a biguanide. It is effective against a wide range of gram-positive and gram-negative bacteria, lipophilic viruses and yeasts (Hibbard 2002a). It is not sporicidal. Although its immediate antimicrobial activity is slower than that of alcohols, it is more persistent because it binds to the outermost layer of skin, the stratum corneum (Larson 1990). Over time, repeated exposure can lead to a cumulative effect where both transient and resident organisms are reduced (Larson 1990). Chlorhexidine gluconate is effective in the presence of blood and other protein-rich biological materials (Hibbard 2002a).

\section{Quaternary ammonium compounds}

Quaternary ammonium compounds (QACs) are composed of a nitrogen atom linked to four alkyl groups. Alkyl benzalkonium chlorides are the most widely used as antiseptics, though other compounds include benzethonium chloride, cetrimide and cetylpyridium chloride. QACs are primarily bacteriostatic and fungistatic, although they are microbicidal against some organisms at high concentrations.They are more active against gram-positive bacteria than against gram-negative bacilli. QACs have relatively weak activity against mycobacteria and fungi and greater activity against lipophilic viruses. Their antimicrobial activity is adversely affected by the presence of organic material, and they are not compatible with anionic detergents. In 1994, the Food and Drug Administration (FDA) Tentative Final Monograph (TFM) tentatively classified benzalkonium chloride and benzethonium chloride as having insufficient data to classify as safe and effective for use as an antiseptic handwash (WHO 2009).

\section{Hexachlorophene}

Hexachlorophene is a halophenol compound. It is a slow-acting antiseptic that forms a film over the skin (Crowder 1967). The film retains bacteriostatic properties and is effective against grampositive bacteria but is less effective with gram-negative bacteria and fungi (Crowder 1967). A report of toxicity in neonates led to restricted usage (Kimborough 1973), and today, hexachlorophene has mostly been replaced by triclosan.

\section{Triclosan}

Triclosan (2,4,4'-trichloro-2'-hydroxydiphenyl ether) has been incorporated in detergents $(0.4 \%$ to $1 \%)$ and alcohols $(0.2 \%$ to $0.5 \%$ ) used for hygienic and surgical hand antisepsis or preoperative skin disinfection. It inhibits staphylococci, coliforms, enterobacteria and a wide range of gram-negative intestinal and skin flora (Bartzokas 1983). Most strains of pseudomonas are resistant, and triclosan has only fair activity against mycobacterium tuberculosis and poor activity against fungi (Faoagali 1995).

\section{Chloroxylenol}

Chloroxylenol, also known as para-chloro-meta-xylenol (PCMX), is a halogen-substituted phenolic compound. It is not as quickacting as chlorhexidine or iodophors, and its residual activity is less pronounced than that observed with chlorhexidine gluconate (McDonnell 1999). In 1994, the FDA TFM tentatively classified chloroxylenol as having insufficient data to classify as safe and effective (WHO 2009).

\section{O B J E C T IVES}

To assess the effects of surgical hand antisepsis on preventing surgical site infections (SSIs) in patients treated in any setting. The secondary objective is to determine the effects of surgical hand antisepsis on the number of bacteria colony-forming units (CFUs) present on the hands of the surgical team.

\section{METHODS}

\section{Criteria for considering studies for this review}

\section{Types of studies}

All published and unpublished randomised controlled trials (RCTs) of surgical hand antiseptic techniques were included. Controlled clinical trials were to be considered in the absence of RCTs. Two possible units of randomisation were considered: the scrub team or individual members of the scrub team.

\section{Types of participants}

All members of the scrub team or personnel working within the operating theatre or day case setting. The SSI outcome is measured in participants who have undergone surgery.

\section{Types of interventions}

This review included comparisons of the following with each other and/or placebo and/or no antisepsis:

- Surgical hand antisepsis;

- Aqueous scrub solutions.

- Alcohol rubs.

- Alcohol rubs containing additional active ingredients.

- Surgical hand antisepsis of different durations.

- Surgical hand antisepsis using different equipment (e.g. brush, sponge, nail pick). 


\section{Types of outcome measures}

\section{Primary outcomes}

Occurrence of postoperative SSI, as defined by the CDC (Mangram 1999) or the study authors. We did not differentiate between superficial and deep-incisional infection.

\section{Secondary outcomes}

Number of bacterial CFUs found on the hands of the surgical team.

\section{Search methods for identification of studies}

\section{Electronic searches}

We describe the search methods of the original version and first update of this review in Appendix 1.

For this first update we searched:

The Cochrane Wounds Group Specialized Register (searched 10 June 2015);

The Cochrane Central Register of Controlled Trials (CENTRAL) (The Cochrane Library 2015, Issue 6);

Ovid MEDLINE (1946 to 9 June 2015);

Ovid MEDLINE - In-Process \& Other Non-Indexed Citations (9 June 2015);

Ovid EMBASE (1974 to 9 June 2015);

EBSCO CINAHL (1982 to 10 June 2015).

The following search strategy was used in the Cochrane Central Register of Controlled Trials (CENTRAL):

\#1 MeSH descriptor Surgical Wound Infection explode all trees \#2 MeSH descriptor Surgical Wound Dehiscence explode all trees \#3 surg* NEAR/5 infect*:ti,ab,kw \#4 surg* NEAR/5 wound*:ti,ab,kw \#5 surg* NEAR/5 site*:ti,ab,kw \#6 surg* NEAR/5 incision*:ti,ab,kw \#7 surg* NEAR/5 dehiscen*:ti,ab,kw \#8 ((post-operative or postoperative) NEAR/5 (wound NEXT infection $\left.{ }^{\star}\right)$ :ti,ab,kw

\#9 MeSH descriptor Preoperative Care explode all trees \#10 MeSH descriptor Perioperative Care explode all trees \#11 ((preoperative or pre-operative) NEXT care):ti,ab,kw \#12 (\#1 OR \#2 OR \#3 OR \#4 OR \#5 OR \#6 OR \#7 OR \#8 OR \#9 OR \#10 $\mathrm{OR} \# 11$ )

\#13 MeSH descriptor Skin explode all trees

\#14 MeSH descriptor Antisepsis explode all trees \#15 (\#13 AND \#14)

\#16 antisepsis:ti,ab,kw

\#17 MeSH descriptor Anti-Infective Agents, Local explode all trees \#18 MeSH descriptor Soaps explode all trees \#19 MeSH descriptor Povidone-lodine explode all trees \#20 MeSH descriptor lodophors explode all trees \#21 MeSH descriptor Chlorhexidine explode all trees \#22 MeSH descriptor Alcohols explode all trees \#23 MeSH descriptor Detergents explode all trees \#24 (iodophor* or povidone-iodine or betadine or chlorhexidine or triclosan or hexachlorophene or benzalkonium or alcohol or alcohols or antiseptic* or soap* or detergent $\left.{ }^{\star}\right)$ :ti,ab,kw \#25 MeSH descriptor Disinfection explode all trees \#26 MeSH descriptor Disinfectants explode all trees \#27 (\#25 OR \#26)
\#28 (\#13 AND \#27)

\#29 (skin NEAR/5 disinfect*):ti,ab,kw

\#30 (\#15 OR \#16 OR \#17 OR \#18 OR \#19 OR \#20 OR \#21 OR \#22 OR \#23 OR \#24 OR \#28 OR \#29)

\#31 MeSH descriptor Handwashing explode all trees

\#32 MeSH descriptor Hand explode all trees

\#33 ("hand" or "hands" or handwash* or (hand NEXT wash*) or (surgical NEXT scrub*)):ti,ab,kw

\#34 (\#31 OR \#32 OR \#33)

\#35 (\#12 AND \#30 AND \#34)

The search strategies for Ovid MEDLINE, Ovid EMBASE and EBSCO CINAHL are available in Appendix 2, Appendix 3 and Appendix 4, respectively. We combined the Ovid MEDLINE search with the Cochrane Highly Sensitive Search Strategy for identifying randomised trials in MEDLINE: sensitivity- and precision-maximising version (2008 revision) (Lefebvre 2011). We combined the EMBASE search with the Ovid EMBASE filter terms developed by the UK Cochrane Centre (Lefebvre 2011). We combined the CINAHL search with the trial filters developed by the Scottish Intercollegiate Guidelines Network (SIGN) (SIGN 2011). There were no restrictions with respect to language, date of publication or study setting.

\section{Searching other resources}

We handsearched the bibliographies of all retrieved and relevant publications identified by these strategies for further studies.

\section{Data collection and analysis}

\section{Selection of studies}

For the original review, three authors independently assessed the titles and abstracts of potentially relevant studies identified through the search strategy, retrieving the full text of all studies that potentially met the criteria. If it was unclear from the title or abstract whether a study met the criteria or there was a disagreement over the eligibility, we retrieved the full text of the study. The three authors then decided independently whether or not to include the studies. There were no disagreements among authors regarding which studies to include.

For the update, two authors independently assessed all titles and abstracts using the same methods, seeking assistance from translators where necessary. Again, there were no disagreements among authors about which studies to include.

\section{Data extraction and management}

We piloted a standardised data extraction form, and two authors independently used the finalised version to extract the following data from studies:

\section{Trial data extracted}

- Duration of surgical antisepsis

- Antiseptic solution used

- Equipment used (e.g. brush, sponge, nail pick)

- Role of the person carrying out the hand antisepsis, for example, scrub nurse or surgeon

- Scrub history of the person scrubbing, for example, initial or subsequent scrub 
- Surgical specialty, for example, orthopaedics, ophthalmics, urology, etc.

- Type of surgical procedure: elective or emergency

- Duration of surgical procedure

- Surgical glove material

- Size of groups

- Method of SSI detection

- Duration of follow-up

\section{Trial outcomes}

- Number of SSIs

- Number of CFUs (bacteria) on hands of surgical team

\section{Assessment of risk of bias in included studies}

Two review authors independently assessed the included studies using the Cochrane tool for assessing risk of bias (Higgins 2011). This tool addresses six specific domains: sequence generation, allocation concealment, blinding, incomplete data, selective outcome reporting and other issues (Appendix 5). In this review we recorded issues with unit of analysis, for example where a cluster trial had been undertaken but analysed at the individual level in the study report. We assessed blinding of outcome assessment and completeness of outcome data for each of the review outcomes separately. For this review, we anticipated that blinding of participants (surgical staff) may not be possible. For this reason the assessment of the risk of detection bias focused on whether trials reported blinded outcome assessment (because wound infection can be a subjective outcome, it can be at high risk of measurement bias when outcome assessment is not blinded).

We presented our assessment of risk of bias using two 'Risk of bias' summary figures; one which is a summary of bias for each item across all studies, and a second which shows a cross-tabulation of each trial by all of the risk of bias items. We summarised a study's risk of selection bias, detection bias, attrition bias, reporting bias and other bias.

\section{Data synthesis}

Data were entered into Review Manager software (RevMan 2014). Continuous outcomes (i.e. CFUs) were reported as mean differences (MDs) with 95\% confidence intervals (CI). Dichotomous outcomes (i.e. SSIs) were presented as risks ratio (RR) with $95 \% \mathrm{Cl}$. We reported findings narratively and considered pooling of data after exploring clinical and statistical heterogeneity. We examined clinical heterogeneity by looking at the type of intervention, the participant population and the type of surgery. For assessment of statistical and related heterogeneity we used 12 values (Higgins 2003). $1^{2}$ examines the percentage of total variation across RCTs that is due to heterogeneity rather than chance (Higgins 2003). Very broadly, we considered that $\mathrm{I}^{2}$ values of $25 \%$, or less, may mean a low level of heterogeneity Higgins 2003, and values of more than $75 \%$, or more, indicate very high heterogeneity.

\section{Handling of data where the appropriateness of the analysis reported in the paper was unclear.}

Where the trial had a cross-over design or was cluster-randomised but the analysis did not appear to take this into account, we reported the available raw data (e.g. mean values) as well as the effect estimate calculated in the paper and discussed the likely effect of an incorrect analysis on the effect estimate.

\section{'Summary of findings' tables}

In the update, in line with current Cochrane methods, we planned to present the main results of the review in 'Summary of findings' tables where we had pooled data. These tables present key information concerning the quality of the evidence, the magnitude of the effects of the interventions examined and the sum of available data for the main outcomes (Schünemann 2011a). The 'Summary of findings' tables also include an overall grading of the evidence related to each of the main outcomes using the GRADE (Grades of Recommendation, Assessment, Development and Evaluation) approach. The GRADE approach defines the quality of a body of evidence as the extent to which one can be confident that an estimate of effect or association is close to the true quantity of specific interest. The quality of a body of evidence involves consideration of within-trial risk of bias (methodological quality), directness of evidence, heterogeneity, precision of effect estimates and risk of publication bias (Schünemann 2011b). We planned to present the following outcomes in the 'Summary of findings' tables for each comparison.

- SSI events

- Number of CFUs

Where we did not pool data, we decided to conduct the GRADE assessment for each comparison and present this narratively within the Results section without the presentation of separate 'Summary of findings' tables.

\section{RE S U L T S}

\section{Description of studies}

Also see Characteristics of included studies and Characteristics of excluded studies.

\section{Results of the search}

The search for this update took place in June 2015 and yielded 274 abstracts. We obtained 18 of these as full-text records for further assessment, subsequently excluding 14 (see Excluded studies) and including four (Al-Naami 2009; Nthumba 2010; Tanner 2009; Vergara-Fernandez 2010). The addition of these four new studies to the 10 studies in the previous version of the review brought the total number of studies included in this update to 14 .

Over the life of the review, we have made attempts to contact seven authors to obtain further information (Gupta 2007, Hajipour 2006; Herruzo 2000; Kappstein 1993; Pereira 1997; Pietsch 2001; Sensoz 2003). Five authors responded (Hajipour 2006; Herruzo 2000; Kappstein 1993; Pereira 1997; Sensoz 2003). We included Hajipour 2006, Herruzo 2000, Kappstein 1993, Pereira 1997 and Pietsch 2001 in the review. We also included Gupta 2007 , although we have not carried out any independent analyses on their findings. The update identified one study (from a bibliographic search) that is awaiting assessment pending further information (Chen 2012).

\section{Included studies}

We present an overview of included studies and comparisons in Table 1. 
We identified and included 14 eligible trials in this review. Four trials reported the primary outcome, namely SSI (Al-Naami 2009; Nthumba 2010; Parienti 2002; Vergara-Fernandez 2010). The remaining 10 trials reported the number of CFUs (on the hands of the surgical team), which is a surrogate outcome that is thought to give an impression of the likelihood of infection. All 14 trials took place in operating departments, with 8 studies involving surgery and 6 testing interventions in surgical staff but without surgery taking place. Of the included studies, four compared different durations of scrubs or rubs (Kappstein 1993; Pereira 1990; Pereira 1997; Wheelock 1997).

Some of the included studies had complicated designs: Parienti 2002 was an equivalence, cluster, cross-over trial where the unit of randomisation was the surgical service. Each surgical service carried out one intervention for one month and then switched to the alternative intervention the following month. Nthumba 2010 also used a cluster, cross-over design, whereby operating theatres were allocated to an intervention with cross-over every two months. We also considered Hajipour 2006 to be a cluster trial, as it randomised four surgeons to different antisepsis methods which they used prior to surgery on multiple participants. Seven other studies (Gupta 2007, Herruzo 2000, Kappstein 1993, Pereira 1990; Pereira 1997; Pietsch 2001; Wheelock 1997) were also crossover trials.

\section{Definition of scrub procedure}

Six trials gave detailed protocols for their antisepsis techniques (Furukawa 2005; Parienti 2002; Pereira 1990; Pereira 1997; Tanner 2009; Wheelock 1997). Authors from eight trials reported using a brush or sponge (Gupta 2007; Furukawa 2005; Herruzo 2000; Parienti 2002; Pereira 1990; Pereira 1997; Vergara-Fernandez 2010), while Tanner 2009 compared a nail brush and nail pick. Parienti 2002 and Wheelock 1997 stated that antisepsis protocols met with national guidelines. Seven of the trials employed a 'supervisor' to observe compliance with the antisepsis protocol (Furukawa 2005; Nthumba 2010; Parienti 2002; Pereira 1990; Pereira 1997; Tanner 2009; Wheelock 1997). Three trials presented minimal details of the antisepsis protocol (Gupta 2007; Hajipour 2006; Nthumba 2010), and the remaining five trials did not comment on antisepsis techniques (Al-Naami 2009; Herruzo 2000; Kappstein 1993; Pietsch 2001; Vergara-Fernandez 2010).

\section{Excluded studies}

\section{See Characteristics of excluded studies}

\section{Risk of bias in included studies}

We summarise our 'Risk of bias' assessment in Figure 1, Figure 2 and in the 'Risk of bias' assessment tables. Overall, most studies were at unclear risk or high risk of bias for one of the following: selection bias, detection bias and attrition bias. Only two studies were at low risk of bias for all these (Nthumba 2010; Tanner 2009).

Figure 1. Risk of bias graph: review authors' judgements about each risk of bias item presented as percentages across all included studies.

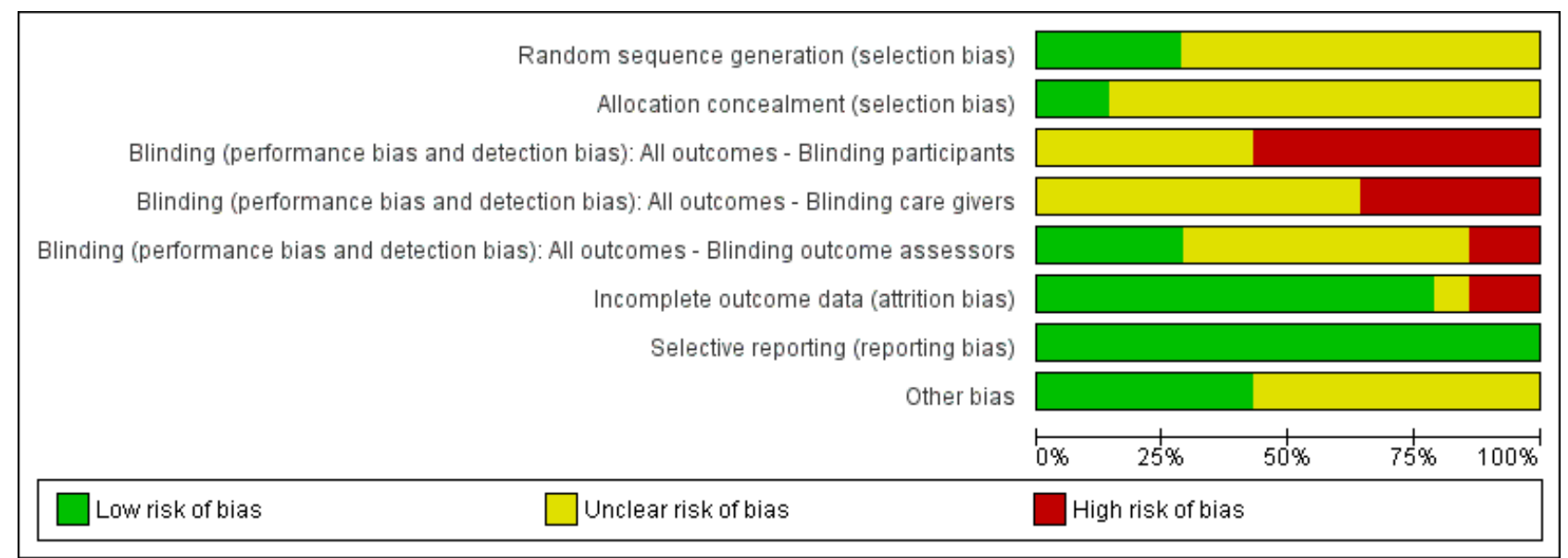


Figure 2. Risk of bias summary: review authors' judgements about each risk of bias item for each included study.

\begin{tabular}{|c|c|c|c|c|c|c|c|c|}
\hline & 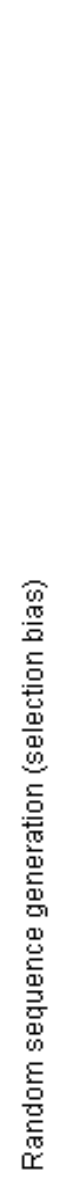 & 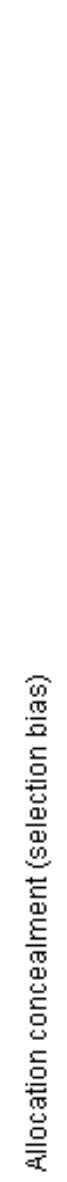 & 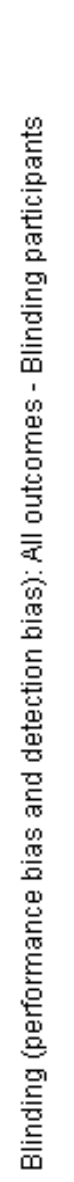 & 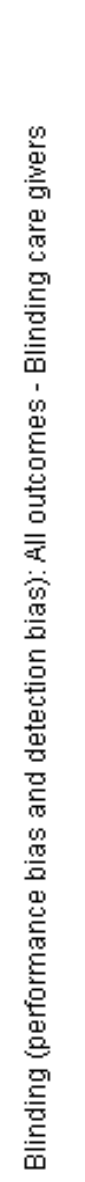 & 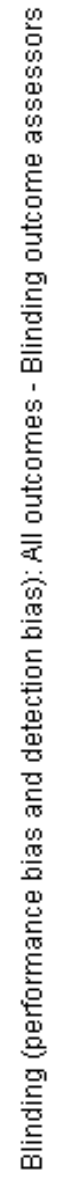 & 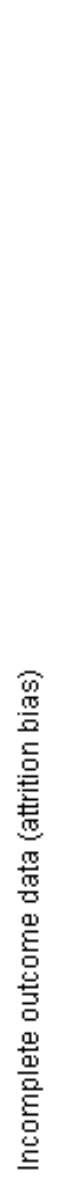 & 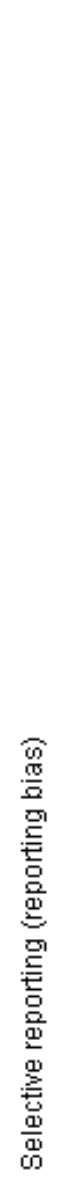 & 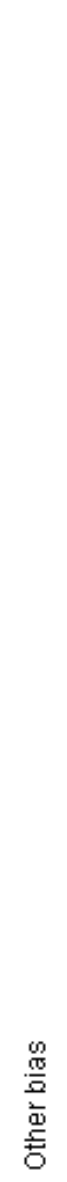 \\
\hline Al-Naami 2009 & $?$ & $?$ & $\odot$ & $?$ & + & $\odot$ & + & + \\
\hline Furukawa 2005 & $?$ & $?$ & $?$ & $?$ & $?$ & + & + & + \\
\hline Gupta 2007 & $?$ & $?$ & $\odot$ & $?$ & $?$ & $\oplus$ & + & $?$ \\
\hline Hajipour 2006 & + & $?$ & $?$ & $?$ & + & + & + & $?$ \\
\hline Herruzo 2000 & $?$ & $?$ & - & $\Theta$ & $?$ & + & $\odot$ & $?$ \\
\hline Kappstein 1993 & $?$ & $?$ & $?$ & $?$ & $?$ & + & $\odot$ & $?$ \\
\hline Nthumba 2010 & + & + & 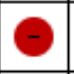 & $?$ & + & + & + & + \\
\hline Parienti 2002 & + & $?$ & - & $\odot$ & - & + & + & $?$ \\
\hline Pereira 1990 & $?$ & $?$ & $?$ & $?$ & $?$ & + & $\odot$ & $?$ \\
\hline Pereira 1997 & $?$ & $?$ & $\theta$ & $\Theta$ & $?$ & $\Theta$ & + & $?$ \\
\hline Pietsch 2001 & $?$ & $?$ & $?$ & $?$ & $?$ & $?$ & $\odot$ & $\odot$ \\
\hline Tanner 2009 & + & $\odot$ & - & $\odot$ & + & $\oplus$ & $\odot$ & $\odot$ \\
\hline Vergara-Fernandez 2010 & $?$ & $?$ & $?$ & $?$ & $?$ & $\oplus$ & + & $\odot$ \\
\hline Wheelock 1997 & $?$ & ? & 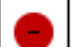 & $\odot$ & $\theta$ & $\oplus$ & + & $?$ \\
\hline
\end{tabular}


Figure 2. (Continued)

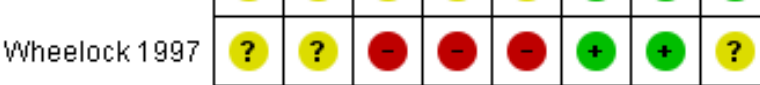

We considered four studies to be at low risk of detection bias, as they blinded outcome assessors (Al-Naami 2009; Nthumba 2010; Hajipour 2006; Tanner 2009). We considered two studies to be at high risk of detection bias (Parienti 2002; Wheelock 1997).

We also judged two studies to be at high risk of attrition bias. Pereira 1997 reported that 9/32 randomised members of staff failed to complete with no reasons given for withdrawal. Al-Naami 2009 excluded 100 of 600 patients from the analysis for reasons such as their condition was revised on subsequent histopathological examination, they had incomplete forms, or they "failed follow-up".

We judged several studies to be at unclear risk of other bias due to uncertainty as to whether a cluster-randomised or cross-over design had been taken into account in the analysis. Parienti 2002 and Hajipour 2006 were at unclear risk of other bias as a cluster design was detected but it did not seem that clustering had been taken into account in the analyses. Herruzo 2000, Kappstein 1993 , Pereira 1990, Pereira 1997; Wheelock 1997 were at unclear risk because it appeared that the crossover designs had not been taken into consideration in the analyses.

\section{Effects of interventions}

We included 14 trials in this review. In total, the trials evaluated nine basic comparisons related to the type (i.e. scrub or rub, active ingredients), duration and tools used for surgical hand antisepsis.

- Comparison 1: basic hand hygiene versus alcohol rub containing additional active ingredients (Nthumba 2010).

- Comparison 2: different aqueous scrub solutions: chlorhexidine gluconate versus povidone iodine (Furukawa 2005; Herruzo 2000; Pereira 1990; Pereira 1997).

- Comparison 3: comparison of different alcohol rubs containing additional active ingredients (Gupta 2007; Pereira 1997).

- Comparison 4: aqueous scrubs versus alcohol-only rubs (AlNaami 2009).

- Comparison 5: aqueous scrubs versus alcohol rubs containing additional active ingredients (Gupta 2007; Hajipour 2006; Herruzo 2000; Parienti 2002; Pietsch 2001; Vergara-Fernandez 2010).

- Comparison 6: duration of surgical antisepsis (Kappstein 1993; Pereira 1990; Pereira 1997; Wheelock 1997).

- Comparison 7: surgical hand antisepsis using a nail pick versus surgical hand antisepsis not using a nail pick (Tanner 2009).

- Comparison 8: surgical hand antisepsis using a brush versus surgical hand antisepsis not using a brush (Tanner 2009).

- Comparison 9: surgical hand antisepsis using a nail pick versus surgical hand antisepsis using a brush (Tanner 2009).

Comparison 1: basic hand hygiene versus alcohol rub containing additional active ingredients (1 study)

Basic hand hygiene (soap and water) compared with $75 \%$ isopropyl alcohol plus $0.125 \%$ hydrogen peroxide
Nthumba 2010 compared soap and water with an alcohol rub which contained hydrogen peroxide as an additional active ingredient. Surgeons in both groups scrubbed with soap and water for 4 to 5 minutes before the first procedure of the day and subsequently if there was visible soiling. For subsequent procedures, surgeons were randomised in clusters based on operating theatre to soap and water or 7 to $10 \mathrm{ml}$ of a locally produced hand rub based on isopropyl alcohol with hydrogen peroxide, which they applied for 3 minutes and kept wet. The trial used a total of 10 clusters, each defined by six operating theatres, across five two-month intervals, with cross-over after each two-month period. The trial included 3317 patients undergoing clean and clean-contaminated surgery and assessed SSI at 30 days using modified CDC definitions. There appeared to be a low risk of bias for all domains except the blinding of participants and personnel, which would have been difficult to achieve. Trialists accounted for both the clustering and cross-over in the power calculation and in the analyses.

\section{Outcomes}

\section{Surgical site infection (SSI)}

Nthumba 2010 collected SSI data for 30 days after discharge. There was no clear difference in the number of SSIs between groups. In total, $8 \%(128 / 1596)$ of participants developed SSI in the soap and water scrub group compared with $8.3 \%(127 / 1537)$ in the alcohol rub group (RR $0.97,95 \% \mathrm{Cl} 0.77$ to 1.23 ). This was based on a complete case analysis; data were unavailable for $5.5 \%$ (184/3317) of participants and were not imputed. Losses to follow-up were comparable between the two arms, at 5.1\% (86/1682) for soap and water scrub versus 6.0\% (98/1635) for alcohol rub (Analysis 1.1).

Moderate quality evidence, downgraded once for imprecision. A GRADE assessment of moderate quality evidence means that further research is likely to have an important impact on our confidence in the estimate of effect and may change the estimate.

\section{Number of colony forming units (CFUs)}

Not reported

\section{Comparison 1 Summary: Basic hand hygiene compared to alcohol rubs containing additional active ingredients}

It is not clear whether hand antisepsis with soap and water is more or less effective in preventing subsequent SSI than antisepsis with an alcohol rub containing hydrogen peroxide (moderate quality evidence).

\section{Comparison 2: different aqueous scrub solutions: chlorhexidine gluconate versus povidone iodine (4 trials)}

Four studies compared chlorhexidine gluconate versus povidone iodine but used different regimens.

Pereira 1990 randomly assigned 34 participants (operating room nurses) to one of four groups. The four interventions (which were used for 1 week) were $4 \%$ chlorhexidine gluconate (Hibiclens) or $7.5 \%$ povidone iodine (Betadine), using a 5 minute initial and 3 minute subsequent scrub; and $4 \%$ chlorhexidine gluconate 
(Hibiclens) or $7.5 \%$ povidone iodine (Betadine) using a 3 minute initial and 30 second subsequent scrub. Control of the order of interventions was through a Latin square design. Investigators took hand bacterial samples immediately after the initial scrub, 2 hours after the initial scrub and 2 hours after the subsequent scrub. Although the study had a cross-over design, it did not appear that this was taken into consideration in the analysis, thus $95 \%$ Cls may be overestimated.

Furukawa 2005 compared 4\% chlorhexidine gluconate (Hibiscrub) with $7.5 \%$ povidone iodine (Isodine) using a 3 minute scrub. Twenty-two operating room nurses were randomised to one of the two intervention groups. Each nurse took part only once. The nurses did not take part in any actual surgery.

Herruzo 2000 randomised 154 members of surgical teams and compared three intervention groups: relevant to this comparison was a 3 minute scrub of either aqueous chlorhexidine gluconate $4 \%$ or aqueous povidone iodine $7.5 \%$. The study had a cross-over design, which appears to have been accounted for. The study also reports repeated measures which does not appear to have been accounted for in the analysis.

Pereira 1997 compared 4\% chlorhexidine gluconate (Hibiclens) with $5 \%$ povidone iodine plus $1 \%$ triclosan (Microshield PVP) using a 3 minute initial and 2.5 minute subsequent scrub. Twenty-three operating room nurses were randomised to carry out each of five interventions for one week each. The order of interventions was controlled through a Latin square design. Participants did not take part in any actual surgery. Investigators took hand bacterial samples immediately after the first antisepsis, 2 hours after the first antisepsis and 2 hours after the subsequent antisepsis. Although the study had a cross-over design, it did not appear that trialists took this into consideration in the analysis, thus the $95 \% \mathrm{Cl}$ may be overestimated.

\section{Outcomes}

\section{Surgical site infection}

Not reported

\section{Number of colony forming units (CFUs)}

Chlorhexidine gluconate compared with povidone iodine

Pereira 1990 compared 4\% chlorhexidine gluconate (Hibiclens) with $7.5 \%$ povidone iodine (Betadine) using a 5 minute initial and 3 minute subsequent scrub. There was some evidence that scrubbing with chlorhexidine might be more effective than with povidone iodine in reducing the number of CFUs on the hand immediately after scrubbing (MD $-0.34,95 \% \mathrm{Cl}-0.64$ to $-0.04 ;$ ), 2 hours after the initial scrub (MD $-0.75,95 \% \mathrm{Cl}-1.06$ to -0.44$)$ and 2 hours after the subsequent scrub (MD $-1.10,95 \% \mathrm{Cl}-1.42$ to -0.78 ; Analysis 2.1).

Because the analysis did not account for the effects of paired data resulting from the cross-over design, the study may have overestimated the uncertainty of the effect estimate; the correct $95 \% \mathrm{Cls}$ for the estimate may be narrower than those reported here. However, the study also used a repeated measures design which the analysis did not account for; this could lead to an underestimation of the uncertainty. The interaction of these two factors makes the true confidence intervals unclear, so we have downgraded the evidence twice due to imprecision.
Very low quality evidence due to imprecision and indirectness of outcome. Downgraded twice for imprecision due to two analytical issues which mean precision estimates may change upon correct analysis of data, and downgraded twice for indirectness as CFU is a surrogate outcome and because the intervention was used in the absence of surgery being conducted. A GRADE assessment of very low quality evidence means any estimate of effect is very uncertain.

Pereira 1990 compared 4\% chlorhexidine gluconate (Hibiclens) with $7.5 \%$ povidone iodine (Betadine) using a 3 minute initial and 30 second subsequent scrub. There was evidence that chlorhexidine may be more effective than povidone iodine in reducing the number of CFUs immediately post scrubbing (MD $-0.17,95 \% \mathrm{Cl}-$ 0.28 to -0.06$), 2$ hours after the initial scrub (MD $-0.41,95 \% \mathrm{Cl}-$ 0.72 to -0.10$)$ and 2 hours after the subsequent scrub (MD -0.65 , $95 \% \mathrm{Cl}-0.93$ to -0.37 Analysis 2.1 ).

Very low quality evidence due to imprecision and indirectness of outcome (as above).

In Furukawa 2005, there were fewer CFUs in the chlorhexidine gluconate group after scrubbing (MD $-2.40,95 \% \mathrm{Cl}-3.26$ to -1.54 ; Analysis 2.1).

Low quality evidence: downgraded twice for indirectness as CFU is a surrogate outcome and because the intervention was used in the absence of surgery being conducted.

In Herruzo 2000, there was evidence that a 3 minute aqueous scrub using chlorhexidine gluconate was more effective in reducing CFUs on hands than a 3 minute aqueous scrub using povidone iodine, both immediately after antisepsis (MD - 48.00, 95\% Cl50.57 to -45.4 ) and at the end of a surgical procedure (MD - 132.0, $95 \% \mathrm{Cl}-141.20$ to -122.80 ; Analysis 2.1). Because the analysis did not account for the repeated measures, the study may have underestimated uncertainty around the effect estimate: the true confidence intervals for the estimate may be wider than those reported here.

Low quality evidence; downgraded once as precision estimates may change upon correct analysis of data and downgraded once due to indirectness as CFU is a surrogate outcome.

We considered pooling the three studies (four comparisons) (Furukawa 2005; Herruzo 2000; Pereira 1990); however, in light of the high degree of statistical heterogeneity for each possible comparison (ranging from $100 \%$ to $56 \%$ ) and the differences in interventions noted, we did not undertake this.

\section{Chlorhexidine gluconate compared with povidone iodine plus triclosan}

Pereira 1997 reported no evidence of a difference in CFUs immediately after the first antisepsis (MD $-0.38,95 \% \mathrm{Cl}-0.84$ to 0.08 ) (Analysis 3.1) and 2 hours after the first antisepsis (MD -0.38 , $95 \% \mathrm{Cl}-0.90$ to 0.14 ) (Analysis 3.2). The trial found a difference in favour of chlorhexidine 2 hours after the subsequent antisepsis (MD $-0.69,95 \% \mathrm{Cl}-1.13$ to -0.25 ) (Analysis 3.1).

Because the analysis did not account for the effects of paired data resulting from the cross-over design or for the effect of using repeated measures, the true confidence intervals for the estimate are uncertain. 
Very low quality evidence downgraded once for risk of attrition bias; twice for imprecision and twice for indirectness - once for indirectness of outcome and once because the intervention was used in the absence of surgery being conducted.

Comparison 2 Summary : Comparison of different aqueous scrub solutions - chlorhexidine gluconate compared with povidone iodine

Data from four trials (five comparisons) of chlorhexidine-containing aqueous scrub solutions with povidone iodine containing solutions (all having initial longer duration of use followed by shorter subsequent use) suggest that chlorhexidine containing agents may reduce the numbers of CFU on the hands to a greater extent than povidone iodine containing solutions. However, overall this is low or very low quality evidence, and the number of CFUs is a surrogate outcome for SSI. Some of the studies included appeared to have been incorrectly analysed and one was at high risk of attrition bias. No trials reported SSI events so there is no evidence to link the number of CFUs to clinical outcomes.

Comparison 3: comparison of different alcohol rubs containing additional active ingredients ( 2 trials)

Two trials compared alcohol rubs containing additional active ingredients (Gupta 2007; Pereira 1997).

Gupta 2007 compared three $2 \mathrm{ml}$ aliquots of $1 \%$ chlorhexidine gluconate in $61 \%$ ethyl alcohol (Avagard) against a 3 minute application of zinc pyrithione in $70 \%$ ethyl alcohol (Triseptin). The $61 \%$ alcohol solution is a waterless product, and the $70 \%$ alcohol solution is a water aided product which requires rinsing with water. Eighteen operating room staff used each product for five consecutive days. Testing was carried out immediately before and after antisepsis on day one, and at the end of days two and five.

Pereira 1997 compared $0.5 \%$ chlorhexidine gluconate in isopropanol compared with $0.5 \%$ chlorhexidine gluconate in ethanol. The alcohol rubs were used immediately after an aqueous scrub (with $4 \%$ chlorhexidine gluconate) and also as the subsequent antiseptic agent. The active ingredient in both alcohol rubs was the same (i.e. $0.5 \%$ chlorhexidine gluconate), and both preparations had $70 \%$ strength alcohol, the only difference being the alcohol (isopropanol versus ethanol). Scrubs lasted for 2 minutes, and the initial and subsequent applications of alcohol rubs lasted for 30 seconds.

\section{Outcomes}

\section{Surgical site infection}

Not reported

\section{Number of colony forming units (CFUs)}

Pereira 1997 did not find a difference in the number of CFUs between the isopropanol- and ethanol-based rubs immediately after the first antisepsis (MD $0.00,95 \% \mathrm{Cl}-0.57$ to 0.57 ), 2 hours after the first antisepsis (MD $0.07,95 \% \mathrm{Cl}-0.45$ to 0.59 ) or 2 hours after the subsequent antisepsis (MD $0.11,95 \% \mathrm{Cl}-0.49$ to 0.71 ); see Analysis 4.1. Differences between groups were consistently small and imprecise. As previously noted, the true confidence intervals for the effect estimates is uncertain because of the issues with the analysis.
Very low quality evidence due to risk of bias of attrition bias; imprecision and indirectness of outcome.

Gupta 2007 did not present sufficient raw data in the trial report to allow us to conduct independent statistical analyses, so we have contacted the author for further information. In the interim, we present Gupta 2007's own analysis. Although the trial used a crossover design, we could not determine if this was accounted for in the analysis. When the CFUs were compared over the duration of the study, Gupta 2007 found no statistically significant difference between the solutions $(P=0.21)$. It must be noted that this analysis has not been independently verified.

Very low quality evidence downgraded due to indirectness of aggregate data that has not be checked or verified by review authors; also downgraded due to indirectness of outcome and imprecision as no Cls available.

\section{Comparison 3 Summary: Comparison of different alcohol rubs containing additional active ingredients.}

The comparative effects of different alcohol rubs (each containing additional active ingredients) on number of CFUs are unclear, as the existing evidence is very sparse and of very low quality.

\section{Comparison 4: aqueous scrubs versus alcohol-only rubs (1 trial)}

Al-Naami 2009 compared a traditional 3 to 5 minute scrub with either chlorhexidine or povidone iodine versus $10 \mathrm{ml}$ of a $62 \%$ ethyl alcohol handrub, which was allowed to dry. Surgeons in both groups scrubbed with the aqueous solution for the first procedure of the day. The study was described as an equivalence trial. Six hundred patients undergoing clean and clean-contaminated surgery were randomised to the two arms; investigators reported data for 500 patients. Reasons for participants being excluded from the analysis included a revised assessment of their condition on subsequent histopathological examination, incomplete forms or failed follow-up. More patients in the traditional scrub arm (24\%, $72 / 300$ ) were excluded from the analysis than in the alcohol rub arm $(9 \%, 28 / 300)$.

\section{Outcomes}

\section{Surgical site infection (SSI)}

Al-Naami 2009 collected SSI data over 30 days from surgery. There was no clear evidence of a difference in number of SSIs, with $2.9 \%(8 / 272)$ of participants in the alcohol rub arm having an SSI compared with $5.2 \%(12 / 228)$ in the aqueous scrub group (RR 0.56, $95 \% \mathrm{Cl} 0.23$ to 1.34 ) (Analysis 5.1). This trial was considered to be at high risk of attrition bias.

Very low quality evidence; downgraded once due to risk of attrition bias and twice for imprecision.

Number of colony forming units

Not reported

Comparison 4 Summary: Aqueous scrubs compared with alcohol only rubs

It is unclear whether there is a difference in SSIs between aqueous handscrubs and alcohol-only rubs (very low quality evidence from one study). 
Comparison 5: aqueous scrubs versus alcohol rubs containing additional active ingredients ( 6 trials)

Six studies compared traditional scrubs with alcohol rubs containing additional active ingredients (Gupta 2007; Hajipour 2006; Herruzo 2000; Parienti 2002; Pietsch 2001; Vergara-Fernandez 2010). The six trials used different antiseptic solutions, therefore it was not appropriate to perform a meta-analysis. Each trial is considered separately.

Parienti 2002 compared a 5 minute scrub using either $4 \%$ povidone iodine (Betadine) or $4 \%$ chlorhexidine gluconate (Hibiscrub) versus a 5 minute handrub using $75 \%$ propanol-1, propanol-2 with mecetronium ethylsulphate (Sterillium). Participants in the aqueous scrub group could choose between chlorhexidine gluconate or povidone iodine solutions. Participants in the handrubbing group carried out a single handwash for 1 minute with non-antiseptic soap at the start of each day. The entire scrub team in each of six hospitals took part. The trial included 4387 consecutive patients undergoing clean and clean-contaminated surgery and assessed SSI at $30 \mathrm{~d}$ using the CDC definition. The study was an equivalence, cluster cross-over trial but did not appear to have accounted for the clustering in the analysis.

Vergara-Fernandez 2010 compared an aqueous scrub with 4\% chlorhexidine gluconate (which involved the use of a brush and a sponge) versus a handrub using $61 \%$ ethyl alcohol plus $1 \%$ chlorhexidine gluconate. Mean duration of the aqueous scrub was 3.9 minutes (SD 1.07), and mean duration of the alcohol rub was 2.0 minutes (SD 0.47). This trial took place in a single institution and involved 400 staff operating on 100 patients undergoing clean and clean-contaminated surgery, who were randomised to the two hand antisepsis groups. Investigators assessed SSI at one month using the CDC definition. Twenty per cent of the included staff had hand samples sent for microbiological examination, and samples were assessed as positive or negative for hand cultures.

Herruzo 2000 compared three intervention groups: chlorhexidine gluconate scrub versus povidone iodine scrub versus an alcohol rub with $\mathrm{N}$-duopropenide. Each scrub or rub lasted 3 minutes. We successfully contacted Herruzo 2000 for additional information regarding sample size. 154 members of the surgical team were randomised for 55 operations. Investigators measured CFUs before antisepsis, immediately after antisepsis and at the end of the surgical procedure.

Pietsch 2001 compared scrubbing using 4\% chlorhexidine gluconate (Hibiscrub) with hand rubbing using an alcoholic solution of $45 \%$ propanol-2, $30 \%$ propanol-1 plus $0.2 \%$ ethylhexadecyldimethyl ammonium ethylsulphate (Sterillium). Seventy-five surgeons from one hospital participated in this randomised cross-over trial, using one product for four weeks then changing to the alternative product following a rest week. CFUs were measured before antisepsis, immediately after antisepsis and after the surgical procedure.

Hajipour 2006 compared a 3 minute $4 \%$ chlorhexidine gluconate scrub versus a 3 minute chlorhexidine in alcohol rub (Hydrex). We contacted the trial authors, who provided additional study details. Following an aqueous chlorhexidine scrub at the start of each day, four surgeons were randomised to one or other intervention and were evaluated repeatedly in that condition. Testing was carried out using the finger press method at the end of each surgical procedure.

Gupta 2007 compared $7.5 \%$ povidone iodine aqueous scrub against two alcohol rubs: three $2 \mathrm{ml}$ aliquots of $1 \%$ chlorhexidine gluconate in $61 \%$ ethyl alcohol (Avagard) and a 3 minute application of zinc pyrithione in $70 \%$ ethyl alcohol (Triseptin). The paper does not provide further details regarding the application of the products. Eighteen operating room staff used each of the three products for five consecutive days. Testing was carried out immediately before and after antisepsis on day one, and at the end of days two and five.

\section{Outcomes}

Surgical site infection (SSI)

Aqueous povidone iodine or chlorhexidine gluconate versus $75 \%$ propanol-1, propanol-2 plus mecetronium ethylsulphate

Parienti 2002 collected data for 30 days following surgery. There was no clear evidence of a difference in the rates of SSI between aqueous scrub and alcohol rub: 2.5\% (53/2135) of participants developed an SSI in the scrub group compared with $2.4 \%$ (55/2252) in the handrub group (RR $1.02,95 \% \mathrm{Cl} 0.70$ to 1.48 ) (Analysis 6.1).

\section{Low quality evidence downgraded once due to risk of detection} bias and once due to imprecision.

\section{Aqueous chlorhexidine gluconate compared with $61 \%$ ethyl alcohol plus $1 \%$ chlorhexidine gluconate}

Vergara-Fernandez 2010 found no clear evidence of a difference in SSI rates between groups. In total $2 \%$ of participants $(1 / 50)$ had a SSI in the aqueous scrub group compared with $4 \%(2 / 50)$ in the alcohol handrub group (RR 0.50, 95\% $\mathrm{Cl} 0.05$ to 5.34). The study was small and the resulting $95 \% \mathrm{Cl}$ intervals wide, ranging from a 95\% reduction in risk of SSI to a $400 \%$ increased risk of SSI (Analysis 6.1).

\section{Low quality evidence downgraded twice due to imprecision.}

Number of colony-forming units

\section{Aqueous chlorhexidine gluconate versus $\mathrm{N}$-duopropenide}

Herruzo 2000 reported CFU data $\left(\log _{10}\right)$ after antisepsis and after surgery (Analysis 7.1). We were unable to produce an estimate of treatment effect for the review. Using bivariate analysis, Herruzo 2000 reports that $\mathrm{N}$-duopropenide is more effective than chlorhexidine in reducing the number of CFUs on participants' hands immediately after antisepsis $(P$ value $<0.01)$ and at the end of a surgical procedure ( $P$ value $<0.01)$; the paper did not provide any further information on estimates.

Very low quality evidence downgraded twice as precision estimates are not available and once due to indirectness of outcome.

\section{Aqueous povidone iodine versus $\mathrm{N}$-duopropenide}

Herruzo 2000 reported CFU data $\left(\log _{10}\right)$ after antisepsis and after surgery (Analysis 8.1). We were unable to produce an estimate of treatment effect for the review. Using bivariate analysis, Herruzo 2000 reports that $\mathrm{N}$-duopropenide was statistically significantly more effective than povidone iodine in reducing the number of CFUs on participants hands immediately after antisepsis ( $P$ value $<0.01$ ) and at the end of a surgical procedure ( $P$ value $<0.01$ ). 
Very low quality evidence downgraded twice as precision estimates are not available and once due to indirectness of outcome.

Aqueous chlorhexidine gluconate versus 45\% propanol-2, 30\% propanol-1 plus $0.2 \%$ ethylhexadecyldimethyl ammonium ethylsulphate (Sterillium)

Pietsch 2001 reported that rubbing using 45\% propanol-2, $30 \%$ propanol-1 plus $0.2 \%$ ethylhexadecyldimethyl ammonium ethylsulphate (Sterillium) was more effective in reducing CFUs on participants' hands than scrubbing using $4 \%$ chlorhexidine gluconate, both immediately after antisepsis (MD - 1.27, 95\% Cl1.23 to -1.31 ) and at the end of the surgical procedure (MD - 1.07, $95 \% \mathrm{Cl}-1.03$ to -1.11 ); Analysis 9.1 .

\section{Moderate quality evidence downgraded once due to indirectness} of outcome.

Aqueous $4 \%$ chlorhexidine gluconate versus $0.5 \%$ chlorhexidine gluconate in $70 \%$ alcohol

Hajipour 2006 reported finding fewer CFUs following an aqueous scrub than after an alcohol rub (MD - 135.60, 95\% Cl - 153.39 to 117.81; Analysis 10.1).

This study had a cluster design, in which each surgeon constituted a cluster, giving two clusters in each trial arm. However, the analysis did not take this into consideration, so the reliability of the effect estimate reported by the authors is uncertain and could be wider than reported.

Very low quality evidence downgraded twice due to potential imprecision as re-analysis of data could increase the confidences intervals and change study conclusions and once due to indirectness of outcome.

Aqueous povidone iodine versus $61 \%$ ethyl alcohol and $70 \%$ ethyl alcohol

Gupta 2007 did not present sufficient raw data for us to be able to conduct independent statistical analysis, so we contacted the author to request additional data. In the interim we present Gupta 2007 's own analysis. When CFUs were compared collectively from all the sample times, Gupta 2007 reports 'no statistically significant difference' between the solutions $(P=0.21)$. It must be noted that this analysis has not been independently verified and it is unclear if investigators adjusted this analysis to account for the cross-over design.

Very low quality evidence downgraded twice for imprecision as Cls not available and twice for indirectness as we were unable to assess the actual results and the analysis undertaken and because the outcome is a surrogate outcome.

Comparison 5 summary: Aqueous scrubs compared with alcohol rubs containing additional active ingredients

It is unclear if there is a difference in numbers of SSIs between aqueous scrubs and alcohol rubs. The CFU outcome data were varied with two studies finding in favour of the alcohol rubs (moderate and very low quality evidence), one favouring the scrub arm (very low quality evidence) and one study reporting a 'nonstatistically significant difference' with no other data (very low quality evidence).

\section{Comparison 6: duration of surgical antisepsis (4 trials)}

Four trials compared surgical antisepsis of different durations but used different antiseptic agents, which prevented us from pooling results (Kappstein 1993; Pereira 1990; Pereira 1997; Wheelock 1997).

Wheelock 1997 randomised 25 operating room nurses and surgical technologists to either a 2 minute or a 3 minute scrub. After carrying out the trial scrub, and following a one-week washout period in which they continued to undertake scrubbing as part of their usual work, the participants switched to the other intervention. Though the intention of the trial authors was for participants to use aqueous $4 \%$ chlorhexidine gluconate (Hibiclens), participants with a history of skin irritation (15/25 participants) used either $2 \%$ chlorhexidine gluconate or parachlorometaxylenol (PCMX). CFUs were measured 1 hour after the surgical scrub.

Kappstein 1993 compared a five minute rub with a three minute rub using alcoholic disinfectant. The disinfectant is not identified. Both rubs followed 1 minute handwashes using soap and water. Twentyfour surgeons carried out each of three intervention groups once in a random order. Samples were taken before and immediately after antisepsis.

Pereira 1990 compared a 5 minute initial and 3 minute subsequent scrub with a 3 minute initial and 30 second subsequent scrub using chlorhexidine gluconate. Thirty-four participants were randomly assigned to one of four groups, and each group was assigned to one of four interventions, each lasting one week.

Pereira 1990 also compared a 5 minute initial and 3 minute subsequent scrub with a 3 minute initial and 30 second subsequent scrub using povidone iodine.

Pereira 1997 compared a 5 minute initial and a 3.5 minute subsequent scrub with a 3 minute initial and a 2.5 minute subsequent scrub using $4 \%$ chlorhexidine gluconate. Twenty-three operating room nurses were randomised to carry out each of five interventions for one week each.

\section{Outcomes}

Surgical site infection (SSI)

Not reported

Number of colony forming units (CFUs)

Three minute scrub versus two minute scrub

Wheelock 1997 presented paired data, which the review authors re-analysed but did not present. There were fewer CFUs on hands immediately after a 3 minute scrub compared with a 2 minute scrub (MD $-0.29,95 \% \mathrm{Cl}-0.06$ to -0.52 ).

Very low quality evidence downgraded once due to risk of detection bias and twice due to indirectness, once due to indirectness of outcome and once because the intervention was used in the absence of surgery being conducted.

Five minute rub versus three minute rub (Analysis 11.1)

Kappstein 1993 favoured the 3 minute scrub over the 5 minute scrub when assessed immediately after antisepsis (MD 0.26, 95\% Cl 0.14 to 0.38 ; Analysis 11.1). Because the use of a cross-over design 
was not accounted for in the analysis the true confidence intervals may be narrower than those reported here.

Low quality evidence: downgraded once due to imprecision and once due to indirectness.

Five minute initial and three minute subsequent scrub versus three minute initial and $\mathbf{3 0}$ second subsequent scrub using chlorhexidine (Analysis 12.1)

Pereira 1990 reported no clear difference between groups in the number of CFUs immediately after the initial scrub (MD - 0.19, 95\% $\mathrm{Cl}-0.51$ to 0.13 ) or 2 hours after the initial scrub (MD $-0.23,95 \% \mathrm{Cl}$ -0.52 to 0.06). There was evidence of a difference in CFUs favouring the 5 minute arm 2 hours after the subsequent scrub (MD -0.58 , $95 \% \mathrm{Cl}-0.92$ to -0.24$)$; see Analysis 12.1 .

Very low quality evidence down graded twice due to imprecision and once due to indirectness of outcome.

Five minute initial and three minute subsequent scrub compared with a three minute initial and $\mathbf{3 0}$ second subsequent scrub using povidone iodine (Analysis 13.1)

In Pereira 1990, there was no clear difference in the number of CFUs at any time point, whether immediately after the initial scrub (MD $0.02,95 \% \mathrm{Cl}-0.28$ to 0.32 ), 2 hours after the initial scrub (MD 0.12, $95 \% \mathrm{Cl}-0.21$ to 0.45 ) or 2 hours after the subsequent scrub (MD $0.13,95 \% \mathrm{Cl}-0.37$ to 0.11 ); see Analysis 13.1 .

Very low quality evidence downgraded due to imprecision and indirectness of outcome.

Five minute initial and three and $\mathbf{3 0}$ second subsequent scrub compared with a three minute initial and two and a half minute subsequent scrub using chlorhexidine (Analysis 14.1)

In Pereira 1997, there was no clear difference in the number of CFUs at any time point reported, whether immediately after the initial antisepsis (MD 0.08, 95\% Cl -0.44 to 0.60), 2 hours after the initial antisepsis (MD $-0.19,95 \% \mathrm{Cl}-0.78$ to 0.40 ) or 2 hours after subsequent antisepsis (MD $-0.17,95 \% \mathrm{Cl}-0.71$ to 0.37 ); see Analysis 14.1.

Very low quality evidence due to risk of bias of attrition bias; imprecision and indirectness of outcome.

\section{Comparison 6 summary: duration of surgical antisepsis}

Outcome data were only available for CFUs. One study reported evidence of fewer CFUs on hands after using a 3 minute rather than 2 minute chlorhexidine scrub. Another study reported fewer CFUs after a 3 minute alcohol rub compared with a 5 minute alcohol rub; evidence was low quality in both cases. One study reported that 3 minute subsequent scrubs with aqueous chlorhexidine (following initial scrubs) were more effective in reducing the number of CFUs on hands than 30 second subsequent scrubs; this difference was not observed with povidone iodine treatments used in the same way: estimates from this study was classed as being of very low quality. Other comparisons reported no clear differences in number of CFUs.

Comparison 7: surgical hand antisepsis using a nail pick versus surgical hand antisepsis not using a nail pick (1 trial)

One three-arm trial compared the effect of surgical hand antisepsis using a nail pick with surgical hand antisepsis alone (Tanner 2009).
The study randomised 164 participants to one of three groups. All groups scrubbed with two measured doses of $2 \mathrm{ml}$ aqueous chlorhexidine gluconate 4\% (Hibiscrub) for 1 minute per dose; the total scrub time, which was observed and timed, was 2 minutes. One group performed only this surgical hand antisepsis. A second group used a disposable nail pick to clean their nails under running water before the hand antisepsis procedure. The third group used a disposable nail brush to clean their nails under running water before the hand antisepsis procedure. Participants then undertook circulating duties in the operating room for one hour but did not participate in any surgeries.

\section{Outcomes}

Surgical site infection

Not reported

Number of colony forming units (CFUs)

There was no clear evidence of a difference between nail pick and no nail pick in the number of CFU detected after one hour on the dominant hands of participants (MD $0.13,95 \% \mathrm{Cl}-0.14$ to 0.40 ; Analysis 15.1).

Very low quality evidence - downgraded once due to imprecision and once due to indirectness of outcome and further again for indirectness as no surgery was performed.

Comparison 8 surgical hand antisepsis using a brush versus surgical hand antisepsis not using a brush (1 trial)

In the same three-arm trial (Tanner 2009) compared the effect of surgical hand antisepsis and using a brush with surgical hand antisepsis alone. Participants were allocated to groups as described above. There was no clear evidence of a difference between using and not using a brush during hand antisepsis on the number of CFUs (MD 0.24, 95\% Cl -0.04 to 0.51; Analysis 16.1).

Very low quality evidence; downgraded once due to imprecision and once due to indirectness of outcome and further again for indirectness as no surgery was performed.

Comparison 9: surgical hand antisepsis using a nail pick versus surgical hand antisepsis using a brush (1 trial)

In the same three-arm trial (Tanner 2009) compared the effect of surgical hand antisepsis using a nail pick with surgical hand antisepsis using a brush. There was no difference in the number of CFUs detected after 1 hour on the dominant hands of participants who used a brush before hand antisepsis compared with those who used a nail pick before hand antisepsis (MD $0.10,95 \% \mathrm{Cl}-0.17$ to 0.37; Analysis 17.1).

Very low quality evidence - downgraded once due to imprecision and once due to indirectness of outcome and further again for indirectness as no surgery was performed.

Summary of Comparisons 7 to 9: Surgical hand antisepsis using a nail pick and brush

There was no clear evidence of a difference in CFUs when a nail pick was compared with a brush or with no pick or brush.

Brief overview of findings 


\begin{tabular}{|c|c|c|c|c|c|}
\hline Comparison & Evidence & SSI & $\begin{array}{l}\text { GRADE } \\
\text { ASSESS- } \\
\text { MENT }\end{array}$ & CFUs (on hands) & $\begin{array}{l}\text { GRADE } \\
\text { ASSESS- } \\
\text { MENT }\end{array}$ \\
\hline $\begin{array}{l}\text { Comparison 1: } \\
\text { basic hand hygiene } \\
\text { versus alcohol rub } \\
\text { containing addition- } \\
\text { al active ingredients }\end{array}$ & 1 study & $\begin{array}{l}\text { There was } \\
\text { no clear } \\
\text { evidence } \\
\text { of a differ- } \\
\text { ence be- } \\
\text { tween treat- } \\
\text { ments: RR } \\
0.97 \text { (95\% Cl } \\
0.77 \text { to } 1.23 \text { ) } \\
\text { (Nthumba } \\
2010)\end{array}$ & $\begin{array}{l}\text { Moderate } \\
\text { quality ev- } \\
\text { idence }\end{array}$ & Not reported & - \\
\hline
\end{tabular}

\section{Comparison 2:differ- 4 studies Not reported -} ent aqueous scrub solutions: chlorhexidine gluconate versus povidone iodine
In 4 comparisons (3 studies: Furukawa 2005; Herruzo 2000; Pereira 1990), there was evidence of lower CFU counts immediately following scrubs with chlorhexidine, and in Pereira 1990, also after subsequent scrubbing.

In 1 comparison (1 study) there was no evidence of a difference in the CFU count between an aqueous scrub of chlorhexidine gluconate and an aqueous scrub of povidone iodine plus triclosan (Pereira 1997).
Low quality evidence for Furukawa 2005 and Herruzo 2000 and very low quality evidence for Pereira 1990 and Pereira 1997

Very low quality evidence parison of different alcohol rubs containing additional active ingredients

1 study reported small mean difference values with imprecision around estimates at the 3 time points reported (Pereira 1997). We could not verify the findings of 1 study, which study authors reported as not statistically significant (Gupta 2007).

\begin{tabular}{|c|c|c|c|c|c|}
\hline $\begin{array}{l}\text { Comparison 4: aque- } \\
\text { ous scrubs versus al- } \\
\text { cohol-only rubs }\end{array}$ & 1 study & $\begin{array}{l}\text { RR } 0.56 \text { (95\% } \\
\text { Cl } 0.23 \text { to } \\
1.34 \text { ) (Al- } \\
\text { Naami 2009) } \\
\text { The esti- } \\
\text { mates was } \\
\text { imprecise, } \\
\text { and it was } \\
\text { not possible } \\
\text { to rule out } \\
\text { an effect in } \\
\text { either direc- } \\
\text { tion. }\end{array}$ & $\begin{array}{l}\text { Very low } \\
\text { quality ev- } \\
\text { idence }\end{array}$ & Not reported & - \\
\hline $\begin{array}{l}\text { Comparison 5: aque- } \\
\text { ous scrubs versus al- } \\
\text { cohol rubs contain- } \\
\text { ing additional active } \\
\text { ingredients }\end{array}$ & 6 studies & $\begin{array}{l}2 \text { studies re- } \\
\text { ported SSI } \\
\text { data: } \\
\text { RR } 1.02,95 \% \\
\text { Cl } 0.70 \text { to }\end{array}$ & $\begin{array}{l}\text { Low qual- } \\
\text { ity evi- } \\
\text { dence }\end{array}$ & $\begin{array}{l}\text { Reported for } 5 \text { sub-comparisons based on prod- } \\
\text { uct type } \\
\text { In } 3 \text { sub-comparisons ( } 2 \text { studies), there was evi- } \\
\text { dence that an alcohol rub with added ingredient } \\
\text { reduced the CFU count on the hands compared to } \\
\text { aqueous scrubs (different types) immediately af- }\end{array}$ & $\begin{array}{l}\text { Moderate } \\
\text { quality ev- } \\
\text { idence for } \\
\text { Pietsch } \\
2001 \text {, and } \\
\text { very low } \\
\text { quality for }\end{array}$ \\
\hline
\end{tabular}


1.48 (Parienti

$$
\text { 2002) }
$$

RR $0.56,95 \%$

$\mathrm{Cl} 0.05$ to

5.34 (Ver-

gara-Fernan-

dez 2010)

Both esti-

mates were

imprecise,

and it was

not possible

to rule out

an effect in

either direc-

tion ter antisepsis and at the end of the surgical procedure (Pietsch 2001; Herruzo 2000).

One sub-comparison (1 study) suggested that the aqueous scrub was more effective in reducing CFUs than the alcohol rub with added ingredient (Hajipour 2006).

One sub-comparison (1 study) suggested no evidence of a difference between interventions (Gupta 2007).
Hajipour 2006, Herruzo 2000 and Gupta 2007

Comparison 6: dura- 4 studies Not reported
tion of surgical anti-
sepsis

$\mathbf{3}$ min versus $\mathbf{2}$ min scrub: evidence of fewer
CFUs in 3 min scrub group immediately after
scrubbing (MD 0.29, 95\% Cl 0.06 to 0.52; Wheelock
1997)

5 min scrub versus 3 min scrub: evidence of fewer CFUs immediately after scrubbing in the $3 \mathrm{~min}$ group (MD 0.26, 95\% Cl 0.14 to 0.38; Kappstein 1993)

5 min initial and 3 min subsequent scrub versus a 3 min initial and 30 s subsequent scrub:

Chlorhexidine scrub: evidence of fewer CFUs in the longer scrub duration group after the subsequent scrubs (Pereira 1990)

Povidone iodine scrub: no evidence of a difference in CFUs between groups at any stage (Pereira 1990)

5 min initial and 3.5 min subsequent scrub versus a $3 \mathrm{~min}$ initial and $2.5 \mathrm{~min}$ subsequent scrub using chlorhexidine: no evidence of a difference in CFUs at any stage (Pereira 1997)

\begin{tabular}{|c|c|c|c|c|c|}
\hline $\begin{array}{l}\text { Comparison 7: surgi- } \\
\text { cal hand antisepsis } \\
\text { using a nail pick ver- } \\
\text { sus surgical hand an- } \\
\text { tisepsis not using a } \\
\text { nail pick }\end{array}$ & 1 study & Not reported & - & $\begin{array}{l}\text { Mean difference in CFUs } 1 \mathrm{~h} \text { after antisepsis was } \\
0.13(95 \% \mathrm{Cl}-0.14 \text { to } 0.40 ; \text { Tanner 2009). No clear } \\
\text { evidence of a difference. }\end{array}$ & $\begin{array}{l}\text { Very low } \\
\text { quality evi- } \\
\text { dence }\end{array}$ \\
\hline $\begin{array}{l}\text { Comparison 8: sur- } \\
\text { gical hand antisep- } \\
\text { sis using a brush ver- } \\
\text { sus surgical hand an- } \\
\text { tisepsis not using a } \\
\text { brush }\end{array}$ & 1 study & Not reported & - & $\begin{array}{l}\text { Mean difference in CFUs } 1 \mathrm{~h} \text { after antisepsis was } \\
0.24 \text { ( } 95 \% \mathrm{Cl}-0.04 \text { to } 0.51 ; \text { Tanner 2009). No clear } \\
\text { evidence of a difference. }\end{array}$ & $\begin{array}{l}\text { Very low } \\
\text { quality evi- } \\
\text { dence }\end{array}$ \\
\hline $\begin{array}{l}\text { Comparison 9: surgi- } \\
\text { cal hand antisepsis } \\
\text { using a nail pick ver- }\end{array}$ & 1 study & Not reported & - & $\begin{array}{l}\text { Mean difference in CFUs } 1 \mathrm{~h} \text { after antisepsis was } \\
0.10(95 \% \mathrm{Cl}-0.17 \text { to } 0.37 ; \text { Tanner 2009). No clear } \\
\text { evidence of a difference. }\end{array}$ & $\begin{array}{l}\text { Very low } \\
\text { quality evi- } \\
\text { dence }\end{array}$ \\
\hline
\end{tabular}

Surgical hand antisepsis to reduce surgical site infection (Review)

Copyright $\odot 2016$ The Cochrane Collaboration. Published by John Wiley \& Sons, Ltd.
Low quality evidence for Kappstein 1993 and very low quality evidence for Pereira 1990, Pereira 1997 and Wheelock 1997 $\begin{array}{ll}0.10(95 \% \mathrm{Cl}-0.17 \text { to } 0.37 ; \text { Tanner 2009). No clear } & \begin{array}{l}\text { quality evi- } \\ \text { evidence of a difference. }\end{array}\end{array}$ 


\section{DISCUSSION}

\section{Summary of main results}

Fourteen trials met the inclusion criteria and were included in this review.

Only four trials reported risk of surgical site infection (SSI), the primary outcome for this review (Al-Naami 2009; Nthumba 2010; Parienti 2002; Vergara-Fernandez 2010). These results were inconclusive, and it is not clear whether any method of hand antisepsis is any more effective than another in reducing subsequent SSI. Most of the evidence was of low or very low quality, mainly due to risk of bias and imprecision. Most of the studies were too small to detect a difference in SSI rates even if one existed.

The remaining 10 trials measured the number of CFUs on hands. Where trials were cluster and/or crossover trials they were often not analysed correctly, which may impact on the precision of estimates.

In four comparisons of aqueous scrub solutions containing chlorhexidine versus those containing povidone iodine, (three studies) there was evidence that chlorhexidine-gluconate containing scrubs reduce numbers of CFU on the hands more than povidone iodine (Furukawa 2005; Herruzo 2000; Pereira 1990). The evidence was of low or very low quality. High levels of heterogeneity precluded meta-analysis.

Results of studies comparing alcohol rubs with aqueous scrubs were mixed. In three comparisons (two studies) alcohol rubs containing additional active ingredients were found to be more effective than aqueous scrubs in reducing the number of CFUs on hands (moderate and very low quality evidence) (Herruzo 2000; Pietsch 2001). Gupta 2007 reported no difference between povidone iodine scrubs and ethyl alcohol based rubs of $61 \%$ and $70 \%$ (very low quality evidence). Hajipour 2006 found chlorhexidine aqueous scrubs more effective than chlorhexidine in alcohol rubs (very low quality evidence).

In terms of the duration of hand antisepsis, there was evidence that a 3 minute scrub reduced the number of CFUs compared to a 2 minute scrub (Wheelock 1997) (very low quality evidence). Data on other comparisons were not consistent, and interpretation is difficult.

One three-arm trial assessed the use of a disposable nail pick or disposable nail brush under running water prior to scrubbing with chlorhexidine and found no clear difference in the number of CFUs (very low quality evidence) (Tanner 2009).

Nthumba 2010, which found no difference in SSIs when comparing surgical hand antisepsis with basic hand hygiene (moderate quality evidence), has interesting implications for practice, which warrant further research.

\section{Quality of the evidence}

Surgical hand antisepsis is carried out to reduce the number of bacteria on the hands of the surgical team so that in the event of a breach in glove barrier protection, the risk of transferring infections to patients is reduced. Therefore, the most appropriate outcome measure for a study of surgical hand antisepsis is postoperative SSI. Only four studies used this measure (Al-Naami 2009; Nthumba 2010; Parienti 2002; Vergara-Fernandez 2010), while the remaining 10 trials measured CFUs. It is widely assumed that interventions reducing CFUs may impact on incidence of SSIs but there is little evidence to support this assertion. There was considerable variation in the timing of outcome assessment for measuring CFUs as well as some differences in the methods used to obtain samples.

All of the studies included in this review were underpowered in terms of small sample sizes, a limited number of outcome events or both. RCTs need to be adequately powered so that they are able to detect treatment effects of a specified size if they exist, and sample size calculations should be used to help estimate the number of people recruited to a trial. Evidence from limited numbers of participants and/or where limited numbers of events occur can also lead to confidence intervals that are fragile (that is not stable) which is also likely to have been a risk for all comparisons here.

A key issue with the included studies was the incorrect or unclear analysis and presentation of cross-over and cluster data. When these methods are used, correct planning, conduct and reporting are vital to maximise the value of the research. Cross-over studies involve an individual receiving more than one of the treatments of interest, with the randomisation consisting of the sequence in which these are received. The analysis requires statistical tests that take the paired nature of these data into account. If investigators do not use these approaches, they may overestimate standard errors, leading to confidence intervals which are less precise than they might be - that is, there is a risk of a type II error (concluding no significant difference when there is one). Cluster trials, where allocation of treatment is made at a group level and the unit of assessment is at the individual level, require careful planning and analysis to avoid producing artificially small standard errors which can lead to type I errors - that is, finding a statistical significant difference when one does not exist.

\section{Potential biases in the review process}

We attempted to overcome potential publication bias through rigorous searching. We had two studies translated, one from German and one from Spanish (Kappstein 1993; Vergara-Fernandez 2010). Five other trials also took place in countries where English is not the first language: Al-Naami 2009 in Saudi Arabia, Furukawa 2005 in Japan, Herruzo 2000 in Spain, Nthumba 2010 in Kenya and Pietsch 2001 in Germany.

We attempted to contact seven trial authors for additional information (Gupta 2007; Hajipour 2006; Herruzo 2000; Kappstein 1993; Pereira 1997; Pietsch 2001; Sensoz 2003). Five authors responded (Hajipour 2006; Herruzo 2000; Kappstein 1993; Pereira 1997; Sensoz 2003). We included six of these trials in the review (Gupta 2007; Hajipour 2006; Herruzo 2000; Kappstein 1993; Pereira 1997; Pietsch 2001). For the update we excluded Sensoz 2003, as there were no indications from the publication that participants were randomised, and we were unable to obtain information to the 
contrary. For the update we attempted to contact one author (Chen 2012); this trial is awaiting assessment.

Four trials acknowledged the role of commercial companies in supplying antiseptic products (Parienti 2002; Pereira 1990; Pereira 1997; Vergara-Fernandez 2010), and one trial was led by a research employee of a commercial company (Pietsch 2001). Tanner 2009 reported funding from a commercial company. As the lead author of this review was also an author on an included study (Tanner 2009), two other authors independently extracted data from it and drafted related review text to minimise any bias.

\section{Agreements and disagreements with other studies or reviews}

This updated review differs from the earlier review as it includes an additional four studies (Al-Naami 2009; Nthumba 2010; Tanner 2009; Vergara-Fernandez 2010). However the addition of these new studies did not result in a change to the findings of the earlier review.

We identified two other systematic reviews of surgical hand antisepsis (Goncalves 2012; Hsieh 2006). We discussed Hsieh 2006 in the earlier version of this Cochrane review, but Goncalves 2012, published in 2012, is new to this update. Goncalves 2012 included 23 studies and two systematic reviews (the previous version of this Cochrane review and Hsieh 2006), focusing on traditional scrubs versus alcohol rubs. It included randomised trials, non-randomised trials, cohort studies, case-control studies, descriptive studies and case reports. Goncalves 2012 included six randomised studies which fell within the search dates of this update review but are excluded from this review (Larson 1990; Hobson 1998; Mulberry 2001; Larson 2001b; Marchetti 2003; Rotter 2006); Goncalves 2012 also included one unpublished study that we were unable to retrieve (Sigler 2001). However, we did include three of the same randomised studies (Pietsch 2001; Parienti 2002; Gupta 2007). Goncalves 2012 concluded that alcohol preparations can replace traditional scrubs using aqueous chlorhexidine or iodine.

Hsieh 2006 was published in 2006 and includes three trials (Bryce 2001; Larson 2001b; Wheelock 1997). This Cochrane review update also included Wheelock 1997 but excluded Bryce 2001 and Larson 2001b, as they were not randomised. Hsieh 2006 failed to identify six of the eight trials published before 2006 that were included in this Cochrane review (Furukawa 2005; Herruzo 2000; Kappstein 1993; Pereira 1990; Pereira 1997; Pietsch 2001), and they excluded Parienti 2002 because it measured SSIs rather than CFUs. Hsieh 2006 draws two conclusions: that surgical handrubs using alcoholbased products are more effective than 6 minute scrubs using $4 \%$ chlorhexidine, and that there is no evidence that a 2 minute scrub is more effective than a 3 minute scrub using $4 \%$ chlorhexidine.

Guidelines for hand antisepsis have changed slightly since the first version of this Cochrane review was published. The main changes are the increasing status of alcohol rubs, which are now considered to have equal standing to traditional scrubs and are acceptable alternatives (AfPP 2011; ACORN 2012); and the use of brushes which has been downgraded from not necessary to not recommended (AfPP 2011; ACORN 2012).

The conclusions one can draw from the evidence in this review are limited for the following reasons. Ten of the 14 trials included in this review measured CFUs rather than SSIs (Furukawa 2005; Gupta
2007; Hajipour 2006; Herruzo 2000; Kappstein 1993; Pereira 1990; Pereira 1997; Pietsch 2001; Tanner 2009; Wheelock 1997). Two of these trials used the finger press method rather than the recognised standard glove juice test (Hajipour 2006; Herruzo 2000). Sample sizes are small in most of the trials. In three trials, participants in the scrub group had a choice of antiseptic solutions (Al-Naami 2009; Parienti 2002; Wheelock 1997), and details of the randomisation are poor in many of the trials.

\section{AUTHORS' CONCLUSIONS}

\section{Implications for practice}

Uncertainty remains about the optimal method of hand antisepsis for minimising SSI outcomes: only four studies reported this outcome, and they were heterogeneous, at high risk of bias and mainly greatly underpowered. For the secondary (and surrogate) outcome of the number of CFUs on the hands, there is some generally low or very low quality evidence that quality chlorhexidine aqueous scrubs may reduce CFUs compared with povidone iodine aqueous scrubs and that an alcohol rub with added ingredient reduced the number of CFUs on the hand compared with aqueous scrubs (different types) immediately after antisepsis and at the end of the surgical procedure. The evidence regarding the impact of using a nail pick or brush on CFUs is unclear. In terms of duration of antisepsis, scrubbing for 3 minutes rather than 2 minutes may lead to fewer CFUs on the hand (low or very low quality evidence). Other data are more difficult to interpret.

\section{Implications for research}

Trials should attempt to measure the impact of hand antisepsis on SSIs. Investigators should also adhere to a recognised definition of SSI, which includes a 30 day follow-up. Trials should use adequate sample sizes based on a priori sample size calculations and take account of any data cross-over and/or clustering. The following trials might address important clinical questions - these and related uncertainties should be prioritised in conjunction with health professionals and policy makers. Future studies should be adequately designed and powered.

- Antisepsis compared with standard handwashing approaches.

- Relative effectiveness of aqueous scrubs versus alcohol rubs (outcome SSI).

- Optimum duration of aqueous scrubs (outcome SSI).

- Optimum duration of alcohol rubs (outcome SSI).

- Brushes, nail picks and sponges compared with no brushes, nail picks or sponges (outcome SSI).

\section{ACK N O WLEDGEMENTS}

The authors would like to thank Cochrane Wounds Group peer referees (Vickie Arrowsmith, Roy Buffery, Seokuyng Hahn, Anne Humphreys, Anita Kainth, Rachel Richardson and John Timmons); Editors (Nicky Cullum and Andrea Nelson) Mieke Flour, Raj Mani and Managing Editor Sally Bell-Syer for their comments to improve the review.

For this update the authors also thank Sonya Osborne for comments as referee and Rocio Rodriguez Lopez and Jennifer Brown for their assistance with papers in Spanish and German. Jean Stuart, Sandra Swarbook, Wendy Padley and Nathorn Chaiyakunaprik all contributed to the original review and we would 
like to acknowledge their contribution although they were not involved in the production of this update. Thanks to Meggan Harris who copy edited this version of the review.
This work was supported by a grant from the National Institute for Health Research, UK (NIHR Cochrane programme Grant 13/89/08- High Priority Cochrane Reviews in Wound Prevention and Treatment). 


\section{R E F E R E N C E S}

\section{References to studies included in this review}

Al-Naami 2009 \{published data only\}

Al-Naami MY, Anjum MN, Afzal MF, Al-Yami MS, Al-Qahtani SM, Al-Dohayan AD, et al. Alcohol-based hand-rub versus traditional surgical scrub and the risk of surgical site infection: a randomized controlled equivalent trial. EWMA Journal 2009;9(3):5-10.

\section{Furukawa 2005 \{published data only\}}

Furukawa K, Tajiri T, Sudzuki H, Norose Y. Are sterile water and brushes necessary for hand washing before surgery in Japan? Journal of Nippon Medical School 2005;72(3):149-54.

\section{Gupta 2007 \{published data only\}}

Gupta C, Czubatyj AM, Briski LE, Malani AK. Comparison of two alcohol-based surgical scrub solutions with an iodine-based brush for presurgical antiseptic effectiveness in a community hospital. Journal of Hospital Infection 2007;65(1):65-71.

\section{Hajipour 2006 \{published and unpublished data\}}

Hajipour L, Longstaff C, Cleeve V, Brewster N, Bint D, Henman P. Hand washing rituals in trauma theatre: clean or dirty?. Annals of the Royal College of Surgeons of England 2006;88(1):13-5.

\section{Herruzo 2000 \{published and unpublished data\}}

Herruzo Cabrera R, Vizcaino Alcaide MJ, Fdez Acinero MJ. Usefulness of an alcohol solution of $\mathrm{N}$-duopropenide for the surgical antisepsis of the hands compared with handwashing with iodine povidone and chlorhexidine. Journal of Surgical Research 2000;94(1):6-12.

\section{Kappstein 1993 \{published data only\}}

Kappstein I, Schulgen G, Waninger J, Daschner F. Microbiological and economic studies of abbreviated procedures for surgical hand disinfection [Mikrobiologische und okonomische Untersuchungen uber verkurzte Verfahen fur die chirurgische Handedesinfektion]. Der Chirurg 1993;64(5):400-5.

\section{Nthumba 2010 \{published data only\}}

Nthumba PM, Stepita-Poenaru E, Poenaru D, Bird P, Allegranzi B, Pittet $D$, et al. Cluster-randomized, crossover trial of the efficacy of plain soap and water versus alcohol-based rub for surgical hand preparation in a rural hospital in Kenya. British Journal of Surgery 2010;97(11):1621-8.

\section{Parienti 2002 \{published data only\}}

Parienti JJ, Thibon P, Heller R, Le Roux Y, Theobald P, Bensadoun $\mathrm{H}$, et al. Hand-rubbing with an aqueous alcoholic solution vs traditional surgical hand-scrubbing and 30-day surgical site infection rates. JAMA 2002;288(6):722-7.

\section{Pereira 1990 \{published data only\}}

Pereira LJ, Lee GM, Wade KJ. The effect of surgical handwashing routines on the microbial counts of operating room nurses. American Journal of Infection Control 1990;18(6):354-64
Pereira 1997 \{published and unpublished data\}

Pereira LJ, Lee GM, Wade KJ. An evaluation of five protocols for surgical handwashing in relation to skin condition and microbial counts. Journal of Hospital Infection 1997;36(1):49-65.

Pietsch 2001 \{published data only\}

Pietsch $\mathrm{H}$. Hand antiseptics: rubs versus scrubs, alcoholic solutions versus alcoholic gels. Journal of Hospital Infection 2001;48(Suppl A):S33-6.

\section{Tanner 2009 \{published data only\}}

Tanner J, Khan D, Walsh S, Chernova J, Lamont S, Laurent T. Brushes and picks used on nails during the surgical scrub to reduce bacteria: a randomised trial. Journal of Hospital Infection 2009;71(3):234-8.

\section{Vergara-Fernandez 2010 \{published data only\}}

Vergara-Fernandez $\mathrm{O}$, Morales-Olivera JM, Ponce-de-LeonRosales S, Vega-Batista R, Mejfa-Ovaile R, Huertas-Jimenez M. Surgical team satisfaction levels between two preoperative hand-washing methods [Niveles de satisfacción del equipo quirúrgico entre dos métodos de lavado de mano]. Revista de Investigación Clínica 2010;62(6):532-7.

\section{Wheelock 1997 \{published data only\}}

Wheelock SM, Lookinland S. Effect of surgical hand scrub time on subsequent bacterial growth. AORN Journal 1997;65(6):1087-98.

\section{References to studies excluded from this review}

Adjoussou 2009 \{published data only\}

Adjoussou S, Konan Blé R, Séni K, Fanny M, Toure-Ecra A, Koffi A, et al. Value of hand disinfection by rubbing with alcohol prior to surgery in a tropical setting [Intérêt de la désinfection chirugicale des mains par friction alcoolique en milieu tropical]. Médicine Tropicale 2009;69(5):463-6.

Aly 1983 \{published data only\}

Aly R, Maibach HI. Comparative evaluation of chlorhexidine gluconate and povidone-iodine sponge/brushes for presurgical hand scrubbing. Current Therapeutic Research 1983;34(4):740-5.

Aly 1988 \{published data only\}

Aly R, Maibach HI. Comparative antibacterial efficacy of a 2 minute surgical scrub with chlorhexidine gluconate, povidoneiodine, and chloroxylenol brushes. American Journal of Infection Control 1988;16(4):173-7.

Aly 1998 \{published data only\}

Aly R, Bayles C, Bibel DJ, Maibach HI, Orsine CA. Clinical efficacy of a chlorous acid preoperative skin antiseptic. American Journal of Infection Control 1998;26(4):406-12.

Arata 1993 \{published data only\}

Ararat T, Murakami T, Hirai Y. Evaluation of povidone iodine alcoholic solution for operative site disinfection. Postgraduate Medical Journal 1993;69(Suppl 3):S93-6. 
Ayliffe 1984 \{published data only\}

Ayliffe GAJ. Surgical scrub and skin disinfection. Infection Control 1984;5(1):23-7.

\section{Ayliffe 1988 \{published data only\}}

Ayliffe GAJ, Babb JR, Davies JG, Lilly HA. Hand disinfection: a comparison of various agents in laboratory and ward studies. Journal of Hospital Infection 1988;11(3):226-43.

Ayliffe 1990 \{published data only\} Ayliffe GAJ, Babb JR, Davies JG, Newsom SWB, Rowland C, Platt JH, et al. Hygienic hand disinfection tests in three laboratories. Journal of Hospital Infection 1990;16(2):141-9.

\section{Babb 1991 \{published data only\}}

Babb JR, Davies JG, Ayliffe GAJ. A test procedure for evaluating surgical hand disinfection. Journal of Hospital Infection 1991;18(Suppl B):41-9.

\section{Bansal 2002 \{published data only\}}

Bansal BC, Wiebe RA, Perkins SD, Abramo TJ. Tap water for irrigation of lacerations. American Journal of Emergency Medicine 2002;20(5):469-72.

\section{Barsanti 2009 \{published data only\}}

Barsanti MC, Woeltje KF. Infection prevention in the Intensive Care Unit. Infectious Diseases Clinics of North America 2009;23(3):703-25

\section{Bartzokas 1983 \{published data only\}}

Bartzokas CA, Gibson MF, Graham R, Pinder DC. A comparison of triclosan and chlorhexidine preparations with $60 \%$ isopropyl alcohol for hygienic hand disinfection. Journal of Hospital Infection 1983;4(3):245-55.

\section{Bearman 2010 \{published data only\}}

Bearman G, Rosato AE, Duane TM, Elam K, Sanogo K, Haner C, et al. Trial of universal gloving with emollient-impregnated gloves to promote skin heath and prevent the transmission of multidrug-resistant organisms in a surgical intensive care unit. Infection Control and Hospital Epidemiology 2010;31(5):491-7.

\section{Beeuwkes 1986 \{published data only\}}

Beeuwkes H, De Rooij SH. Microbiological tests on operating theatre staff of a new disinfectant foam based on $1 \%$ chlorhexidine gluconate. Journal of Hospital Infection 1986;8(2):200-2.

\section{Bendig 1990 \{published data only\}}

Bendig JWA. Surgical hand disinfection: comparison of $4 \%$ chlorhexidine detergent solution and $2 \%$ triclosan detergent solution. Journal of Hospital Infection 1990;15(2):143-8.

\section{Bernam 2004 \{published data only\}}

Berman M. One hospital's clinical evaluation of brushless scrubbing. AORN Journal 2004;79(2):349-358.

\section{Bibbo 2005 \{published data only\}}

Bibbo C, Patel DV, Gehrmann RM, Lin SS. Chlorhexidine provides superior skin decontamination in foot and ankle surgery. Clinical Orthopeadics and Related Research 2005;438:204-8.

\section{Blomgren 1983 \{published data only\}}

Blomgreng, Hambraeus A, Malmborg AS. The influence of the total body exhaust suit on air and wound contamination in elective hip operations. Journal of Hospital Infection 1983;4(3):257-68.

\section{Borer 2001 \{published data only\}}

Borer A, Gilad J, Meydan N, Riesenberg K, Schlaeffer F, Alkan M, et al. Impact of active monitoring of infection control practices on deep sternal infection after open-heart surgery. Annals of Thoracic Surgery 2001;72(2):515-20.

\section{Boyce 2000a \{published data only\}}

Boyce JM. Using alcohol for hand antisepsis: dispelling old myths. Infection Control and Hospital Epidemiology 2000;21(7):438-41.

Boyce 2000b \{published data only\}

Boyce JM, Kelliher S, Vallande. Skin irritation and dryness associated with two hand hygiene regimens: soap and water hand washing versus hand antisepsis with an alcoholic hand gel. Infection Control and Epidemiology 2000;21(7):442-8.

Braumann 2008 \{published data only\}

Braumann C, Pirlich M, Menenakos C, Lochs H, Mueller JM. Implementation of the clean and close concept for treatment of surgical and chronic wounds in three university centres in Berlin-Germany. EWMA Journal 2008;8(2 Suppl):41. Abstract no 44.

\section{Breeze 1994 \{published data only\}}

Breeze W. It is time to standardize surgical hand scrubs?. AORN Journal 1994;60(2):294-306.

Brooks 2001 \{published data only\}

Brooks RA, Hollinghurst D, Ribbans WJ, Severn M. Bacterial recolonisation during foot surgery. Foot and Ankle International 2001;22(4):347-50.

\section{Bruckner 2009 \{published data only\}}

Bruckner M, Wild T, Schwarz C, Payrich M, Eberlein T. Autolytic wound cleansing potential of different cellulose-based dressings. EWMA Journal 2009;9(2):170, Abstract P146.

Bryce 2001 \{published data only\}

Bryce EA, Spence D, Roberts FJ. An in-use evaluation of an alcohol-based pre-surgical hand disinfectant. Infection Control and Hospital Epidemiology 2001;22(10):635-40.

\section{Caelli 2000 \{published data only\}}

Caelli M, Porteous J, Carson CF, Heller R, Riley TV. Tea tree oil as an alternative topical decolonization agent for methicillinresistant Staphylococcus aureus. Journal of Hospital Infection 2000;46(3):236-7.

\section{Carro 2007 \{published data only\}}

Carro C, Camilleri L, Traore O, Badrikian L, Legauly B, Azarnoush K, et al. An in-use microbiological comparison of two surgical hand disinfection techniques in cardiothoracic surgery: hand rubbing versus hand scrubbing. Journal of Hospital Infection 2007;67(1):62-6. 
Cheng 2001 \{published data only\}

Cheng SM, Garcia M, Espin S, Conly J. Literature review and survey comparing surgical scrub techniques. AORN Journal 2001;74(2):218-24.

\section{Coelho 1984 \{published data only\}}

Coelho JCU, Lerner H, Murad I. The influence of the surgical scrub on hand bacterial flora. International Surgery 1984;69(4):305-7.

\section{Cremieux 1989 \{published data only\}}

Cremieux A, Reverdy ME, Pons JL, Savage C, Chevalier J, Fleurette J, et al. Standardised method for evaluation of hand disinfection by surgical scrub formulations. Applied and Environmental Microbiology 1989;55(11):2944-8.

\section{Crowder 1967 \{published data only\}}

Crowder VH, Welsh JS, Bornside GH, Cohn I. Bacterial comparison of hexachlorophen and polyvinylpyrrolideone iodine surgical scrub soaps. The American Surgeon 1967;33(11):906-11.

\section{Culligan 2005 \{published data only\}}

Culligan PJ, Kubik K, Murphy M, Blackwell L, Snyder J. A randomised trial that compared povidone iodine and chlorhexidine as antiseptics for vaginal hysterectomy. Americal Journal of Obstetrics and Gynecology 2005;192(2):422-5.

\section{Curti 1974 \{published data only\}}

Curti Junior A, Pagani C. Use of chemical agents germ hand, germekil, savlon and valmicid GI in disinfection of rubber dam as an integral part of total isolation of the surgical field [O uso dos agentes químicos germ hand, germekil instrumental, savlon e valmicid $\mathrm{GI}$ na desinfecção do lencol de borracha odontológico como parte integrante do isolamento absoluto do campo operatório]. Ars curandi Em Odontologia 1974;1(3):56-60.

\section{Da Cunha 2011 \{published data only\}}

Da Cunha ER, De Oliveira Azevedo Matos FG, Da Silva AM, De Araujo EAC, Ferreira KA, Graziano KU. The efficacy of three hand asepsis techniques using chlorhexidine gluconate (CHG 2\%) [Eficácia de três métodos de degermação das mãos utilizando Gluconato de clorexidina degermante (GCH 2\%)]. Revista da Escola de Enfermagem da USP 2011;45(6):1440-5.

\section{Dahl 1990 \{published data only\}}

Dahl J, Wheeler B, Muhkerjee D. Effect of chlorhexidine scrub on postoperative bacterial counts. American Journal of Surgery 1990;159(5):486-8.

\section{Das 2005 \{published data only\}}

Das JKL, Sharma SN, Prasad MK, Tiwari S, Singh UN, Kolhapure SA. Evaluation of the efficacy and safety of "pure hands" in hand hygiene: a prospective, randomized, double blind, placebo-controlled, phase III clinical trial. Indian Practitioner 2005;58(5):275-82.

\section{De Castro Peraza 2010 \{published data only\}}

De Castro Peraza ME, Garzon Rodriguez E, Rodriguez Perez V, Sosa Alvarez I, Gutierrez Hernandez J, Asianin Ugarte C. Glove perforation in surgery and protective effect of double gloves
[Incidencia de la perforación de los guantes en cirugía y efecto protector del doble guante]. Enfermeria Clínica 2010;20(2):73-9.

Demir 2009 \{published data only\}

Demir F. A survey on prevention of surgical infections in operating theatres. Worldviews on Evidence-Based Nursing 2009;6(2):102-13.

\section{Deshmukh 1998 \{published data only\}}

Deshmukh N, Kramer JW. A comparison of 5 minute povidone iodine scrub and 1 minute povidone iodine scrub followed by alcohol foam. Military Medicine 1998;163(3):145-7.

Dineen 1969 \{published data only\}

Dineen P. An evaluation of the duration of the surgical scrub. Surgery, Gynecology and Obstetrics 1969;129(6):1181-4.

Dineen 1978 \{published data only\}

Dineen P. Hand-washing degerming: a comparison of povidoneiodine and chlorhexidine. Clinical Pharmacology and Therapies 1978;23(1):63-7.

Dohmen 2006 \{published data only\}

Dohmen PM. Influence of skin flora and preventive measures on surgical site infection during cardiac surgery. Surgical Infections 2006;7(Suppl 1):S13-7.

Durani 2008 \{published data only\}

Durani P, Leaper D. Povidone-iodine: use in hand disinfection, skin preparation and antiseptic irrigation. International Wound Journal 2008;5(3):376-87.

Elenbaas 1982 \{published data only\}

Elenbaas RM, McNabney WK, Robinson WA. Prophylactic oxacillin in dog bite wounds. Annals of Emergency Medicine 1982;11(5):248-51.

\section{Ellenhorn 2005 \{published data only\}}

Ellenhorn JD, Smith DD, Schwartz RE, Kawachi MH, Wilson TG, McGonigle KF, et al. Paint-only is equivalent to scrub and paint in preoperative preparation of abdominal surgery. Journal of the American College of Surgeons 2005;201(5):737-41.

Faoagali 1995 \{published data only\}

Faogali J, Fong J, George N, Mahoney P, O'Rourke V. Comparison of the immediate residual and cumulative antibacterial effects of Novaderm R, Novascrub R, Betadine Surgical Scrub, Hibiclens and liquid soap. American Journal of Infection Control 1995;23(6):337-43.

\section{Ford 2005 \{published data only\}}

Ford, HR, Jones P, Gaines B, Reblock K, Simpkins DL. Intraoperative handling and wound healing: controlled clinical trial comparing coated VICRYL plus antibacterial suture (coated polyglactin 910 suture iwth triclosan) with coated VICRYL suture (coated polyglactin 910 suture). Surgical Infections 2005;6(3):313-21. 
Grabsch 2004 \{published data only\}

Grabsch EA, Mitchell DJ, Hooper J, Turnidge JD. In-use efficacy of a chlorhexidine in alcohol surgical rub: a comparative study. Australia and New Zealand Journal of Surgery 2004;74(9):769-72.

\section{Grinbaum 1995 \{published data only\}}

Grinbaum RS, De Mendonca JS, Cardo DM. An outbreak of hand scrubbing related surgical site infections in vascular surgical procedures. Infection Control and Hospital Epidemiology 1995;16(4):198-202.

\section{Gruendemann 2001 \{published data only\}}

Gruendemann BJ, Bjerke NB. Is it time for brushless scrubbing with an alcohol based agent?. AORN Journal 2001;74(6):859-73.

Guilhermetti 2001 \{published data only\}

Guilhermetti M, Hernandes SE, Fukushigue Y, Garcia LB, Cardoso CL. Effectiveness of hand-cleaning agents for removing methicillin-resistant Staphylococcus aureus from contaminated hands. Infection Control and Hospital Epidemiology 2001;22(2):105-8.

\section{Hagen 1995 \{published data only\}}

Hagen KS, Treston Aurand J. A comparison of two skin preps using in cardiac surgical procedures. AORN Journal 1995;62(3):393-402.

\section{Harnoss \{published data only\}}

Harnoss JC, Brune L, Ansorg J, Heidecke CD, Assadian O, Kramer A. Practice of skin protection and skin care among German surgeons and influence on the efficacy of surgical hand disinfection and surgical glove perforation. BMC Infectious Diseases 2014;14:315. [DOI: 10.1186/1471-2334-14-315]

\section{Heeg 1986 \{published data only\}}

Heeg P, Osswald W, Schwenzer N. A trial on the efficacy of various surgical hand disinfection method under experimental and clinical conditions [Wirksamkeitsvergleich von desinfektionsverfahren zur chirurgischen handedesinfektion unter experimentellen und klinischen bedingungen]. Hygiene + Medizin 1986;11(3):107-10.

Heeg 2001 \{published data only\}

Heeg P. Does hand care ruin hand disinfection?. Journal of Hospital Infection 2001;48(Suppl A):S37-9.

\section{Heeg 2008 \{published data only\}}

Heeg P, Octermeyer C, Kampf G. Comparative review of the test design Tenative Monograph (TFM) and EN 12791 for surgical hand disinfectants. Journal of Hospital Infection 2008;70(Suppl 1):22-6.

\section{Hibbard 2002a \{published data only\}}

Hibbard JS, Mulbery GK, Brady AR. A clinical study comparing the skin antisepsis and safety of chloraprep, $70 \%$ isopropyl alcohol and $2 \%$ aqueous chlorhexidine. Journal of Infusion Nursing 2002;25(4):244-9.

\section{Hibbard 2002b \{published data only\}}

Hibbard JS. Administration of $2 \%$ chlorhexidine gluconate in 70\% isopropyl alcohol is effective in 30 seconds (letter). Infection Control and Hospital Epidemiology 2002;23(5):233-5.

\section{Hingst 1992 \{published data only\}}

Hingst V, Juditzki I, Heeg P, Sonntag HG. Evaluation of the efficacy of surgical hand disinfection following a reduced application time of 3 instead of 5 min. Journal of Hospital Infection 1992;20(2):79-86.

\section{Hobson 1998 \{published data only\}}

Hobson DW, Woller W, Anderson L, Guthery E. Development and evaluation of a new alcohol-based surgical hand scrub formulation with persistent antimicrobial characteristics and brushless application. American Journal of Infection Control 1998;26(5):507-12.

\section{Hubner 2006 \{published data only\}}

Hubner NO, Kampf G, Loffler H, Kramer A. Effect of a 1 min hand wash on the bactericidal efficacy of consecutive surgical hand disinfection with standard alcohols and on skin hydration. International Journal of Hygiene and Environmnetal Health 2006;209(3):285-91.

\section{Incoll 2009 \{published data only\}}

Incoll I, Saravanja D, Thorvaldson KT, Small T. Comparison of the effectiveness of painting onto the hand and immersing the hand in a bag, in pre-operative skin preparation of the hand. Journal of Hand Surgery: European Volume 2009;34(3):371-3.

\section{Jeng 1998 \{published data only\}}

Jeng DK, Severin JE. Povidone iodine gel alcohol: a 30 second, one time application preoperative skin preparation. American Journal of Infection Control 1998;26(5):488-94.

\section{Jeng 2001 \{published data only\}}

Jeng DK. A new water-resistant film-forming, 30 second, onestep application iodophor preoperative skin preparation. American Journal of Infection Control 2001;29(6):370-6.

\section{Jones 2000 \{published data only\}}

Jones RD, Jampani H, Mulberry G, Rizer RL. Moisturing alcohol hand gels for surgical hand preparation. AORN Journal 2000;71(3):584-7, 589-90, 592.

\section{Joress 1962 \{published data only\}}

Joress SM. A study of disinfection of the skin. Annals of Surgery 1962;155(2):296-304.

\section{Kampf 2005 \{published data only\}}

Kampf G, Ostermeyer C, Heeg P. Surgical hand disinfection with a propanol-based hand rub:equivalence of shorter application times. Journal of Hospital Infection 2005;59(4):304-10.

\section{Kargi 2008 \{published data only\}}

Kargie, Babuccu O, Altunkaya H, Hosnuter M, Ozer Y, Babuccu B, et al. Tramadol as a local anaesthetic in tendon repair surgery of the hand. The Journal of International Medical Research 2008;36(5):971-8. 
Keser 2005 \{published data only\}

Keser A, Bozkurt M, Taner OF, Yorgancigil B, Dogan M, Sensoz O. Evaluation of antiseptic use in plastic and hand surgery. Annals of Plastic Surgery 2005;55(5):490-4.

\section{Kikuchi 1999 \{published data only\}}

Kikuchi Numagami K, Saishu T, Fukaya M, Kanazawa E, Tagami H. Irritancy of scrubbing up for surgery with or without a brush. Acta Dermato- Venereologica 1999;79(3):230-2.

\section{Kjellander 1960 \{published data only\}}

Kjellander J, Nygren B. Trial of a synthetic cream (pHisoHex) for preoperative disinfection of the hands. Svenska Lakartidningen 1960;57:1307-16.

\section{Kong 1994 \{published data only\}}

Kong KC, Sheppard M, Serne G. Dispensing surgical gloves onto the open surgical gown pack does not increase the bacterial contamination rate. Journal of Hospital Infection 1994;26(4):293-6.

\section{Kramer 2007 \{published data only\}}

Kramer A, Hubner N, Below H, Heidecke CD, Assadian O. Improving adherence to surgical hand preparation. Journal of Hospital Infection 2008;70(Suppl 1):35-43.

\section{Kramer 2008 \{published data only\}}

Kramer A, Hubner N, Below H, Heidecke CD, Assadian O. Improving adherence to surgical hand preparation. Journal of Hospital Infection 2008;70(Suppl 1):35-43.

\section{Larson 1984 \{published data only\}}

Larson E. Effects of handwashing agent, handwashing frequency, and clinical area on hand flora. American Journal of Infection Control 1984;11:76-82.

\section{Larson 1986a \{published data only\}}

Larson EL, Eke PI, Laughton BE. Efficacy of alcohol-based hand rinses under frequent-use conditions. Antimicrobial Agents and Chemotherapy 1986;30(4):542-4.

\section{Larson 1986b \{published data only\}}

Larson EL, Leyden JJ, McGinley KJ, Grove GL, Talbot GH. Physiologic and microbiologic changes in skin related to frequent hand washing. Infection Control 1986;7(2):59-63.

\section{Larson 1990 \{published data only\}}

Larson EL, Butz AM, Gullette DL, Laughton BA. Alcohol for surgical scrubbing. Infection Control Hospital Epidemiology 1990;11:139-43.

\section{Larson 1993 \{published data only\}}

Larson E, Anderson JK, Baxendale L, Bobo L. Effects of a protective foam on scrubbing and gloving. American Journal of Infection Control 1993;21(6):297-301.

\section{Larson 2001a \{published data only\}}

Larson E, Aiello A, Lyle C, Stahl J, Cronquist A, Lai L, et al. Assessment of two hand hygiene regimens for intensive care unit personnel. Critical Care Medicine 2001;29(5):944-51.

\section{Larson 2001b \{published data only\}}

Larson EL, Aiello AE, Heilman JM, Lyle C, Cronquist A, Stahl JB, et al. Comparison of different regimens for surgical hand preparation. AORN Journal 2001;73(2):412-32.

\section{Lehmann 1985 \{published data only\}}

Lehmann KA, Horrichs G, Hoeckle W. The significance of tramadol as an intraoperative analgesic. A randomized double-blind study in comparison with placebo. Anaesthetist 1985;34(1):11-9.

\section{Lepor 2009 \{published data only\}}

Lepor NE, Madyoon H. Antiseptic skin agents for percutaneous procedures. Reviews in Cardiovascular Medicine 2009;10(4):187-93.

Lilly 1978 \{published data only\}

Lilly HA, Lowbury JL, Wilkins MD. Detergents compared with each other and with antiseptics as skin degerming agents. Journal of Hygiene of Cambridge 1979;82(1):89-93.

Lio 2009 \{published data only\} Lio PA, Kaye ET. Topical antibacterial agents. Infectious Disease Clinics of North America 2009;23(4):945-63.

\section{Llanos 2006 \{published data only\}}

Llanos S, Danilla S, Barraza C, Armijo E, Piñeros JL, Quintas M, et al. Effectiveness of negative pressure closure in the integration of split thickness skin grafts: a randomized, double masked, controlled trial. Annals of Surgery 2006;244(5):700-5.

\section{Loeb 1997 \{published data only\}}

Loeb MB, Wilcox L, Smaill F, Walter S, Duff Z. A randomized trial of surgical scrubbing with a brush compared to antiseptic soap alone. American Journal of Infection Control 1997;25(1):11-5.

Lowbury 1974a \{published data only\}

Lowbury E, Lilly $\mathrm{H}$. The effect of blood on disinfection of surgeon's hands. British Journal of Surgery 1974;61(1):19-21.

Lowbury 1974b \{published data only\}

Lowbury EJL, Lilly HA, Ayliffe GAJ. Preoperative disinfection of surgeons' hands: use of alcoholic solutions and effects of gloves on skin flora. British Medical Journal 1974;4:369-72.

Lung 2004 \{published data only\}

Lung DC, Man JHK, Tang THC, Wong LKY, Leung GKK. Surgical hand washing. Annals of the College of Surgeons of Hong Kong 2004;8(3):71-5.

\section{Magann 1993 \{published data only\}}

Magann EF, Dodson MK, Ray MA, Harris RL, Martin JN, Morrison JC. Preoperative skin preparation and intraoperative pelvic irrigation: impact on post-Cesarean endometritis and wound infection. Occupational Therapy Journal of Research 1993;81(6):922-5.

\section{Magera 2007 \{published data only\}}

Magera JS, Inman BA, Elliott DS. Does preoperative topical antimicrobial scrub reduce positive surgical site culture rates in 
men undergoing artificial urinary sphincter placement?. Journal of Urology 2007;178(4 Pt 1):1328-2. Discussion 1332.

\section{Marchetti 2003 \{published data only\}}

Marchetti MG, Kampf G, Finzi G, Salvatorelli G. Evaluation of the bactericidal effect of five products for surgical hand disinfection according to prEN 12054 and prEN12791. Journal of Hospital Infection 2003;54(1):63-67.

\section{Marra 2008 \{published data only\}}

Marra AP, D'Arco C, Bravim Bde A, Martino MD, Silva CV, Lamblet LC, et al. Controlled trial measuring the effect of a feedback intervention on hand hygiene compliance in a step-down unit. Infection Control and Hosptial Epidemiology 2008;29(8):730-5.

\section{Mathias 2000 \{published data only\}}

Mathias JM. Sould we discard ritual of scrubbing with brush?. OR Manager 2000;16(9):20-2.

Mathias 2002 \{published data only\}

Mathias JM. Soap, alcohol rub OK for surgical scrub. $O R$ Manager 2002;18(12):6.

\section{McBride 1973 \{published data only\}}

McBride ME, Duncan WC, Knox JM. An evaluation of surgical scrub brushes. Surgery, Gynecology and Obstetrics 1973;137(6):934-6

\section{Meers 1978 \{published data only\}}

Meers PD, Yeo GA. Shedding of bacteria and skin squames after handwashing. Journal of Hygiene 1978;81(1):99-105.

\section{Minakuchi 1993 \{published data only\}}

Minakuchi K, Yamamoto Y, Matsunaga K, Hayata M, Yasuda T, Katsuno Y, et al. The antiseptic effect of a quick drying rubbing type povidone iodine alcoholic disinfectant solution. Postgraduate Medicine 1993;69(Suppl 3):S23-6.

\section{Misterka 1991 \{published data only\}}

Misterka S. Clinical evaluation of hydrogel-type dressing materials after their 8-year use [Kliniczna ocena hydrozelowych materiałów opatrunkowych po 8-letnim ich zastosowaniu]. Polimery w Medycynie 1991;21(1-2):23-30.

\section{Moralejo 2003 \{published data only\}}

Moralejo D, Jull A. Handrubbing with an alcohol based solution reduced healthcare workers' hand contamination more than handwashing with antiseptic soap. Evidence based Nursing 2003;6(2):54

\section{Mulberry 2001 \{published data only\}}

Mulberry G, Snyder AT, Heilman J, Pyrek J, Stahl J. Evaluation of a waterless, scrubless chlorhexidine gluconate/ethanol surgical scrub for antimicrobial efficiency. American Journal of Infection Control 2001;29(6):377-82.

\section{Murie 1980 \{published data only\}}

Murie JA, Macpherson SG. Chlorhexidine in methanol for the preoperative cleansing of surgeons' hands: a clinical trial. Scottish Medical Journal 1980;25(4):309-11.

\section{Nakano 2008 \{published data only\}}

Nakano H, Asakura T, Sakurai J, Loizumi S, Asano T, Watanabe T, et al. Prophylactic irrigation around a pancreaticojejunostomy for the treatment of a pancreatic fistula after a pancreaticoduodenectomy in patients with a risky pancreatic remnant. Hepato-gastroenterology 2008;55(82-83):717-21.

Nowak 1982 \{published data only\}

Nowak W, Erbe HJ. Wound infection prophylaxis in colonic rectal surgery with metronidazole and neomycin - a prospective study. Zentralblatt fur Chirurgie 1982;107(13):763-7.

O'Shaughnessy 1991 \{published data only\}

O'Shaughnessy M, O'Malley VP, Corbett G, Given HF. Optimum duration of surgical scrub-time. British Journal of Surgery 1991;78(6):685-6

Olson 2012 \{published data only\}

Olson LKM, Morse DJ, Duley C, Savell BK. Prospective, randomized in vivo comparison of a dual-active waterless antiseptic versus two alcohol-only waterless antiseptics for surgical hand antisepsis. American Journal of Infection Control 2012;40(2):155-159.

\section{Ortiz 2012 \{published data only\}}

Ortiz H, Armednariz P, Kreisler E, Garcia-Granero E, EspinBasany E, Roig JV, et al. Influence of rescrubbing before laparotomy closure on abdominal wound infection after colorectal cancer surgery. Archives of Surgery 2012;147(7):614-20.

\section{Parienti 2004 \{published data only\}}

Parienti JJ, Du Cheyron D, Ramakers M, MAlbruny B, Leclerq R, Le Coutour X, et al. members of the NACRE Study Group. Alcoholic povidone-iodine to prevent central venous catheter colonization: a randomized unit-crossover study. Critical Care Medicine 2004;32(3):708-13.

\section{Paulson 1994 \{published data only\}}

Paulson DS. Comparative evaluation of five surgical hand scrub preparations. AORN Journal 1994;60(2):246-6.

\section{Paulson 1999 \{published data only\}}

Paulson DS, Fendler EJ, Dolan MJ, Williams RA. A close look at alcohol gel as an antimicrobial sanitizing agent. American Journal of Infection Control 1999;27(4):332-8.

Peterson 1978 \{published data only\}

Peterson AF, Rosenberg A, Alatary SD. Comparative evaluation of surgical scrub preparations. Surgery, Gynecology and Obstetrics 1978;146(1):63-5.

\section{Phimolsarnti 1986 \{published data only\}}

Phimolsarnti R, Kongsamrarn S, Limwongse K, Jitniyom P, Vutavipart P. Effectiveness of surgical hand scrub solutions. Southeast Asian Journal of Surgery 1986;9(1):96-100. 
Poon 1998 \{published data only\}

Poon C, Morgan DJ, Pond K, Kane J, Tulloh B. Studies of the surgical scrub. Australian and New Zealand Journal of Surgery 1998;68(1):65-7.

\section{Rehork 1991 \{published data only\}}

Rehork B, Ruden $\mathrm{H}$. Investigations into the efficacy of different procedures for surgical hand disinfection between consecutive operations. Journal of Hospital Infection 1991;19(2):115-27.

\section{Reid 1991 \{published data only\}}

Reid AB, Stranc MF. Healing of infected wounds following iodine scrub or $\mathrm{CO}_{2}$ laser treatment. Lasers in Surgery and Medicine 1991;11(5):475-80.

\section{Reverdy 1984 \{published data only\}}

Reverdy ME, Martra A, Fleurette J. A Comparative study of nine disinfectants and / or soaps for surgical disinfection of hands [Efficacite de neuf savons et /ou antiseptiques sur la flore des main apres un lavage de type chirugical]. Pathologie Biologie 1984;32(5):591-5.

\section{Rotter 1980 \{published data only\}}

Rotter ML, Koller W, Wewalka G. Povidone iodine and chlorhexidine gluconate containing detergents for disinfection of the hands. Journal of Hospital Infection 1980;1(2):149-58.

\section{Rotter 1984 \{published data only\}}

Rotter ML. Hygienic hand disinfection. Infection Control 1984;5(1):18-22.

\section{Rotter 1986 \{published data only\}}

Rotter ML, Koller W, Wewalka G. Evaluation of procedures for hygienic hand disinfection. Journal of Hygiene 1986;96(1):27-37.

\section{Rotter 1998 \{published data only\}}

Rotter ML, Simpson RA, Koller W. Surgical hand disinfection with alcohols at various concentrations. Infection Control and Hospital Epidemiology 1998;19:778-81.

\section{Rotter 2005 \{published data only\}}

Rotter M, Satter SA, Dharan S, Webber P, Voss A, Pittet D. Comparative efficacy of hand hygiene agents in the reduction of bacteria and viruses. American Journal of Infection Control 2005;339:558-60.

\section{Rotter 2006 \{published data only\}}

Rotter M, Kundi M, Suchomel M, Karke HP, Kramer A, Ostermeyer C, et al. Reproducibility and workability of the European test standard EN 12791 regarding the effectiveness of surgical hand antisepsis: a randomised, multicentre trial. Infection Control and Hospital Epidemiology 2006;27:935-9.

\section{Sattar 2000 \{published data only\}}

Sattar AB, Abebe M, Jampani H, Newman J, Hua S. Activity of an alcohol based hand gel against human adeno-rhino- and rotaviruses using the finger pad method. Infection Control and Hospital Epidemiology 2000;21(8):516-9.

\section{Scheibel 1991 \{published data only\}}

Scheibel JH, Jensen I, Pedersen S. Bacterial contamination of air and surgical wounds during joint replacement operations comparison of two different types of staff clothing. Journal of Hospital Infection 1991;19(3):167-74.

Scott 1991 \{published data only\}

Scott D, Barnes A, Lister M, Arkell P. An evaluation of the user acceptability of chlorhexidine handwash formulations. Journal of Hospital Infection 1991;18(Suppl B):51-5.

\section{Sensoz 2003 \{published and unpublished data\}}

Sensoz O, Uysal AC, Baran CN. Presurgical scrubbing in plastic and reconstructive surgery: a prospective study. European Journal of Plastic Surgery 2003;25(7-8):369-73.

\section{Serra 2005 \{published data only\}}

Serra N, Torres OG, Romo MI, Llovera JM, Vigil Escalera LJ, Soto MA, et al. Hydro-colloidal dressings which release hydrosilver. Revista de Enfermeria 2005;28(2):13-8.

\section{Shirahatti 1993 \{published data only\}}

Shirahatti RG, Joshi RM, Vishwanath YK, Shinkre N, Rao S, Sankpal JS, et al. Effect of pre-operative skin preparation on post-operative wound infection. Journal of Postgraduate Medicine 1993;39(3):134-6.

\section{Simor 2007 \{published data only\}}

Simor AE, Phillips E, McGeer A, Konvalinka A, Loeb M, Devlin HR, et al. Ramdomized controlled trial of chlorhexidine gluconate for washing, intranasal mupirocin, and rifampin and doxycycline versus no treatment for the eradication of methicillin-resistant Staphylococcus aureus colonization. Clinical Infectious Diseases 2007;44(2):178-85.

\section{Springer 2002 \{published data only\}}

Springer R. To brush or not to brush. Plastic Surgery Nursing 2002;22(4):185-8.

\section{Stahl 2007 \{published data only\}}

Stahl JB, Morse D, Parks PJ. Resistance of antimicrobial skin preparations to saline rinse using a seeded bacteria model. American Journal of Infection Control 2007;35(6):367-73.

\section{Starr 2005 \{published data only\}}

Starr RV, Zurawaski J, Ismail M. Preoperative vaginal preparations with povidone iodine and the risk of postcesarean endometritis. Obstetrics and Gynecology 2005;105(5 Pt1):1024-9.

\section{Stevenson 2003 \{published data only\}}

Stevenson J, McNaughton G, Riley J. The use of prophylactic flucloxacillin in treatment of open fractures of the distal phalanx within an accident and emergency department. Journal of Hand Surgery 2003;28B(5):388-94.

\section{Sullivan 2008 \{published data only\}}

Sullivan PJ, Healy CE, Hirpara KM, Hussey AJ, Potter SM, Kelly JL. An assessment of skin preparation in upper limb surgery. Journal of Hand Surgery: European Volume 2008;33(4):513-4. 
Tanner 2008 \{published data only\}

Tanner J. Surgical hand antisepsis: the evidence. Journal of Periopertive Practice 2008;18(8):339.

Thiele 2008 \{published data only\}

Thiele RH, Huffmyer JL, Nemergut EC. The "six stigma approach" to the operating room environment and infection. Best Practice and Research: Clinical Anaesthesiology 2008;22(3):537-52.

Tucci 1977 \{published data only\}

Tucci V, Stone AM, Thompson C. Studies of the surgical scrub. Surgery, Gynecology and Obstetrics 1977;145:415-6.

\section{Valente 2003 \{published data only\}}

Valente JH, Forti RJ, Freundlich LF, Zandieh SO, Crain EF. Wound irrigation in children:saline solution or tap water?. Annals of Emergency Medicine 2003;41(5):609-16.

\section{Vogt 2006 \{published data only\}}

Vogt PM, Remier K, Hauser J, Rossbach O, Steinau HU, Bosse B, et al. PVP-iodine in hydrosomes and hydrogel - a novel concept in wound therapy leads to enhanced epithelialization and reduced loss of skin grafts.. Burns 2006;32(6):698-705.

\section{Voss 1997 \{published data only\}}

Voss A, Widmer AF. No time for handwashing? Handwashing versus alcoholic rub: can we afford $100 \%$ compliance?. Infection Control and Hospital Epidemiology 1997;18(3):205-8.

\section{Vossinakis 2004 \{published data only\}}

Vossinakis IC, Stavroulaki P, Paleochorlidis, Badras LS. Reducing the pain associated with local anaesthetic infiltration for open carpal tunnel decompression. Journal of hand surgery 2004;29(4):399-401.

\section{Walwaikar 2002 \{published data only\}}

Walwaikar PP, Morye VK, Gawde AS. Open, prospective trial to evaluate the efficacy and safety of combination of metronidazole and povidone iodine in comparison to povidone iodine alone in pre- and post sterilisation and surgical wound healing. Journal of the Indian Medical Association 2002;100(10):615-8.

\section{Waterman 2006 \{published data only\}}

Waterman TR, Smeak DD, Kowalski J, Hade EM. Comparison of bacterial counts in glove juice of surgeons wearing smooth band rings versus those without rings. American Journal of Infection Control 2006;34(7):421-5.

\section{Webster 1989 \{published data only\}}

Webster J, Faoagali JL. An in-use comparison of chlorhexidine gluconate $4 \% \mathrm{w} / \mathrm{v}$. glycol-poly-siloxane plus methylcellulose and a liquid soap in a special care baby unit. Journal of Hospital Infection 1989;14(2):141-51.

\section{Wernze 1975 \{published data only\}}

Wernze H, HIlfenhaus M, Rietbrock I, Schuttke R, Kuhn K. Plasma renin activity and plasma aldosterone during anaesthesia and operative stress and beta-adrenergic blockade. Anaesthesist 1975;24(11):476-6.

\section{Whittaker 2005 \{published data only\}}

Whittaker JP, Nancarrow JD, Sterne GD. The role of antibiotic prophylaxis in clean incised hand injuries: a prospective randomized placebo controlled double blind trial. Journal of Hand Surgery 2005;30(2):162-7.

Yeung 2007 \{published data only\} Yeung JWK, Tam WWS, Wong T-W. A review of the evidence for hand hygiene in different clinical and community settings for family physicians. Hong Kong Practitioner 2007;29(4):157-63.

Yuldashkhan 2008 \{published data only\}

Yuldashkhan M, Bolurchifard F, Amiri Z. Comparing two antiseptic solutions for scrubbing "decosept with povidone iodine" [Original article in Farsi]. SBMU Faculty of Nursing and Midwifery Quarterly 2008;18(60):14-20.

Zaragoza 1999 \{published data only\}

Zaragoza M, Salles M, Gomez J, Baya JM, Trilla A. Handwashing with soap or alcoholic solutions? A randomised clinical trial of its effectiveness. American Journal on Infection Control 1999;27:258-61.

\section{References to studies awaiting assessment}

Chen 2012 \{published and unpublished data\}

Chen CF, Han CL, Kan CP, Chen SG, Hung PW. Effect of surgical site infections with waterless and traditional hand scrubbing protocols on bacterial growth. American Journal of Infection Control 2012;40(4):e15-e17.

\section{Additional references ACORN 2012}

Australian College of Operating Room Nurses. Standards for Perioperative Nursing. O'Halloran Hill, Australia: ACORN Ltd, 2012.

\section{AfPP 2011}

Association for Perioperative Practice. Standards and Recommendations for Safe Perioperative Practice. http:// www.afpp.org.uk/books-journals/books/book-123. AfPP, 2011.

\section{AORN 2010}

Association of Operating Room Nurses. Perioperative Standards and Recommended Practices. http://www.afpp.org.uk/booksjournals/books/book-123. http://www.aorn.org/Guidelines/: AORN Ltd, 2010.

\section{Arrowsmith 2014}

Arrowsmith V, Taylor R. Removal of nail polish and finger rings to prevent surgical infection. Cochrane Database of Systematic Reviews 2014, Issue 8. [DOI: 10.1002/14651858.CD003325.pub3]

\section{CDC 2002}

Centres for Disease Control and Prevention. Guideline for hand hygiene in health care settings. Morbidity and Mortality Weekly Report 2002; Vol. 51:16. 


\section{Goncalves 2012}

Goncalves K, Graziano K, Kawagoe J. A systematic review of surgical hand antisepsis using an alcohol preparation compared to traditional products. Revista de Escola de Enfermagem 2012;46(6):1484-93.

\section{Higgins 2003}

Higgins JPT, Green S, editors. Cochrane Handbook for Systematic Review of Interventions Version 4.2.5 [updated May 2005]. The Cochrane Collaboration, 2005. Available from www.cochrane-handbook.org. Chichester, UK: John Wiley \& Sons, Ltd.

\section{Higgins 2011}

Higgins JPT, Altman DG, Sterne JAC (editors). Chapter 8: Assessing risk of bias in included studies. In:Higgins JPT, Green S (editors). Cochrane Handbook for Systematic Reviews of Interventions Version 5.1.0 [updated March 2011]. The Cochrane Collaboration, 2011. Available from www.cochranehandbook.org. The Cochrane Collaboration.

\section{HIS 2001}

Woodhead K, Taylor EW, Bannister G, Chesworth T, Hoffman P, Humphreys H, Hospital Infection Society. Behaviours and rituals in the operating theatre: a report from the Hospital Infection Society Working Group in Infection Control in the Operating Room. Hospital Infection Society, 2001. Available from: www.his.org.uk.

\section{Hsieh 2006}

Hsieh HF, Chui HH, Lee FP. Surgical hand scrubs in relation to microbial counts: systematic literature review. Journal of Advanced Nursing 2006;55(1):68-78.

\section{Kimborough 1973}

Kimborough RD. Review of the toxicity of hexachlorophene, including its neurotoxicity. Journal of Clinical Pharmacology 1973;13(11):439-51.

\section{Larson 1995}

Larson 1995. APIC guideline for handwashing and hand antisepsis in health care settings. American Journal of Infection Control 1995;23(4):251-69.

\section{Leaper 2015}

Leaper D, Tanner J, Kiernan M, Assadian O, Edmiston C. Surgical site infection: poor compliance with guidelines and care bundles. International Wound Journal 2015;12(3):357-62.

\section{Lefebvre 2011}

Lefebvre C, Manheimer E, Glanville J. Chapter 6: Searching for studies. In: Higgins JPT, Green S (editors). Cochrane Handbook forSystematic Reviews of Interventions Version 5.1.0 [updated March 2011]. The Cochrane Collaboration, 2011.. Available from www.cochrane-handbook.org.

\section{Mangram 1999}

Mangram AJ, Horan TC, Pearson ML, Silver LC, Jarvis WR. Guideline for prevention of surgical site infection. Infection Control and Hospital Epidemiology 1999;20(4):247-78.

\section{McDonnell 1999}

McDonnell G, Denver RA. Antiseptics and disinfectants: activity, action and resistance. Clinical Microbiology Review 1999;12(1):147-79.

\section{NICE 2008}

National Institute for Health and Clinical Excellence. Surgical site infection: prevention and treatment of surgical site infection Clinical Guideline 74. National Institute for Health and Clinical Excellence, 2008. Available from: https:// www.nice.org.uk/guidance/cg74.

\section{Plowman 2000}

Plowman R, Graves N, Griffin M. The socio-economic burden of hospital acquired infection. London: Public Health Laboratory Service, 2000.

\section{RevMan 2014 [Computer program]}

The Nordic Cochrane Centre, The Cochrane Collaboration. Review Manager (RevMan). Version 5.3. Copenhagen: The Cochrane Collaboration, 2014.

\section{Schünemann 2011a}

Schünemann HJ, Oxman AD, Higgins JPT, Deeks JJ, Glasziou P, Guyatt GH. Chapter 12: Interpreting results and drawing conclusions. In: Higgins JPT, Green S (editors). Cochrane Handbook for Systematic Reviews of Interventions Version 5.1.0 [updated March 2011]. The Cochrane Collaboration, 2011. Available from www.cochrane-handbook.org.

\section{Schünemann 2011b}

Schünemann HJ, Oxman AD, Higgins JPT, Vist GE, Glasziou P, Guyatt GH. Chapter 11: Presenting results and 'Summary of findings' tables. In: Higgins JPT, Green S (editors). Cochrane Handbook for Systematic Reviews of Interventions Version 5.1.0 [updated March 2011]. The Cochrane Collaboration, 2011. Available from www.cochrane-handbook.org.

\section{Sigler 2001}

Sigler M, Bastyr J, Stahl J, Pyrek JD. Comparison of a waterless, scrubless CHG/ethanol surgical scrub to traditional CHG and povidone iodine surgical scrubs. 3M Health Care 2001.

\section{SIGN 2011}

Scottish Intercollegiate Guidelines Network (SIGN). Search filters. http://www.sign.ac.uk/methodology/ filters.html\#random (accessed December 2011).

\section{WHO 2009}

World Health Organization. WHO guidelines on hand hygiene in health care. WHO Guideline series. Geneva: World Health Organization, 2009.

\section{References to other published versions of this review \\ Tanner 2003}

Swarbrook S, Stuart J, Tanner J. Surgical hand antisepsis to reduce surgical site infection (Protocol). Cochrane Database of Systematic Reviews 2003, Issue 2. [DOI: 10.1002/14651858.CD004288] 


\section{Tanner 2008}

Tanner J, Swarbrook S, Stuart J. Surgical hand antisepsis to reduce surgical site infection. Cochrane Database of Systematic Reviews 2008, Issue 1. [DOI: 10.1002/14651858.CD004288.pub2]

\section{CHARACTERISTICS OF STUDIES}

Characteristics of included studies [ordered by study ID]

\section{Al-Naami 2009}

Rethods
Rendomised controlled trial (described as an equivalence study)
Allocation concealment: no details given
Blinding: blinding of outcome assessors; no other details given
A priori sample calculations: yes
Antisepsis protocol: yes (partial)
Withdrawals: incomplete details given
Intention-to-treat analysis: no
Clear inclusion or exclusion criteria: no

Participants
$\begin{aligned} & 1 \text { hospital General Surgery division; surgeons (no further information on personnel) } \\ & 600 \text { patients initially randomised from general surgery; data reported on } 500 \\ & \text { General Surgery: abdominal (e.g. cholecystectomy) and other; mixture of clean and clean-contaminat- } \\ & \text { ed operations }\end{aligned}$

\begin{tabular}{ll}
\hline Interventions & $\begin{array}{l}\text { Group } 1 \text { - traditional surgeons' handscrub for 3-5 min using } 7.5 \% \text { povidone iodine (Betadine) or } 4 \% \\
\text { chlorhexidine gluconate (Hibiscrub) (228 patients) }\end{array}$ \\
Group 2 - As with group 1 for first case; subsequent antisepsis with alcohol handrub with $62 \%$ ethanol \\
(Purrel) $10 \mathrm{ml}$, allowed to dry (272 patients)
\end{tabular}

\begin{tabular}{ll}
\hline Outcomes & Surgical site infection defined as any one or more of the following: symptoms and signs (pain, swelling, \\
redness, hotness, tenderness, indurations, purulent discharge, opened wound) occurring within $30 \mathrm{~d}$ \\
from surgery (examinations before discharge, at 1 week, at 1 month, and C/S results); no further detail \\
supplied.
\end{tabular}

\begin{tabular}{ll}
\hline Notes & All patients had standardised skin preparation. $76 \%$ of patients had prophylactic antibiotics (indicated \\
for specified surgeries); no difference between arms.
\end{tabular}

\section{Risk of bias}

\begin{tabular}{lll}
\hline Bias & Authors' judgement & Support for judgement \\
\hline $\begin{array}{l}\text { Random sequence genera- } \\
\text { tion (selection bias) }\end{array}$ & Unclear risk & $\begin{array}{l}\text { No information on sequence generation } \\
\text { Quote: "Participants were randomised to either a routine hand scrub or an al- } \\
\text { cohol hand-rub upon } \\
\text { selecting a sealed envelope for each case." No further information. }\end{array}$ \\
\hline $\begin{array}{l}\text { Allocation concealment } \\
\text { (selection bias) }\end{array}$ & Unclear risk & $\begin{array}{l}\text { No further information; not clear if envelopes were opaque or sequentially } \\
\text { numbered }\end{array}$ \\
\hline $\begin{array}{l}\text { Blinding (performance } \\
\text { bias and detection bias) } \\
\begin{array}{l}\text { All outcomes - Blinding } \\
\text { participants }\end{array}\end{array}$ & High risk & $\begin{array}{l}\text { Clear differences between the procedures employed mean blinding of partici- } \\
\text { pants was not possible }\end{array}$ \\
\hline \hline
\end{tabular}


Al-Naami 2009 (Continued)
Blinding (performance
Unclear risk
No information reported

bias and detection bias)

All outcomes - Blinding care givers

\begin{tabular}{|c|c|c|}
\hline $\begin{array}{l}\text { Blinding (performance } \\
\text { bias and detection bias) }\end{array}$ & Low risk & $\begin{array}{l}\text { Assessment of wound appearance and swab by personnel unaware of alloca- } \\
\text { tion. }\end{array}$ \\
\hline $\begin{array}{l}\text { All outcomes - Blinding } \\
\text { outcome assessors }\end{array}$ & & $\begin{array}{l}\text { Quote: "Surgeons who examined surgical sites were unaware of the groups' al- } \\
\text { location"; "A swab was sent for C/S from any suspected SSI. Health care per- } \\
\text { sonnel taking swabs and interpreting results of C/S were also unaware of how } \\
\text { hand disinfection for each group had been allocated." }\end{array}$ \\
\hline
\end{tabular}

\section{Incomplete outcome data High risk} (attrition bias)

All outcomes
100 (1 in 6) participants originally randomised were excluded from analysis. The reasons for this are not fully explored.

Quote: "Initially an equal number of cases (300 patients in each group) were randomised to each method. However, more cases were further excluded from each group as they turned out to be non-eligible for inclusion after the original randomization (e.g. acute or chronic cholecystitis on histopathological examination), incomplete forms, failed follow-ups, etc."

$\begin{array}{ll}\begin{array}{l}\text { Selective reporting (re- } \\ \text { porting bias) }\end{array} & \text { Low risk } \\ & \begin{array}{l}\text { Quote: "The objective of this study is to determine the equal efficacy of alco- } \\ \text { hol-based hand-rub as compared to traditional surgical scrub in the preven- } \\ \text { tion of SSI as the primary outcome measure; the compliance of surgical staff } \\ \text { and skin tolerance as the secondary outcome measure; also keeping in mind } \\ \text { cost effectiveness and the potential change in surgical practice at least in our } \\ \text { institution" }\end{array}\end{array}$

Other bias Low risk No other sources of bias detected

\section{Furukawa 2005}

\begin{tabular}{ll}
\hline Methods & Randomised controlled trial \\
& Generation of random number sequence: no details given \\
& Allocation concealment: no details given \\
& Blinding: no details given \\
& A priori sample calculations: no \\
& Antisepsis protocol: yes \\
& Withdrawals: no details given \\
& Intention-to-treat analysis: no \\
& Clear inclusion or exclusion criteria: no \\
& 22 operating room nurses \\
& Baseline comparability: baseline bacterial counts \\
\hline Participants & Group 1 - 3 min scrub using aqueous chlorhexidine gluconate \\
& Group 2 - 3 min scrub using aqueous povidone iodine \\
\hline Interventions & Outcome measure: CFUs on participants' hands \\
& Method of testing: glove juice method \\
Timing of testing: before antisepsis and after antisepsis (no information regarding how long after anti- \\
Sepsis testing was conducted)
\end{tabular}


Furukawa 2005 (Continued)

Risk of bias

\begin{tabular}{lll}
\hline Bias & Authors' judgement & Support for judgement \\
\hline $\begin{array}{ll}\text { Random sequence genera- } \\
\text { tion (selection bias) }\end{array}$ & Unclear risk & $\begin{array}{l}\text { Quote: "Twenty-two operating room nurses were randomly divided into two } \\
\text { groups as follows: the PVI group }(n=11) \text { and the CHG group }(n=11) \text {. All the } \\
\text { nurses were examined for bacterial contamination of their hands before and } \\
\text { after surgical handwashing". }\end{array}$
\end{tabular}

Comment: Evidence of randomisation, however not enough evidence to suggest truly randomised sequence generation

\begin{tabular}{|c|c|c|}
\hline $\begin{array}{l}\text { Allocation concealment } \\
\text { (selection bias) }\end{array}$ & Unclear risk & $\begin{array}{l}\text { Quote: "Twenty-two operating room nurses were randomly divided into two } \\
\text { groups as follows: the PVI group }(n=11) \text { and the CHG group }(n=11) \text {. All the } \\
\text { nurses were examined for bacterial contamination of their hands before and } \\
\text { after surgical handwashing". }\end{array}$ \\
\hline
\end{tabular}

Comment: No evidence that appropriate allocation concealment took place

\begin{tabular}{|c|c|c|}
\hline \multirow[t]{2}{*}{$\begin{array}{l}\text { Blinding (performance } \\
\text { bias and detection bias) } \\
\text { All outcomes - Blinding } \\
\text { participants }\end{array}$} & Unclear risk & $\begin{array}{l}\text { Quote: "All the nurses were examined for bacterial contamination of their } \\
\text { hands before and after surgical handwashing" }\end{array}$ \\
\hline & & $\begin{array}{l}\text { Comment: No evidence of blinding of participants or personnel to blinding to } \\
\text { intervention }\end{array}$ \\
\hline
\end{tabular}

\begin{tabular}{|c|c|c|}
\hline $\begin{array}{l}\text { Blinding (performance } \\
\text { bias and detection bias) }\end{array}$ & Unclear risk & $\begin{array}{l}\text { Quote: "All the nurses were examined for bacterial contamination of their } \\
\text { hands before and after surgical handwashing" }\end{array}$ \\
\hline
\end{tabular}

All outcomes - Blinding

care givers

Comment: No evidence of blinding of participants or personnel to blinding to intervention

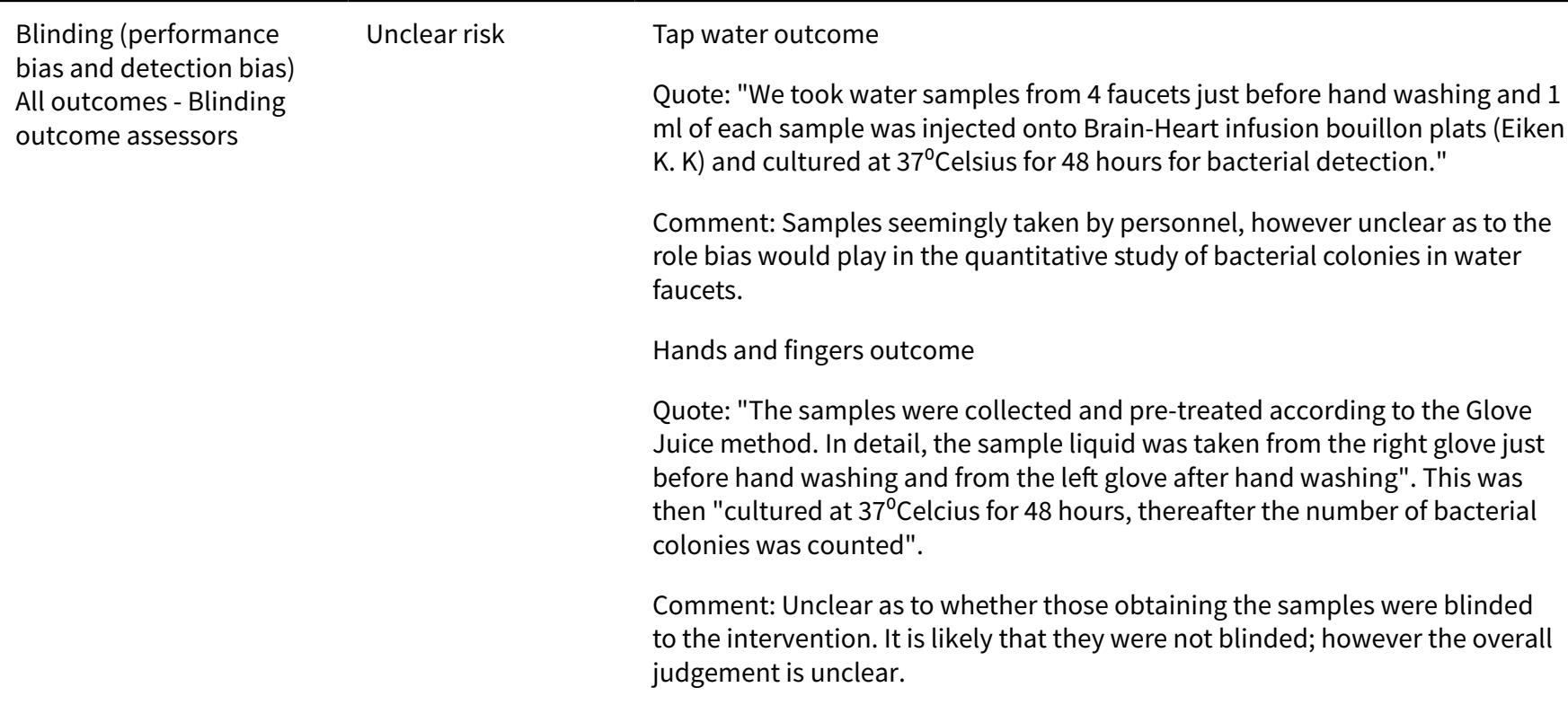


Furukawa 2005 (Continued)
Incomplete outcome data
Low risk
No direct quotes, however no losses to follow-up encountered

(attrition bias)

All outcomes

Comment: Low risk of attrition bias.

\begin{tabular}{ll}
\hline $\begin{array}{l}\text { Selective reporting (re- } \\
\text { porting bias) }\end{array}$ & Quote: no direct quotes. \\
& $\begin{array}{l}\text { Comment: Both outcome assessments of bacterial contamination of tap water } \\
\text { and hands and fingers before and after surgical handwashing were accounted } \\
\text { for in the results. }\end{array}$ \\
\hline
\end{tabular}

Other bias Low risk No other sources of bias detected

Gupta 2007

\begin{tabular}{ll}
\hline Methods & Randomised cross-over controlled trial \\
Generation of random number sequence: no details given & Allocation concealment: no details given \\
Blinding: not possible to blind participants \\
A priori sample calculations: yes \\
Antisepsis protocol: no \\
Withdrawals: 2 \\
Intention-to-treat analysis: no \\
Clear inclusion or exclusion criteria: yes
\end{tabular}

$\begin{array}{ll}\text { Participants } & 18 \text { operating room staff working in ophthalmic, podiatric and general surgery } \\ \text { Baseline comparability: baseline bacterial counts }\end{array}$

Baseline comparability: baseline bacterial counts

$\begin{array}{ll}\text { Interventions } & \text { Group } 1 \text { - brush application of } 7.5 \% \text { povidone iodine aqueous scrub } \\ \text { Group } 2 \text { - three } 2 \mathrm{ml} \text { application of } 1 \% \text { chlorhexidine gluconate in } 61 \% \text { ethyl alcohol } \\ \text { Group } 3 \text { - } 3 \text { min application of zinc pyrithione in } 70 \% \text { ethyl alcohol and rinsed with wate }\end{array}$

\begin{tabular}{ll}
\hline Outcomes & Outcome measure: CFUs on participants' hands \\
& Method of testing: glove juice method \\
& Timing of testing: before antisepsis and immediately after antisepsis on day 1 , after 6 hours on days 2 \\
& and 5
\end{tabular}

Notes $-\quad-$

\section{Risk of bias}

\section{Bias \\ Authors' judgement Support for judgement}

Random sequence genera- Unclear risk tion (selection bias)

Quote: Participants "were assigned to at random to one of three groups. Each group used one of the three solutions for five consecutive days. The following week, each group used a different scrub solution, such that all participants used each product over the study duration"

Comment: Unclear as to whether a random sequence generator was used.

\begin{tabular}{ll}
\hline $\begin{array}{l}\text { Allocation concealment } \\
\text { (selection bias) }\end{array}$ & Unclear risk \\
& $\begin{array}{l}\text { Quote: Participants "were assigned to at random to one of three groups. Each } \\
\text { ing week, each group used a different scrub solution, such that all participants } \\
\text { used each product over the study duration" }\end{array}$
\end{tabular}

Surgical hand antisepsis to reduce surgical site infection (Review)

Copyright $\odot 2016$ The Cochrane Collaboration. Published by John Wiley \& Sons, Ltd. 
Blinding (performance bias and detection bias) All outcomes - Blinding participants
High risk

Quote: "Participants could not be blinded to the three solutions due to differences in their nature and method of application".

Comment: Study describes that blinding of participants was not possible.There is no information given as to whether the investigators were blinded, but it is likely there were similarly unblinded to the intervention for the reasons given for the participants above. The judgement for participant blinding is therefore high risk.

\section{Blinding (performance Unclear risk} bias and detection bias) All outcomes - Blinding care givers

\section{Quote: "Participants could not be blinded to the three solutions due to differ-} ences in their nature and method of application".

Comment: Study describes that blinding of participants was not possible.There is no information given as to whether the investigators were blinded, but it is likely there were similarly unblinded to the intervention for the reasons given for the participants above. The judgement for blinding of caregivers here is unclear.

\begin{tabular}{|c|c|c|}
\hline $\begin{array}{l}\text { Blinding (performance } \\
\text { bias and detection bias) }\end{array}$ & Unclear risk & Bacterial sampling \\
\hline $\begin{array}{l}\text { All outcomes - Blinding } \\
\text { outcome assessors }\end{array}$ & & $\begin{array}{l}\text { Quote: "The subject introduced their hands into this bag and the investigator } \\
\text { massaged their hands externally with emphasis on web spaces and subungual } \\
\text { areas" }\end{array}$ \\
\hline
\end{tabular}

Comment: no attempt made at blinding method of obtaining bacterial sample, which would advise a high risk of bias decision

\section{Microbial assay}

Quote: "Samples were sent to the microbiology laboratory immediately after collection in a blinded manner"

Comment: There was adequate evidence that approach microbial testing was blinded.

Therefore, overall assessment of the risk of bias for outcome assessment is unclear.

Incomplete outcome data Low risk (attrition bias)

All outcomes
Quote: "Eighteen surgical staff members participated in this study. All members used each of the three scrub solutions over the duration or the study... Two volunteers developed a skin rash and a burning sensation on their hands within and a few minutes after their first scrub with the ABWA product. They also reported a metallic taste in their mouth and palpitations. Although none of their symptoms were severe and resolved shortly thereafter without any medical intervention, they were removed from the study. All the remaining staff volunteers completed the study".

Comment: small loss to follow-up and full explanations given as to the reasons for dropout

No direct quotes, although the efficacy of the product in terms of reduction of log reduction in bacterial counts and product preference by participants are both included in the Results in full and comprehensive manner, as outlined in the Methods.

$\begin{array}{ll}\begin{array}{l}\text { Selective reporting (re- } \quad \text { Low risk } \\ \text { porting bias) }\end{array} & \begin{array}{l}\text { No direct quotes, although the efficacy of the product in terms of reduction of } \\ \text { log reduction in bacterial counts and product preference by participants are } \\ \text { both included in the Results in full and comprehensive manner, as outlined in } \\ \text { the Methods. }\end{array}\end{array}$

Other bias Unclear risk Cross-over design, unclear if accounted for in analysis


Hajipour 2006

\begin{tabular}{|c|c|}
\hline Methods & $\begin{array}{l}\text { Cluster randomised controlled trial } \\
\text { Generation of random number sequence: random number table } \\
\text { Allocation concealment: no details given } \\
\text { Blinding: microbiologist was blinded } \\
\text { A priori sample calculations: no } \\
\text { Antisepsis protocol: yes } \\
\text { Withdrawals: no details given } \\
\text { Intention-to-treat analysis: no } \\
\text { Clear inclusion or exclusion criteria: no }\end{array}$ \\
\hline Participants & $\begin{array}{l}4 \text { surgeons working in a trauma surgery } \\
\text { Baseline comparability: surgeon's grade, order of patient on the operating list, duration of surgery }\end{array}$ \\
\hline Interventions & $\begin{array}{l}\text { Group } 1 \text { - } 3 \text { min scrub using aqueous chlorhexidine gluconate } \\
\text { Group } 2 \text { - } 3 \text { min application of } 0.5 \% \text { chlorhexidine gluconate in } 70 \% \text { alcohol } \\
\text { All surgeons washed with chlorhexidine (no further detail) for } 5 \text { min for first procedure with thorough } \\
\text { cleaning under fingernails. }\end{array}$ \\
\hline Outcomes & $\begin{array}{l}\text { Outcome measure: CFUs on participants' hands } \\
\text { Method of testing: finger press testing with agar plates } \\
\text { Timing of testing: at the end of the surgical procedure }\end{array}$ \\
\hline
\end{tabular}

\section{Risk of bias}

\begin{tabular}{lll}
\hline Bias & Authors' judgement & Support for judgement \\
\hline $\begin{array}{ll}\text { Random sequence genera- } \\
\text { tion (selection bias) }\end{array}$ & Low risk & $\begin{array}{l}\text { Quote: "Orthopaedic surgeons were allocated to one of two different hand- } \\
\text { washing protocols using a randomisation table" }\end{array}$
\end{tabular}

Comment: evidence of random sequence generation, therefore judged as low risk

\begin{tabular}{ll}
\hline $\begin{array}{l}\text { Allocation concealment } \\
\text { (selection bias) }\end{array}$ & Unclear risk
\end{tabular}

Comment: no evidence that there was an attempt at allocation concealment

\begin{tabular}{|c|c|c|}
\hline $\begin{array}{l}\text { Blinding (performance } \\
\text { bias and detection bias) } \\
\text { All outcomes - Blinding } \\
\text { participants }\end{array}$ & Unclear risk & $\begin{array}{l}\text { Quote: "The hand-washing protocol dictated that all surgeons should wash for } \\
5 \text { min with chlorhexidine for their first case with thorough cleaning under the } \\
\text { fingernails. Thereafter, the surgeon was randomised to wash for } 5 \text { min with ei- } \\
\text { ther the chlorhexidine or alcohol gel. Alcohol was allowed to dry on the hands } \\
\text { prior to double gloving". }\end{array}$ \\
\hline
\end{tabular}

Comment: no evidence that participants or personnel were blinded to intervention

\begin{tabular}{|c|c|c|}
\hline $\begin{array}{l}\text { Blinding (performance } \\
\text { bias and detection bias) } \\
\text { All outcomes - Blinding } \\
\text { care givers }\end{array}$ & Unclear risk & $\begin{array}{l}\text { Quote: "The hand-washing protocol dictated that all surgeons should wash for } \\
5 \text { min with chlorhexidine for their first case with thorough cleaning under the } \\
\text { fingernails. Thereafter, the surgeon was randomised to wash for } 5 \text { min with ei- } \\
\text { ther the chlorhexidine or alcohol gel. Alcohol was allowed to dry on the hands } \\
\text { prior to double gloving". }\end{array}$ \\
\hline
\end{tabular}


Hajipour 2006 (Continued)

Comment: no evidence that participants or personnel were blinded to intervention

Blinding (performance Low risk bias and detection bias) All outcomes - Blinding outcome assessors
Quote: "The number of bacterial colonies present after $24 \mathrm{~h}$ and $48 \mathrm{~h}$ of incubation were recorded for each agar plate by a microbiologist blinded to the washing protocol used"

Comment: adequate blinding of assessment outcome

Incomplete outcome data Low risk (attrition bias)

All outcomes
Quote: "Overall, 41 procedures and 82 episodes of handwashings were included in the study. Two episodes were discarded due to contamination at the time of glove removal. There was no incidence of outer glove perforation during this study"

Comment: good evidence to suggest losses to follow-up were accounted for and there was minimal effect of attrition bias

\begin{tabular}{lll}
\hline $\begin{array}{l}\text { Selective reporting (re- } \\
\text { porting bias) }\end{array}$ & Low risk & $\begin{array}{l}\text { No direct quotes, but the assessment variable of bacterial colonisation after } \\
\text { different methods of handwashing (which was outlined in the methodology) is } \\
\text { accounted for in the results. }\end{array}$ \\
\hline Other bias & Unclear risk & $\begin{array}{l}\text { This appears to be a clustered randomised trial; it does not seem that cluster- } \\
\text { ing was taken into account in the analysis. }\end{array}$ \\
\hline
\end{tabular}

\section{Herruzo 2000}

\begin{tabular}{|c|c|}
\hline Methods & $\begin{array}{l}\text { Randomised cross-over controlled trial } \\
\text { Generation of random number sequence: no details given } \\
\text { Allocation concealment: no details given } \\
\text { Blinding: no details given } \\
\text { A priori sample calculations: no } \\
\text { Antisepsis protocol: minimal details } \\
\text { Withdrawals: no details given } \\
\text { Intention-to-treat analysis: no } \\
\text { Clear inclusion or exclusion criteria: no }\end{array}$ \\
\hline Participants & $\begin{array}{l}154 \text { members of the surgical teams working in plastic surgery and traumatology } \\
\text { Baseline comparability: baseline bacterial counts }\end{array}$ \\
\hline Interventions & $\begin{array}{l}\text { Group } 1 \text { - } 3 \text { min scrub using aqueous chlorhexidine gluconate, } n=50 \\
\text { Group } 2 \text { - } 3 \text { min scrub using aqueous povidone iodine, } n=49 \\
\text { Group } 3 \text { - } 3 \text { min rub with N-duopropenide, } n=55\end{array}$ \\
\hline Outcomes & $\begin{array}{l}\text { Outcome measure: CFUs on participants' hands } \\
\text { Method of testing: finger press testing with agar plates } \\
\text { Timing of testing: before antisepsis, immediately after antisepsis and at the end of the surgical proce- } \\
\text { dure }\end{array}$ \\
\hline Notes & - \\
\hline
\end{tabular}

\section{Risk of bias}


Herruzo 2000 (Continued)

\section{Bias Authors' judgement Support for judgement}

Random sequence genera- Unclear risk tion (selection bias)
Quote: "Healthy volunteers washed with one of the three products for 1 week for 3 consecutive weeks. The order of the washings was randomised"

Comment: indication that a randomisation process was undertaken, however not clear how the sequence was generated
Quote: "Healthy volunteers washed with one of the three products for 1 week for 3 consecutive weeks. The order of the washings was randomised"

Comment: no evidence of allocation concealment given
Blinding (performance bias and detection bias) All outcomes - Blinding participants
High risk

Quote: "The effect of standard surgical washings with 7.5\% iodine povidone or $4 \%$ chlorhexidine (both with scrubbing for 3 min following a standard technique) was compared with the effect of washing (without scrubbing with $2.3 \%$ $\mathrm{N}$-duopropenide in $60^{\circ}$ ispopropranol with dermoprotective substance). The latter solution was poured over the hands, which were then rubbed together, and when it began to dry, it was reapplied over 3 min."

Comment: The study design here is a cross-over design, reducing potential effects of bias; however, there is no evidence that participants or personnel were blinded to the intervention given, and the conditions differed sufficiently that blinding would not have been possible.
Blinding (performance bias and detection bias) All outcomes - Blinding care givers
High risk

Quote: "The effect of standard surgical washings with 7.5\% iodine povidone or $4 \%$ chlorhexidine (both with scrubbing for 3 min following a standard technique) was compared with the effect of washing (without scrubbing with $2.3 \%$ $\mathrm{N}$-duopropenide in $60^{\circ}$ isopropanol with dermoprotective substance. The latter solution was poured over the hands, which were then rubbed together, and when it began to dry, it was reapplied over 3 min."

Comment: The study design here is a cross-over design, reducing potential effects of bias; however, there is no evidence that participants or personnel were blinded to the intervention given, and the conditions differed sufficiently that blinding would not have been possible.

\section{Blinding (performance Unclear risk} bias and detection bias) All outcomes - Blinding outcome assessors
Quote: "We used fingertips to sample hand bacteria as the standard European Norm (pr EN 1500) except we had not artificially contaminated the hands: five fingertips are rubbed for 1 min on a Petri dish containing $10 \mathrm{ml}$ of TBS plus an antiseptic neutralize ". These were cultured for " $48 \mathrm{~h}$ at $37^{\circ} \mathrm{C}$, and the then the $\mathrm{CFU} /$ hand (the five fingertips), were counted and transformed into a decimal logarithm".

Comment: Despite the assessment being quantitative, it is not clear whether those who obtained the bacterial samples were independent of the study or blinded to the intervention.

\begin{tabular}{lll}
\hline $\begin{array}{l}\text { Incomplete outcome data } \\
\text { (attrition bias) } \\
\text { All outcomes }\end{array}$ & Low risk & $\begin{array}{l}\text { No direct quotes, although no losses to follow-up recorded in Results } \\
\text { Comment: no obvious source of attrition bias }\end{array}$ \\
\hline $\begin{array}{l}\text { Selective reporting (re- } \\
\text { porting bias) }\end{array}$ & Low risk & No direct quotes \\
& $\begin{array}{l}\text { Comment: tabular format of results incorporates the assessment outcomes } \\
\text { outlined (CFUs) between the groups, suggesting a low risk }\end{array}$ \\
\hline Other bias & Unclear risk & $\begin{array}{l}\text { Although the trial had a cross-over design, it did not appear that this was re- } \\
\text { flected in the analysis. }\end{array}$ \\
\hline
\end{tabular}




Rethods
Generation of random number sequence: no details given
Allocation concealment: no details given
Blinding: no details given
A priori sample calculations: yes
Antisepsis protocol: no
Withdrawals: no details given
Intention-to-treat analysis: no
Clear inclusion or exclusion criteria: no

\begin{tabular}{ll}
\hline Participants & 24 surgeons \\
& Baseline comparability: baseline bacterial counts
\end{tabular}

Interventions

Group 1 - 1 min wash with soap and water followed by 5 min rub with an alcoholic disinfectant Group 2 - 1 min wash with soap and water followed by 3 min rub with an alcoholic disinfectant Group 3 - 1 min was with chlorhexidine soap followed by two min of rubbing with $0.5 \%$ chlorhexidine in isopropanol

\section{Outcomes}

Outcome measure: CFUs on participants' hands

Method of testing: glove juice method

Timing of testing: before antisepsis and immediately after antisepsis

Notes -

\section{Risk of bias}

\begin{tabular}{|c|c|c|}
\hline Bias & Authors' judgement & Support for judgement \\
\hline $\begin{array}{l}\text { Random sequence genera- } \\
\text { tion (selection bias) }\end{array}$ & Unclear risk & Just states "random order" with no further information \\
\hline $\begin{array}{l}\text { Allocation concealment } \\
\text { (selection bias) }\end{array}$ & Unclear risk & As with sequence generation; no further information \\
\hline $\begin{array}{l}\text { Blinding (performance } \\
\text { bias and detection bias) } \\
\text { All outcomes - Blinding } \\
\text { participants }\end{array}$ & Unclear risk & $\begin{array}{l}\text { Standard technique compared with shorter techniques precludes blinding of } \\
\text { personnel but no further information }\end{array}$ \\
\hline $\begin{array}{l}\text { Blinding (performance } \\
\text { bias and detection bias) } \\
\text { All outcomes - Blinding } \\
\text { care givers }\end{array}$ & Unclear risk & $\begin{array}{l}\text { Standard technique compared with shorter techniques precludes blinding of } \\
\text { personnel but no further information }\end{array}$ \\
\hline $\begin{array}{l}\text { Blinding (performance } \\
\text { bias and detection bias) } \\
\text { All outcomes - Blinding } \\
\text { outcome assessors }\end{array}$ & Unclear risk & No information on blinding of assessment reported \\
\hline $\begin{array}{l}\text { Incomplete outcome data } \\
\text { (attrition bias) } \\
\text { All outcomes }\end{array}$ & Low risk & No evidence of dropouts/loss of data \\
\hline $\begin{array}{l}\text { Selective reporting (re- } \\
\text { porting bias) }\end{array}$ & Low risk & All specified outcomes reported \\
\hline
\end{tabular}


Kappstein 1993 (Continued)

$\begin{array}{ll}\text { Other bias } & \text { Unclear risk } \\ \text { flected in the analysis. }\end{array}$
flected in the analysis.

Nthumba 2010

Cluster-randomised controlled cross-over trial
Generation of random number sequence: appropriate
Allocation concealment: no details given but considered unlikely to be an issue in cluster-randomisa-
tion
Blinding: outcome assessors
A priori sample calculations: yes
Antisepsis protocol: yes
Withdrawals: details of patients without postdischarge surveillance
Intention-to-treat analysis: no
Clear inclusion or exclusion criteria: yes

\begin{tabular}{ll}
\hline Participants & 66 surgeons and trainees; 3317 patients \\
\hline Interventions & $\begin{array}{l}\text { Group } 1 \text { - plain soap and water: 4-5 min clean running water and plain soap; sterile cotton hand towel } \\
\text { dry. } 5 \text { clusters ( } \mathrm{n}=1682 \text { patients) }\end{array}$ \\
& $\begin{array}{l}\text { Group } 2 \text { - As group } 1 \text { before first procedure of day and subsequently in case of visible soiling, then alco- } \\
\text { hol-based handrub (75\% isopropyl alcohol, } 1.45 \% \text { glycerol, } 0.125 \% \text { hydrogen peroxide) for } 3 \text { min and } \\
\text { kept wet (7-10 } \mathrm{ml} \text { per preparation) }\end{array}$
\end{tabular}

SSI (defined using modified US Centers for Disease Control and Prevention definitions for nosocomial
infection) detected by tours of hospital wards; reviews in outpatient clinic; telephone contact: diagno-
sis established jointly by study collaborators

Notes -

\section{Risk of bias}

\begin{tabular}{lll}
\hline Bias & Authors' judgement & Support for judgement \\
\hline $\begin{array}{l}\text { Random sequence genera- } \\
\text { tion (selection bias) }\end{array}$ & Low risk & $\begin{array}{l}\text { Surgical hand preparation procedures were assigned randomly to the } 6 \text { partic- } \\
\text { ipating operating theatres by tossing a coin, with a cross-over every } 2 \text { months. } \\
\text { There was no indication of baseline imbalance for important variables such as } \\
\text { type of surgery, contamination level of the surgery or use of antibiotic prophy- } \\
\text { laxis. }\end{array}$ \\
\hline $\begin{array}{l}\text { Allocation concealment } \\
\text { (selection bias) }\end{array}$ & Low risk & $\begin{array}{l}\text { Allocation was decided by toss of a coin. Not clear who undertook this process } \\
\text { and if it was concealed from the sites. Given that this was a cluster trial with } \\
\text { cross-over, the potential for bias stemming from allocation concealment was } \\
\text { limited. As the Cochrane Handbook for Systematic Reviews of Interventions } \\
\text { notes, "Cluster-randomised trials often randomise all clusters at once, so lack } \\
\text { of concealment of an allocation sequence should not usually be an issue." }\end{array}$ \\
\hline $\begin{array}{l}\text { Blinding (performance } \\
\text { bias and detection bias) } \\
\begin{array}{l}\text { All outcomes - Blinding } \\
\text { participants }\end{array}\end{array} \quad$ High risk & $\begin{array}{l}\text { Personnel were aware of allocation as procedures differed in obvious ways. } \\
\text { Compliance by surgical teams was determined by observation of practices. } \\
\text { A trained observer who did not belong to the surgical team checked whether } \\
\text { each sink had the correct hand preparation and whether all surgeons (includ- } \\
\text { ing visiting staff) followed the recommended hand preparation procedures. }\end{array}$ \\
\hline
\end{tabular}


Nthumba 2010 (Continued)
Blinding (performance
Unclear risk
No information reported

bias and detection bias)

All outcomes - Blinding care givers

Blinding (performance Low risk
bias and detection bias)
All outcomes - Blinding
outcome assessors

\begin{abstract}
Diagnosis, documentation and determination of SSI by personnel without knowledge of allocation.

"SSI was diagnosed ... and documented by a trained nurse who visited the surgical wards three to four times each week during the 30 days after surgery. Patients discharged before this were reviewed in the outpatient clinic or contacted by telephone... The nurse was blinded to the method of surgical hand preparation. The diagnosis of SSI was established jointly by the study collaborators; differences in SSI ascertainment were resolved by consensus without knowledge of the study allocation of the patient."
\end{abstract}

$\begin{array}{ll}\text { Incomplete outcome data } & \text { Low risk } \\ \text { (attrition bias) } & 3722 \text { patients underwent a surgical procedure in the operating theatre, and } \\ \text { All outcomes } & 3317 \text { were included in the } 10 \text { study clusters. Postdischarge surveillance data } \\ \text { could not be obtained for } 184 \text { patients }(5.5 \%)\end{array}$

\begin{tabular}{ll}
\hline $\begin{array}{l}\text { Selective reporting (re- } \\
\text { porting bias) }\end{array}$ & The primary objective of this cluster-randomised, cross-over trial was to com- \\
& pare the efficacy of plain soap and water with alcohol-based handrub, using \\
& SSI rates as the main outcome measure. The feasibility and affordability of the \\
local production of an alcohol-based handrub was also investigated, togeth- & er with an assessment of its acceptability among healthcare workers. All speci- \\
& fied outcomes were reported.
\end{tabular}

\begin{tabular}{ll}
\hline Other bias $\quad$ Low risk & $\begin{array}{l}\text { There was no evidence of other sources of bias. Clustered nature of the data } \\
\text { was taken into account in the trial. }\end{array}$
\end{tabular}

\title{
Parienti 2002
}

\begin{tabular}{|c|c|}
\hline Methods & $\begin{array}{l}\text { Cluster-randomised controlled equivalence trial } \\
\text { Generation of random number sequence: random number tables } \\
\text { Allocation concealment: no details given } \\
\text { Blinding: discussed but only conducted during postdischarge follow-up } \\
\text { A priori sample calculations: yes } \\
\text { Antisepsis protocol: yes } \\
\text { Withdrawals: } 51 \text { patients lost during follow-up } \\
\text { Intention-to-treat analysis: yes } \\
\text { Clear inclusion or exclusion criteria: yes }\end{array}$ \\
\hline Participants & $\begin{array}{l}\text { Surgical teams within } 6 \text { hospitals were randomised. } 4387 \text { patients undergoing clean and clean-contam- } \\
\text { inated surgery were included in the study. } \\
\text { Baseline comparability: details of surgical procedures, duration of surgery, patients' ASA classifica- } \\
\text { tions }\end{array}$ \\
\hline Interventions & $\begin{array}{l}\text { Group } 1 \text { - } 5 \text { min scrub using either } 4 \% \text { povidone iodine or } 4 \% \text { chlorhexidine gluconate } \\
\text { Group } 2 \text { - } 5 \text { min handrub with alcohol solution containing } 75 \% \text { propanol-1, propanol }-2 \text { with mecetron- } \\
\text { ium ethylsulphate }\end{array}$ \\
\hline Outcomes & $\begin{array}{l}\text { Outcome measure: SSIs in patients at } 30 \mathrm{~d} \text { using CDC definition } \\
\text { Method of testing: observation by surgeon or infectious disease specialist, case note review, telephone } \\
\text { interview } \\
\text { Timing of testing: } 30 \mathrm{~d} \text { follow-up }\end{array}$ \\
\hline
\end{tabular}


Parienti 2002 (Continued)

Notes Unclear if clustering is adjusted for in the analysis

\section{Risk of bias}

Bias Authors' judgement Support for judgement

Random sequence genera- Low risk tion (selection bias)
Quote: "Each participating surgical service was assigned a 2-digit random number by using a random number table. Surgical services corresponding to the 3 higher numbers were assigned to hand-rubbing with AAS and the remaining 3 services were assigned to traditional hand-scrubbing".

Comment: adequate evidence of random sequence generation
Allocation concealment Unclear risk (selection bias)
Quote: "Each participating surgical service was assigned a 2-digit random number by using a random number table. Surgical services corresponding to the 3 higher numbers were assigned to handrubbing with AAS and the remaining 3 services were assigned to traditional hand-scrubbing"

Comment: no evidence of allocation concealment
Blinding (performance bias and detection bias) All outcomes - Blinding participants
High risk

Quote: "[O]bservers of the clinical outcome could not be blinded to the hand antisepsis protocol." The study also mentions that "compliance observers did not belong to the operating department team but were usually present in the surgical suite. To avoid a Hawthorne effect the surgical teams were not informed of the timing of the evaluations".

Comment: Although the effect of blinding has been considered, in the comparison of different scrubbing protocols it would be difficult to blind the participant or personnel. The risk of bias is still high in this instance, however.

\begin{tabular}{|c|c|c|}
\hline $\begin{array}{l}\text { Blinding (performance } \\
\text { bias and detection bias) } \\
\text { All outcomes - Blinding } \\
\text { care givers }\end{array}$ & High risk & $\begin{array}{l}\text { Quote: "[O]bservers of the clinical outcome could not be blinded to the hand } \\
\text { antisepsis protocol." The study also mentions that "compliance observers } \\
\text { did not belong to the operating department team but were usually present in } \\
\text { the surgical suite. To avoid a Hawthorne effect the surgical teams were not in- } \\
\text { formed of the timing of the evaluations". }\end{array}$ \\
\hline
\end{tabular}

Comment: Although the effect of blinding has been considered, in the comparison of different scrubbing protocols it would be difficult to blind the participant or personnel. The risk of bias is still high in this instance, however.

\begin{tabular}{|c|c|c|}
\hline $\begin{array}{l}\text { Blinding (performance } \\
\text { bias and detection bias) }\end{array}$ & High risk & Surgical site infection outcome \\
\hline $\begin{array}{l}\text { All outcomes - Blinding } \\
\text { outcome assessors }\end{array}$ & & $\begin{array}{l}\text { Quote: "According to CDC guidelines, all SSIs had to be confirmed by the sur- } \\
\text { geon or the physician in charge on the patient. Thus, observers of the clinical } \\
\text { outcome could not be blinded to the hand antisepsis protocol" }\end{array}$ \\
\hline
\end{tabular}

Comment: As the surgeon was the participant in this case. it is clear that this could constitute a high risk of bias.

Tolerance and compliance outcome

Quote: "[T]he surgical personnel (77 subjects) were asked to estimate the effect of the 2 protocols on their skin. We used $210 \mathrm{~cm}$ visual analogue scales, at month 0 and after 3 crossovers; $0 \mathrm{~cm}$ representing absence of an tolerance problem and $10 \mathrm{~cm}$ representing maximal dryness with chapped hands and desquamation or maximal irritation with erythema, burning sensation, and abrasion."

Comment: The surgeon was the (unblinded) participant who reported the variables, so the results may be affected by performance bias. 
Parienti 2002 (Continued)

Incomplete outcome data Low risk (attrition bias)

All outcomes
Quote: "During the study period ... 4823 consecutive patients underwent surgery. Among these, 385 patients underwent contaminated or dirty-contaminated surgery, and 51 were lost to follow up at 30 days (17 in the hand-rubbing group). The remaining 4387 patients (68.5\% of whom underwent clean surgery) were considered for analysis".

Comment: As the sample size is large, the numbers lost to follow-up are not significant enough to warrant a risk of attrition bias.

Selective reporting (re- Low risk porting bias)
Quote: "Thirty-day surgical site infections rates were the primary end point; operating department teams' tolerance of and compliance with hand antisepsis were secondary end points".

Comment: adequate evidence in the results that these endpoints were accounted for comprehensively

This appears to be a clustered cross-over study; it does not seem that clustering was taken into account in the analysis.

\section{Pereira 1990}

Methods Randomised controlled cross-over trial (Latin square design - participants took part in each of 4 interventions)

Generation of random number sequence: no details given

Allocation concealment: no details given

Blinding: no details given

A priori sample calculations: no

Antisepsis protocol: yes

Withdrawals: 2 participants withdrew

Intention-to-treat analysis: no

Clear inclusion or exclusion criteria: no

$\begin{array}{ll}\text { Participants } & 34 \text { anaesthetic, recovery and ward nurses } \\ \text { Baseline comparability: gender, age, ethnicity, hand dominance, baseline bacterial counts }\end{array}$

Interventions Group $1-5$ min initial scrub and 3 min subsequent scrub using chlorhexidine

Group 2 - 3 min initial and 30 s subsequent scrub using chlorhexidine

Group 3 - 5 min initial and 3 min subsequent scrub using povidone iodine

Group 4 - 3 min initial and 30 s subsequent scrub using povidone iodine

\begin{tabular}{ll}
\hline Outcomes & $\begin{array}{l}\text { Outcome measure: CFUs on participants' hands } \\
\text { Method of testing: glove juice method } \\
\text { Timing of testing: before antisepsis, immediately after antisepsis, } 2 \mathrm{~h} \text { after initial antisepsis, } 2 \mathrm{~h} \text { after } \\
\text { subsequent antisepsis }\end{array}$ \\
\hline Notes & Participants did not take part in any surgical procedures
\end{tabular}

\section{Risk of bias}

\begin{tabular}{lll}
\hline Bias & Authors' judgement & Support for judgement \\
\hline $\begin{array}{ll}\text { Random sequence genera- } \\
\text { tion (selection bias) }\end{array}$ & Unclear risk & $\begin{array}{l}\text { Quote: "Subjects were randomly assigned to one of four groups, and each } \\
\text { group was assigned to one of the four scrub regimens each week. Control on } \\
\text { the treatment order was achieved through a Latin square design, as described } \\
\text { by Winder." }\end{array}$
\end{tabular}


Pereira 1990 (Continued)

Comment: adequate evidence of an appropriate study design, but on balance not enough evidence of truly random sequence generation
Quote: "Subjects were randomly assigned to one of four groups, and each group was assigned to one of the four scrub regimens each week. Control on the treatment order was achieved through a Latin square design, as described by Winder."

Comment: no indication that allocation to each group was concealed to the personnel

Blinding (performance bias and detection bias) All outcomes - Blinding participants
Unclear risk

Quote: "Subjects were randomly assigned to one of four groups, and each group was assigned to one of the four scrub regimens each week... Subjects were supervised by the investigator while they scrubbed on all test occasions."

Comment: no evidence to suggest that there was appropriate blinding of participants or personnel during the study

\begin{tabular}{|c|c|c|}
\hline $\begin{array}{l}\text { Blinding (performance } \\
\text { bias and detection bias) } \\
\text { All outcomes - Blinding }\end{array}$ & Unclear risk & $\begin{array}{l}\text { Quote: "Subjects were randomly assigned to one of four groups, and each } \\
\text { group was assigned to one of the four scrub regimens each week... Subjects } \\
\text { were supervised by the investigator while they scrubbed on all test occasions.' }\end{array}$ \\
\hline
\end{tabular}
care givers

Comment: no evidence to suggest that there was appropriate blinding of participants or personnel during the study

\begin{tabular}{|c|c|c|}
\hline Blinding (performance & Unclear risk & Bacterial contamination \\
\hline $\begin{array}{l}\text { All outcomes - Blinding } \\
\text { outcome assessors }\end{array}$ & & $\begin{array}{l}\text { Quote: "While the glove was still on the hand, a sample of the fluid was tak- } \\
\text { en ... [S]amples were collected on four occasions for each condition: (1) im } \\
\text { mediately before scrubbing (both hands), (2) immediately after the initial } \\
\text { surgical scrub (non-dominant hand only) (3) } 2 \text { hours after the initial surgical } \\
\text { scrub, immediately before the consecutive scrub (dominant hand) and (4) } 2 \\
\text { hours after one consecutive surgical scrub (dominant hand)." }\end{array}$ \\
\hline
\end{tabular}

Comment: no indication that those collecting the samples, administering the fluid or those performing the microbial assays were in any way blinded to the intervention or protocol

Incomplete outcome data Low risk (attrition bias)

All outcomes
Quote: "Thirty-six subjects were recruited, but two subjects withdrew from the experiment before completing all four treatments (scrubs) because of skin reactions, including erythema, burning sensations and local swelling"

Comment: adequate evidence that losses to follow-up were small and fully accounted for

\begin{tabular}{lll}
\hline $\begin{array}{l}\text { Selective reporting (re- } \\
\text { porting bias) }\end{array}$ & Low risk & $\begin{array}{l}\text { No direct quotes, but the results of each 'scrub' are displayed fully at baseline } \\
\text { and subsequent time intervals in the Results as laid out in the Methodology. }\end{array}$ \\
\hline Other bias & Unclear risk & $\begin{array}{l}\text { Although the trial had a cross-over design, it did not appear that this was re- } \\
\text { flected in the analysis. }\end{array}$ \\
\hline
\end{tabular}




\section{Methods}

Randomised controlled trial cross-over (Latin square design - participants took part in each of 5 interventions)

Generation of random number sequence: no details given

Allocation concealment: no details given

Blinding: no details given

A priori sample calculations: no

Antisepsis protocol: yes

Withdrawals: yes details provided

Intention-to-treat analysis: no

Clear inclusion or exclusion criteria: no

23 operating room nurses
Baseline comparability: age, gender, skin condition, baseline bacterial counts

Interventions Group 1 - 5 min initial and 3.5 min subsequent scrub using $4 \%$ chlorhexidine Group 2 - 3 min initial and 2.5 min subsequent scrub using 4\% chlorhexidine Group 3 - 3 min initial and 2.5 min subsequent scrub using povidone iodine with triclosan Group 4 - 3 min initial scrub using $4 \%$ chlorhexidine followed by a 30 s application of isopropanol $70 \%$ and chlorhexidine $0.5 \%$, and subsequent scrubs using $30 \mathrm{~s}$ application of isopropanol $70 \%$ and chlorhexidine $0.5 \%$

Group 5 - 2 min initial scrub using 4\% chlorhexidine followed by a $30 \mathrm{~s}$ application of ethanol $70 \%$ and chlorhexidine $0.5 \%$, and subsequent scrubs using $30 \mathrm{~s}$ application of ethanol $70 \%$ and chlorhexidine $0.5 \%$
Outcome measure: CFUs on participants' hands

Method of testing: glove juice method

Timing of testing: before antisepsis, immediately after antisepsis, $2 \mathrm{~h}$ after initial antisepsis, $2 \mathrm{~h}$ after subsequent antisepsis

Notes Participants did not take part in any surgical procedures

\section{Risk of bias}

Bias Authors' judgement Support for judgement

Random sequence genera- Unclear risk tion (selection bias)
Quote: "Subjects who agreed to participate in the study followed each of the scrub protocols in turn, the order controlled by the use of a Latin square design. That is, every nurse was required to complete every protocol but not in the same sequence."

Comment: clear that the study design does reduce selection bias; however not clear whether there is enough evidence to suggest random sequence was generated

Allocation concealment Unclear risk
(selection bias)

Quote: "Subjects who agreed to participate in the study followed each of the scrub protocols in turn, the order controlled by the use of a Latin square design. That is, every nurse was required to complete every protocol but not in the same sequence."

Comment: no evidence to suggest that allocation was concealed to personnel

Blinding (performance High risk
bias and detection bias)
All outcomes - Blinding
participants

Quote: "Subjects who agreed to participate in the study... followed each scrub protocol each day for one week (referred to as the 'test week') with a week of normal activities between each test week. They were issued with a supply of the specific antiseptic to be used in excess to their requirements for scrubbing so that the appropriate antiseptic could be used exclusively dur- 
ing the test week. Subjects were assessed before commencing each scrub protocol and at the end of the test week to determine changes in the number of colony forming units (cfu) after scrubbing and changes in the condition of the hands."

Comment: Although study design allows for repeated testing, there is no evidence that there was effective blinding of participants and personnel to the different interventions, and differences between the conditions would have been clearly apparent to those taking part.

\section{Blinding (performance High risk} bias and detection bias) All outcomes - Blinding care givers

Quote: "Subjects who agreed to participate in the study ... followed each scrub protocol each day for one week (referred to as the 'test week)' with a week of normal activities between each test week. They were issued with a supply of the specific antiseptic to be used in excess to their requirements for scrubbing so that the appropriate antiseptic could be used exclusively during the test week. Subjects were assessed before commencing each scrub protocol and at the end of the test week to determine changes in the number of colony forming units (cfu) after scrubbing and changes in the condition of the hands."

Comment: Although study design allows for repeated testing, there is no evidence that there was effective blinding of participants and personnel to the different interventions, and differences between the conditions would have been clearly apparent to those taking part.

\begin{tabular}{|c|c|c|}
\hline $\begin{array}{l}\text { Blinding (performance } \\
\text { bias and detection bias) }\end{array}$ & Unclear risk & Sampling method \\
\hline $\begin{array}{l}\text { All outcomes - Blinding } \\
\text { outcome assessors }\end{array}$ & & $\begin{array}{l}\text { Quote: "A glove juice sampling method to estimate the numbers of CFU } \\
\text { present on the hands" }\end{array}$ \\
\hline
\end{tabular}

Comment: no indication that those performing the sampling or performing the microbial assays were independent to the study

\section{Skin condition}

Quote: "Larson's Weekly Skin Assessment Rating Scale was used to rate the condition of the hands with respect to appearance, integrity, moisture and sensation. Participants rated themselves on a weekly basis. An independent rater, blind to the protocol being followed by the subject, also rated the subject's dominant hand each week."

Comment: evidence that reasonable measures were undertaken to blind outcome assessment. Overall assessment unclear for outcome assessment blinding.

Incomplete outcome data High risk (attrition bias)

All outcomes
Quote: "Of the 32 participants recruited, 23 completed all five scrub protocols (scrubs) because it was discovered [that several participants] were allergic or sensitive to one of the more antiseptics. One felt that her skin was already too dry to be able to participate further. One person could not complete the study because she was unexpectedly off work for an extended period and the other two gave no reason for withdrawing."

Comment: fairly high rates of losses to follow-up and no information given as to why some participants did not complete the study. Although it seems that the researchers acted appropriately here, it is difficult to give a judgement other than high risk 
Pereira 1997 (Continued)

Selective reporting (re- Low risk No direct quotes, but reasonable evidence to suggest that both bacterial contporting bias) amination and skin condition have been appropriately and fully tested and reported upon effectively.

$\begin{array}{ll}\text { Other bias } \quad \text { Unclear risk } & \begin{array}{l}\text { Although the trial had a cross-over design, it did not appear that this was re- } \\ \text { flected in the analysis. }\end{array}\end{array}$

\section{Pietsch 2001}

\begin{tabular}{ll}
\hline Methods & Randomised cross-over trial \\
& Generation of random number sequence: no details given \\
& Allocation concealment: no details given \\
& Blinding: no details given \\
& A priori sample calculations: no \\
Antisepsis protocol: no & Withdrawals: no details given \\
& Intention-to-treat analysis: no \\
& Clear inclusion or exclusion criteria: no \\
\hline Participants & $\begin{array}{l}\text { 75 surgeons } \\
\text { Baseline comparability: baseline bacterial counts }\end{array}$ \\
\hline Interventions & $\begin{array}{l}\text { Group } 1 \text { - surgical scrub using 4\% chlorhexidine (details of the duration are not given) } \\
\text { Group 2 - alcohol rub using Sterillium (45\% w/w of propan-2-01, 30\% w/w of propan-l-01 and 0.2\% w/w } \\
\text { of ethylhexadecyldimethyl ammonium ethylsulfate)(details of the duration are not given) }\end{array}$ \\
\hline Outcomes & $\begin{array}{l}\text { Outcome measure: CFUs on participants' hands } \\
\text { Method of testing: glove juice method } \\
\text { Timing of testing: before antisepsis, immediately after antisepsis and after surgical procedure com- } \\
\text { pleted }\end{array}$ \\
\hline Notes & -
\end{tabular}

\section{Risk of bias}

\section{Bias}

Authors' judgement Support for judgement

Random sequence genera- Unclear risk tion (selection bias)
Dermal tolerance study

Quote: "The first study was performed with a panel of 60 volunteers divided in two subgroups of 30 persons each."

Comment: no indication of how the subgroups were divided

Surgical hand disinfection study

Quote: "In a randomised cross-over clinical trial the antimicrobial efficacy of Sterillium for the surgical hand-rub was tested against Hibiscrub in the Kantonsspital Basel over a period of 11 weeks ... two weeks were needed for recruitment, four weeks to conduct the Sterillium arm of the study, one week's interval and then four weeks for the Hibiscrub part."

Comment: no further information given as to how participants were recruited and how they were assigned and allocated to which intervention

Hygienic hand disinfection study 
Pietsch 2001 (Continued)

Quote: "The antimicrobial efficacy of each product was compared with that of $60 \%(\mathrm{v} / \mathrm{v})$ 2-propanol on artificially contaminated hands (E. coli K 12, NCTC 10538) using a cross-over design with 15 volunteers."

Comment: no indication of if a randomised sequence was used and what method was implemented

Allocation concealment Unclear risk
(selection bias)

\section{Dermal tolerance}

Quote: "The first study was performed with a panel of 60 volunteers divided in two subgroups of 30 persons each"

Comment: No indication of how allocation was concealed

Surgical hand disinfection

Quote: "In a randomised cross-over clinical trial the antimicrobial efficacy of Sterillium for the surgical hand-rub was tested against Hibiscrub in the Kantonsspital Basel over a period of 11 weeks ... two weeks were needed for recruitment, four weeks to conduct the Sterilium arm of the study, one week's interval and then four weeks for the Hibiscrub part."

Comment: no indication if allocation was concealed

Hygienic hand disinfection

Quote: "The antimicrobial efficacy of each product was compared with that of $60 \%(\mathrm{v} / \mathrm{v})$ 2-propanol on artificially contaminated hands (E. coli K 12, NCTC 10538) using a cross-over design with 15 volunteers."

Comment: no Indication if allocation was concealed
Dermal tolerance

Quote: "The first panel started with Hibiscrub, the second with Sterilium. Both products were used over seven weeks after one week of preconditioning. After an interval of four weeks the second run started with a single crossover of products."

Comment: although cross-over trial used, no indication that the participants or personnel were blinded to the intervention

Surgical hand disinfection

Quote: "Organisms were recovered by the glove juice method. Plastic bags with the sampling fluid were placed on the subjects hands. The bag on each hand was secured and massaged for $1 \mathrm{~min}$ in a uniform manner by a laboratory technician."

Comment: no indication whether participants were blinded to intervention and unclear whether technician was blinded to which intervention had been used

\section{Hygienic hand disinfection}

Quote: "The antimicrobial efficacy of each product was compared with that of $60 \%(\mathrm{v} / \mathrm{v})$ 2-propanol on artificially contaminated hands (E. coli K 12, NCTC 10 538) using a cross-over design with 15 volunteers. The hands were first washed for 1 min with soft soap, dried with paper towels immersed in the contamination fluid up to the mid-metacarpals for $5 \mathrm{~s}$ with fingers spread and then allowed to dry for 3 min" 

interventions

Blinding (performance
bias and detection bias)
All outcomes - Blinding
care givers

Blinding (performance

All outcomes - Blinding

care givers

Unclear risk

Dermal tolerance

Quote: "The first panel started with Hibiscrub, the second with Sterilium. Both products were used over seven weeks after one week of preconditioning. After an interval of four weeks the second run started with a single crossover of products".

Comment: although cross-over design used, no indication that the participants or personnel were blinded to the intervention

Surgical hand disinfection

Quote: "Organisms were recovered by the glove juice method. Plastic bags with the sampling fluid were placed on the subjects hands. The bag on each hand was secured and massaged for $1 \mathrm{~min}$ in a uniform manner by a laboratory technician"

Comment: no indication whether participants were blinded to intervention and unclear whether technician was blinded to which intervention had been used

\section{Hygienic hand disinfection}

Quote: "The antimicrobial efficacy of each product was compared with that of $60 \%(\mathrm{v} / \mathrm{v}$ ) 2-propanol on artificially contaminated hands (E. coli K 12, NCTC 10 538) using a cross-over design with 15 volunteers. The hands were first washed for 1 min with soft soap, dried with paper towels immersed in the contamination fluid up to the mid-metacarpals for $5 \mathrm{~s}$ with fingers spread and then allowed to dry for 3 min."

Comment: unclear as to whether participants or personnel were blinded to the interventions

Blinding (performance bias and detection bias) All outcomes - Blinding outcome assessors
Unclear risk

Dermal tolerance

Quote: "The following parameters were measured before and after application: Clinical assessment by observation of the hands and the forearms of the volunteers by a dermatologist. The number of volunteers which dropped out of the study because of skin damage as decided by a dermatologist"

Comment: no indication that the dermatologist was independent to the study

Surgical hand disinfection

Quote: "The bag on each hand was secured and massaged for $1 \mathrm{~min}$ in a uniform manner by a laboratory technician"

Comment: no indication that the laboratory technician was blinded to the intervention

Hygienic hand disinfection

Quote: "Control microbial counts were obtained by rubbing the fingertips for 1 minute in a Petri dish containing a liquid broth using a separate dish for each hand. Either $3 \mathrm{ml}$ of the hand gel or two aliquots of $3 \mathrm{ml}$ of the reference alcohol were applied to the hands. The rub-in period was $30 \mathrm{~s}$ for the hand gels and $60 \mathrm{~s}$ for the reference alcohol as prescribed by EN 1500."

Comment: no mention of whether those supervising the process or the overseeing the microbial assays were independent of the study 
Pietsch 2001 (Continued)

Incomplete outcome data Unclear risk
(attrition bias)
All outcomes

\section{Dermal tolerance}

Quote: "A dramatic finding is the very high number of subjects dropping out of the Hibiscrub group. Altogether 15 persons gave up using the Hibiscrub for reasons related to the use of the product, but there was only person who discontinued Sterillium."

Comment: This total represented a large proportion of the total participants used. Despite attributing the high rates of dropout to reasons related to the product, the risk of attrition bias is fairly high in this case.

\section{Surgical hand disinfection}

No direct quotes, but no indication given as to the total number of participants used or whether there was any observed loss to follow-up. Therefore the judgement remains unclear.

Hygienic hand disinfection

Quote:"The antimicrobial efficacy of each product was compared with that of $60 \%(\mathrm{v} / \mathrm{v})$ 2-propanol on artificially contaminated hands ( $E$. coli K 12, NCTC 10538) using a cross-over design with 15 volunteers."

Comment: No losses to follow-up were discussed within the results; however, there is no evidence to suggest no losses to follow-up occurred. Overall judgement therefore remains unclear for outcome assessment.

Selective reporting (re- Low risk porting bias)

\section{Dermal tolerance}

No direct quotes; however, the form used to tabulate the results gives no quantitative figures for variables that were predominantly quantitative in nature. For example "D-squames", "Electrical capacity", "Transepidermal water loss" are expressed as either "-- very poor", "- poor", "+ good" or "++ very good". It is unclear why the outcomes have been reported in this way.

Surgical hand disinfection

No direct quotes, although the results indicate the microbial concentration in the sampling fluid before and after treatment, outlined in the methodology and expressed as logarithm.

Hygienic hand disinfection

No direct quotes, although all the hand disinfectants that were discussed in the methodology as appropriate for testing are discussed and tabulated in an appropriate manner. Overall judgement of low risk.

$\begin{array}{ll}\text { Other bias Low risk } & \begin{array}{l}\text { No other sources of bias detected; cross-over design taken into account in } \\ \text { analysis }\end{array}\end{array}$


Tanner 2009 (Continued)

Withdrawals: details given of small number not included in analysis

Intention-to-treat analysis: no

Clear inclusion or exclusion criteria: yes

164 nurses, operating department practitioners and healthcare assistants

Group 1 - chlorhexidine (aqueous chlorhexidine gluconate 4\% (Hibiscrub)) alone. Total application time of $2 \mathrm{~min}, \mathrm{n}=54$

Group 2 - chlorhexidine as group 1 plus cleaning nails with disposable nail pick (before scrub under running water), $\mathrm{n}=54$

Group 3 - chlorhexidine as above plus cleaning nails with disposable nail brush (before scrub under running water), $n=54$

All groups were observed and timed when scrubbing. Total antiseptic application time in each group was $2 \mathrm{~min}$ (measured dose of $2 \times 2 \mathrm{ml}$ for $1 \mathrm{~min} /$ dose).

\begin{tabular}{ll}
\hline Outcomes & Primary outcome: number of CFUs on dominant hand \\
& Method of testing: modified glove juice method (sterile Gammex Powder Free, Ansell glove) \\
\hline Notes & $\begin{array}{l}\text { No surgical procedures were performed; all staff performed circulating duties within the operating the- } \\
\text { atre for } 1 \mathrm{~h} .\end{array}$
\end{tabular}

\section{Risk of bias}

\begin{tabular}{lll}
\hline Bias & Authors' judgement & Support for judgement \\
\hline $\begin{array}{l}\text { Random sequence genera- } \\
\text { tion (selection bias) }\end{array}$ & Low risk & $\begin{array}{l}\text { An appropriate method of generating the randomisation sequence was report- } \\
\text { ed: "Randomisation was in random size blocks in multiples of three and was } \\
\text { generated by a statistician using a computer software package." }\end{array}$ \\
\hline $\begin{array}{l}\text { Allocation concealment } \\
\text { (selection bias) }\end{array}$ & Low risk & $\begin{array}{l}\text { A recognised method for ensuring allocation concealment was reported: } \\
\text { "Group allocation details were placed inside sequentially numbered sealed } \\
\text { opaque envelopes by an individual independent from the study. The en- } \\
\text { velopes were opened by participants after baseline bacterial counts had been } \\
\text { taken and immediately before the scrub intervention was performed. The re- } \\
\text { searcher conducting the baseline sample was unaware of each participant's } \\
\text { group allocation." }\end{array}$ \\
\hline
\end{tabular}

\begin{tabular}{|c|c|c|}
\hline $\begin{array}{l}\text { Blinding (performance } \\
\text { bias and detection bias) } \\
\text { All outcomes - Blinding } \\
\text { participants }\end{array}$ & High risk & $\begin{array}{l}\text { Scrub protocols differed such that all participants were aware of their alloca- } \\
\text { tion }\end{array}$ \\
\hline
\end{tabular}

\begin{tabular}{|c|c|c|}
\hline $\begin{array}{l}\text { Blinding (performance } \\
\text { bias and detection bias) } \\
\text { All outcomes - Blinding } \\
\text { care givers }\end{array}$ & High risk & $\begin{array}{l}\text { For personnel (not caregivers): "The researcher conducting the baseline sam- } \\
\text { ple was unaware of each participant's group allocation. As the researcher ob- } \\
\text { served the participants' scrubbing they were therefore aware of each partici- } \\
\text { pant's group allocation when conducting the post-scrub sample." }\end{array}$ \\
\hline
\end{tabular}

\begin{tabular}{|c|c|c|}
\hline $\begin{array}{l}\text { Blinding (performance } \\
\text { bias and detection bias) } \\
\text { All outcomes - Blinding } \\
\text { outcome assessors }\end{array}$ & Low risk & $\begin{array}{l}\text { CFU assessment was performed in a blinded manner: "Laboratory staff esti- } \\
\text { mating the bacterial counts were unaware of group allocation status." }\end{array}$ \\
\hline $\begin{array}{l}\text { Incomplete outcome data } \\
\text { (attrition bias) }\end{array}$ & Low risk & $\begin{array}{l}\text { Data missing for only } 2 \text { participants; reasons given: " } 164 \text { operating department } \\
\text { staff took part in the study. No participants dropped out, but the laboratory }\end{array}$ \\
\hline
\end{tabular}

(attrition bias) staff took part in the study. No participants dropped out, but the laboratory 
Tanner 2009 (Continued)

results for two people were spoiled. The findings on 162 participants are presented."

\begin{tabular}{|c|c|c|}
\hline $\begin{array}{l}\text { Selective reporting (re- } \\
\text { porting bias) }\end{array}$ & Low risk & $\begin{array}{l}\text { All specified outcomes reported: "The primary purpose of the trial was to com- } \\
\text { pare any two of the trial groups by measuring the difference in post-interven- } \\
\text { tion CFU per hand. A secondary purpose was to identify any relationships be- } \\
\text { tween participants and baseline CFU counts." }\end{array}$ \\
\hline
\end{tabular}

Other bias Low risk No evidence of other sources of bias

\section{Vergara-Fernandez 2010}

\begin{tabular}{|c|c|}
\hline Methods & $\begin{array}{l}\text { Parallel group randomised controlled trial. Unit of randomisation and analysis is patient } \\
\text { Generation of random number sequence: not reported } \\
\text { Allocation concealment: sealed envelopes, no further information } \\
\text { Blinding: not reported } \\
\text { A priori sample calculations: no } \\
\text { Antisepsis protocol: no } \\
\text { Withdrawals: no patient withdrawals for evaluation of SSI; CFUs only assessed for } 20 \% \text { of staff but all } \\
\text { included in analysis. } \\
\text { Intention-to-treat analysis: yes } \\
\text { Clear inclusion or exclusion criteria: types of surgery only }\end{array}$ \\
\hline Participants & $\begin{array}{l}400 \text { staff classified as surgeons, "instrumentalists" and helpers } \\
100 \text { patients undergoing clean or clean-contaminated surgery }\end{array}$ \\
\hline Interventions & $\begin{array}{l}\text { Group } 1 \text { - aqueous scrub with } 4 \% \text { chlorhexidine gluconate with brush and sterile water. Mean duration } \\
\text { of scrub } 3.9 \text { (SD 1.07) min. } \\
\text { Group } 2 \text { - alcohol rub with } 61 \% \text { ethanol, } 1 \% \text { chlorhexidine gluconate. Mean duration } 2.0 \text { (SD } 0.47 \text { ) min. }\end{array}$ \\
\hline Outcomes & $\begin{array}{l}\text { SSI after } 1 \text { month (CDC criteria; method of diagnosis not further reported) } \\
\text { CFUs on hands ( } 20 \% \text { of personnel only): reports number of personnel with positive cultures (no further } \\
\text { detail) }\end{array}$ \\
\hline Notes & $\begin{array}{l}\text { Only } 20 \% \text { of the } 400 \text { enrolled staff were assessed for bacteria on hands; these were classified as having } \\
\text { or not having a positive culture. No data on number of CFUs on hands were reported. }\end{array}$ \\
\hline
\end{tabular}

\section{Risk of bias}

Bias Authors' judgement Support for judgement

Random sequence genera- Unclear risk Just says "used closed envelopes"

tion (selection bias)

Allocation concealment Unclear risk Just says "used closed envelopes"
(selection bias)

Blinding (performance Unclear risk No information given but interventions clearly differed

bias and detection bias)

All outcomes - Blinding

participants 
Vergara-Fernandez 2010 (Continued)

\begin{tabular}{|c|c|c|}
\hline $\begin{array}{l}\text { Blinding (performance } \\
\text { bias and detection bias) } \\
\text { All outcomes - Blinding } \\
\text { care givers }\end{array}$ & Unclear risk & No information given but interventions clearly differed \\
\hline $\begin{array}{l}\text { Blinding (performance } \\
\text { bias and detection bias) } \\
\text { All outcomes - Blinding } \\
\text { outcome assessors }\end{array}$ & Unclear risk & No information on blinding of outcome assessors \\
\hline $\begin{array}{l}\text { Incomplete outcome data } \\
\text { (attrition bias) } \\
\text { All outcomes }\end{array}$ & Low risk & $\begin{array}{l}\text { Data on all patients reported for SSI } \\
\text { Data on } 20 \% \text { of personnel collected for CFUs; results reported for all those col- } \\
\text { lected }\end{array}$ \\
\hline $\begin{array}{l}\text { Selective reporting (re- } \\
\text { porting bias) }\end{array}$ & Low risk & All specified outcomes reported \\
\hline Other bias & Low risk & No other sources of bias detected \\
\hline
\end{tabular}

Wheelock 1997

\begin{tabular}{|c|c|c|}
\hline Methods & \multicolumn{2}{|c|}{$\begin{array}{l}\text { Randomised cross-over trial } \\
\text { Generation of random number sequence: no details given } \\
\text { Allocation concealment: no details given } \\
\text { Blinding: no details given (dermal tolerance) } \\
\text { A priori sample calculations: yes } \\
\text { Antisepsis protocol: yes } \\
\text { Withdrawals: no details given } \\
\text { Intention-to-treat analysis: no } \\
\text { Clear inclusion or exclusion criteria: no }\end{array}$} \\
\hline Participants & \multicolumn{2}{|c|}{$\begin{array}{l}25 \text { operating theatre nurses and surgical technologists } \\
\text { Baseline comparability: age, gender, hand size, role, length of perioperative experience }\end{array}$} \\
\hline Interventions & \multicolumn{2}{|c|}{$\begin{array}{l}\text { Group } 1 \text { - } 3 \text { min surgical scrub using either } 4 \% \text { chlorhexidine, } 2 \% \text { chlorhexidine or } \\
\text { parachlorometaxylenol } \\
\text { Group } 2 \text { - } 2 \text { min surgical scrub using either } 4 \% \text { chlorhexidine, } 2 \% \text { chlorhexidine or } \\
\text { parachlorometaxylenol }\end{array}$} \\
\hline Outcomes & \multicolumn{2}{|c|}{$\begin{array}{l}\text { Outcome measure: CFUs on participants' hands } \\
\text { Method of testing: glove juice method } \\
\text { Timing of testing: } 1 \mathrm{~h} \text { after antisepsis }\end{array}$} \\
\hline Notes & \multicolumn{2}{|c|}{ Participants did not take part in any surgical procedures. } \\
\hline \multicolumn{3}{|l|}{ Risk of bias } \\
\hline Bias & Authors' judgement & Support for judgement \\
\hline $\begin{array}{l}\text { Random sequence genera- } \\
\text { tion (selection bias) }\end{array}$ & Unclear risk & $\begin{array}{l}\text { Quote "We randomly assigned subjects to one of two study groups (i.e., two- } \\
\text { minute, three-minute surgical hand scrub times)." } \\
\text { Comment: no indication as whether a truly randomised sequence was gener- } \\
\text { ated }\end{array}$ \\
\hline
\end{tabular}


Wheelock 1997 (Continued)

Allocation concealment (selection bias)
Unclear risk

Quote "We randomly assigned subjects to one of two study groups (i.e., twominute, three-minute surgical hand scrub times)."

Comment: no indication as to whether allocation was concealed to the participants or personnel. The study was a cross-over trial, therefore all the participants were likely to have undertaken the same interventions; however, the role of bias is unclear in this case.

\begin{tabular}{|c|c|c|}
\hline $\begin{array}{l}\text { Blinding (performance } \\
\text { bias and detection bias) } \\
\text { All outcomes - Blinding } \\
\text { participants }\end{array}$ & High risk & $\begin{array}{l}\text { No direct quotes given, but no mention as to whether the subjects or the per- } \\
\text { sonnel were blinded to the intervention. It is very likely that the personnel } \\
\text { were not blinded as they would be able to calculate the time spent handwash- } \\
\text { ing. }\end{array}$ \\
\hline $\begin{array}{l}\text { Blinding (performance } \\
\text { bias and detection bias) } \\
\text { All outcomes - Blinding } \\
\text { care givers }\end{array}$ & High risk & $\begin{array}{l}\text { No direct quotes given, but no mention as to whether the subjects or the per- } \\
\text { sonnel were blinded to the intervention. It is very likely that the personnel } \\
\text { were not blinded as they would be able to calculate the time spent handwash- } \\
\text { ing. }\end{array}$ \\
\hline
\end{tabular}

Blinding (performance bias and detection bias) All outcomes - Blinding outcome assessors
High risk

No direct quotes given, but investigators were responsible for measurement of time and for preparation of solution for bacterial culture, as well as the sampling and measurement of log CFU counts. Although this is an objective measure, it is reasonable to suggest that as the investigators were not blinded to the intervention then the risk of bias here could be considered as high.

$\begin{aligned} & \text { Incomplete outcome data } \\ & \text { (attrition bias) }\end{aligned}$
$\begin{aligned} & \text { All outcomes risk } \\ & \text { which resulted in } 300 \text { agar plates for incubation and enumeration." }\end{aligned}$

All outcomes

Comment: adequate evidence of no loss to follow-up

$\begin{array}{ll}\begin{array}{l}\text { Selective reporting (re- } \\ \text { porting bias) }\end{array} & \text { Low risk } \\ & \begin{array}{l}\text { The main outcome variable was the log counts of bacterial colonies found on } \\ \text { participants' hands after washing their hands for a specified time. This was ful- } \\ \text { ly represented in table format in the results section. }\end{array}\end{array}$

Other bias Unclear risk

Although the trial had a cross-over design. it did not appear that this was reflected in the analysis

AAS: aqueous alcohol solution;ABWA: alcohol-based water-aided; ASA: American Society of Anesthesiologists; CDC: Centers for Disease Control; CFU: colony forming units; CHG: chlorhexidine gluconate; C/S: culture and sensitivity PVI: povidone iodine; SSI: surgical site infection; v/v: volume/volume per cent.

\section{Characteristics of excluded studies [ordered by study ID]}

\begin{tabular}{ll}
\hline Study & Reason for exclusion \\
\hline Adjoussou 2009 & Not a randomised controlled trial \\
\hline Aly 1983 & A laboratory-based study \\
\hline Aly 1988 & A laboratory-based study \\
\hline Aly 1998 & Evaluated patient skin preparations \\
\hline Arata 1993 & Evaluated patient skin preparations \\
\hline Ayliffe 1984 & A discussion paper \\
\hline
\end{tabular}




\begin{tabular}{|c|c|}
\hline Study & Reason for exclusion \\
\hline Ayliffe 1988 & A laboratory and ward study - not hand antisepsis \\
\hline Ayliffe 1990 & Hand hygiene study \\
\hline Babb 1991 & Study carried out on volunteers, not scrub staff in an operating theatre \\
\hline Bansal 2002 & Wound irrigation study \\
\hline Barsanti 2009 & Infection in ITU \\
\hline Bartzokas 1983 & A laboratory-based study \\
\hline Bearman 2010 & Gloving study \\
\hline Beeuwkes 1986 & Participants were not randomised \\
\hline Bendig 1990 & A laboratory-based study \\
\hline Bernam 2004 & Not a randomised controlled trial \\
\hline Bibbo 2005 & Evaluated patient skin preparations \\
\hline Blomgren 1983 & Body exhaust suit study \\
\hline Borer 2001 & Infection surveillance study \\
\hline Boyce 2000a & An editorial \\
\hline Boyce 2000b & Evaluated skin condition rather than SSIs or CFUs \\
\hline Braumann 2008 & Study of dressings \\
\hline Breeze 1994 & Discussion paper \\
\hline Brooks 2001 & Evaluated patient skin preparations \\
\hline Bruckner 2009 & Study of dressings \\
\hline Bryce 2001 & $\begin{array}{l}\text { Not a randomised controlled trial. Participants used product A for } 2 \text { weeks then swapped to prod- } \\
\text { uct B for the following } 2 \text { weeks. }\end{array}$ \\
\hline Caelli 2000 & Study of MRSA decolonisation \\
\hline Carro 2007 & Not a randomised controlled trial \\
\hline Cheng 2001 & Literature review \\
\hline Coelho 1984 & Not relevant to this review \\
\hline Cremieux 1989 & A laboratory-based study \\
\hline Crowder 1967 & $\begin{array}{l}\text { Study was not randomised. Participants performed antisepsis using their usual solution. There } \\
\text { were no comparison groups }\end{array}$ \\
\hline Culligan 2005 & Randomised controlled trial comparing antiseptic solutions on patients' skin \\
\hline
\end{tabular}




\begin{tabular}{|c|c|}
\hline Study & Reason for exclusion \\
\hline Curti 1974 & Chemical agents \\
\hline Da Cunha 2011 & Not a randomised controlled trial \\
\hline Dahl 1990 & $\begin{array}{l}\text { Chlorhexidine scrub which was left on the surgeons arm was compared with a surgeons arm where } \\
\text { the chlorhexidine scrub was rinsed off. Did not meet the objectives of this review }\end{array}$ \\
\hline Das 2005 & Study on hygienic hand washing \\
\hline De Castro Peraza 2010 & Study of gloves in surgery \\
\hline Demir 2009 & Staff survey \\
\hline Deshmukh 1998 & $\begin{array}{l}\text { Participants were randomised to } 2 \text { groups. Group } 1 \text { participants were tested after } 1 \text { hour and group } \\
2 \text { participants were tested after } 2 \text { hours. Participants in both groups used product A } 1 \text { day and } \\
\text { product B the next day }\end{array}$ \\
\hline Dineen 1969 & Participants' hands were covered with bacterial inoculum. A laboratory-based study \\
\hline Dineen 1978 & A laboratory-based study \\
\hline Dohmen 2006 & Antibiotic prophylaxic study \\
\hline Durani 2008 & Non-systematic literature review \\
\hline Elenbaas 1982 & Dog bite study \\
\hline Ellenhorn 2005 & Evaluated patient skin preparations \\
\hline Faoagali 1995 & A laboratory style study using non clinical hospital staff \\
\hline Ford 2005 & Antimicrobial suture study \\
\hline Grabsch 2004 & Not randomised \\
\hline Grinbaum 1995 & A retrospective study \\
\hline Gruendemann 2001 & Discussion paper \\
\hline Guilhermetti 2001 & MRSA decontamination study \\
\hline Hagen 1995 & Evaluated patient skin preparations \\
\hline Harnoss & Study carried out on volunteers, not scrub staff in an operating theatre \\
\hline Heeg 1986 & Experimental and clinical conditions \\
\hline Heeg 2001 & Measured the impact of hand care products on alcohol rubs \\
\hline Heeg 2008 & Testing methods not suitable; not randomised \\
\hline Hibbard 2002a & A laboratory-based study \\
\hline Hibbard 2002b & A laboratory-based study \\
\hline
\end{tabular}




\begin{tabular}{|c|c|}
\hline Study & Reason for exclusion \\
\hline Hingst 1992 & A laboratory-based study \\
\hline Hobson 1998 & A laboratory-based study \\
\hline Hubner 2006 & A laboratory-based study \\
\hline Incoll 2009 & Skin preparation of patient \\
\hline Jeng 1998 & A laboratory-based study \\
\hline Jeng 2001 & A study of skin antiseptics used on patients skin \\
\hline Jones 2000 & A laboratory-based study and participants were not randomised \\
\hline Joress 1962 & $\begin{array}{l}\text { No comparison group was used in the first part of the trial. Comparison groups were used in the } \\
\text { second part of the trial, but solutions were applied to the forearm rather than as surgical scrubs }\end{array}$ \\
\hline Kampf 2005 & A laboratory-based study \\
\hline Kargi 2008 & Anaesthetic agents study \\
\hline Keser 2005 & Not a randomised controlled trial \\
\hline Kikuchi 1999 & Measured condition of skin on hands of participants; did not compare CFUs or SSIs \\
\hline Kjellander 1960 & Not randomised \\
\hline Kong 1994 & Not relevant topic. \\
\hline Kramer 2007 & Not randomised \\
\hline Kramer 2008 & Descriptive paper of scrubbing methods \\
\hline Larson 1984 & Study focused on handwashing rather than hand antisepsis \\
\hline Larson 1986a & A laboratory-based study \\
\hline Larson 1986b & A laboratory-based study \\
\hline Larson 1990 & A laboratory-based study \\
\hline Larson 1993 & A laboratory-based study \\
\hline Larson 2001a & Study of handwashing in intensive care \\
\hline Larson $2001 b$ & $\begin{array}{l}\text { Not randomised to appropriate groups. } 5 \text { participants were randomised to a reference group at the } \\
\text { beginning of the study. The participants randomised to the intervention group used an alcohol rub } \\
\text { for } 3 \text { weeks and then a surgical scrub for } 3 \text { weeks }\end{array}$ \\
\hline Lehmann 1985 & Analgesics study \\
\hline Lepor 2009 & Patient skin prep study \\
\hline Lilly 1978 & A laboratory-based study \\
\hline
\end{tabular}




\begin{tabular}{|c|c|}
\hline Study & Reason for exclusion \\
\hline Lio 2009 & Study on topical agents \\
\hline Llanos 2006 & Wound management \\
\hline Loeb 1997 & Study carried out on volunteers, not scrub staff in an operating theatre \\
\hline Lowbury 1974a & Not relevant to this review \\
\hline Lowbury 1974b & A laboratory-based study \\
\hline Lung 2004 & A literature review \\
\hline Magann 1993 & Evaluated patient skin preparations \\
\hline Magera 2007 & Patient skin preparation study \\
\hline Marchetti 2003 & Laboratory-based study \\
\hline Marra 2008 & Hand hygiene study \\
\hline Mathias 2000 & A discussion paper \\
\hline Mathias 2002 & A discussion paper \\
\hline McBride 1973 & A laboratory-based study \\
\hline Meers 1978 & Not relevant topic \\
\hline Minakuchi 1993 & A study of handwashing rather than hand antisepsis. \\
\hline Misterka 1991 & Study of dressings \\
\hline Moralejo 2003 & Not a randomised controlled trial; summary of previously published studies \\
\hline Mulberry 2001 & A laboratory-based study \\
\hline Murie 1980 & Cross-over trial but without any randomisation \\
\hline Nakano 2008 & Wound irrigation study \\
\hline Nowak 1982 & Bowel prep study \\
\hline \multirow[t]{2}{*}{ O'Shaughnessy 1991} & $\begin{array}{l}\text { All participants carried out intervention } 1 \text { on day } 1 \text {, intervention } 2 \text { on day } 2 \text { and intervention } 3 \text { on } \\
\text { day } 3 .\end{array}$ \\
\hline & No randomisation \\
\hline Olson 2012 & Study carried out on volunteers, not scrub staff in an operating theatre \\
\hline Ortiz 2012 & Assessed intra-operative rescrubbing \\
\hline Parienti 2004 & Central venous catheter study \\
\hline Paulson 1994 & A laboratory-based study \\
\hline
\end{tabular}




\begin{tabular}{|c|c|}
\hline Study & Reason for exclusion \\
\hline Paulson 1999 & A laboratory-based study \\
\hline Peterson 1978 & A laboratory-based study \\
\hline Phimolsarnti 1986 & Not randomised \\
\hline Poon 1998 & Not randomised \\
\hline Rehork 1991 & Study carried out on volunteers, not scrub staff in an operating theatre \\
\hline Reid 1991 & Study of wound management \\
\hline Reverdy 1984 & A laboratory-based study \\
\hline Rotter 1980 & A laboratory-based study \\
\hline Rotter 1984 & Study of handwashing rather than hand antisepsis \\
\hline Rotter 1986 & A laboratory-based study \\
\hline Rotter 1998 & A laboratory-based study \\
\hline Rotter 2005 & Explores hand hygiene rather than hand antisepsis \\
\hline Rotter 2006 & Laboratory-based study \\
\hline Sattar 2000 & A laboratory-based study \\
\hline Scheibel 1991 & Study of clean air systems \\
\hline Scott 1991 & Evaluated user satisfaction \\
\hline Sensoz 2003 & No evidence that the study was randomised \\
\hline Serra 2005 & Study of dressings \\
\hline Shirahatti 1993 & Evaluated patient skin preparations \\
\hline Simor 2007 & MRSA decolonisation \\
\hline Springer 2002 & Discussion paper \\
\hline Stahl 2007 & Lab based study of effect of saline in antimicrobial skin preparations \\
\hline Starr 2005 & Evaluated patient skin preparations \\
\hline Stevenson 2003 & Study of antibiotics \\
\hline Sullivan 2008 & Patient skin preparation study \\
\hline Tanner 2008 & Earlier systematic review \\
\hline Thiele 2008 & Literature review \\
\hline Tucci 1977 & Not a randomised controlled trial; no control group \\
\hline
\end{tabular}




\begin{tabular}{|c|c|}
\hline Study & Reason for exclusion \\
\hline Valente 2003 & Wound irrigation study \\
\hline Vogt 2006 & Evaluated iodine based wound dressings \\
\hline Voss 1997 & Looked at compliance with various handwashing methods \\
\hline Vossinakis 2004 & Study of local anaesthetic \\
\hline Walwaikar 2002 & $\begin{array}{l}\text { Each intervention group contained a scrub solution, a patient prep solution and a follow-up wound } \\
\text { cleansing product. It was not possible to look at the effect of the scrub solution on its own }\end{array}$ \\
\hline Waterman 2006 & Study of glove juice and rings \\
\hline Webster 1989 & Study of handwashing in a neo-natal unit \\
\hline Wernze 1975 & Anaesthetics study \\
\hline Whittaker 2005 & Study of antibiotics in hand injuries \\
\hline Yeung 2007 & Hand hygiene literature review \\
\hline Yuldashkhan 2008 & Not a randomised controlled trial \\
\hline Zaragoza 1999 & A study of handwashing, not hand antisepsis. \\
\hline
\end{tabular}

MRSA: methicillin-resistant Staphylococcus aureus

Characteristics of studies awaiting assessment [ordered by study ID]

Chen 2012

Methods

\section{Participants}

Interventions

\section{Outcomes}

\section{DATA AND ANALYSES}

Comparison 1. basic hand hygiene versus alcohol rub

\begin{tabular}{lllll}
\hline $\begin{array}{l}\text { Outcome or subgroup } \\
\text { title }\end{array}$ & $\begin{array}{l}\text { No. of } \\
\text { studies }\end{array}$ & $\begin{array}{l}\text { No. of partici- } \\
\text { pants }\end{array}$ & Statistical method & Effect size \\
\hline $1 \mathrm{SSI}$ & 1 & 3133 & Risk Ratio (M-H, Fixed, 95\% Cl) & $0.97[0.77,1.23]$ \\
\hline
\end{tabular}


Analysis 1.1. Comparison 1 basic hand hygiene versus alcohol rub, Outcome 1 SSI.

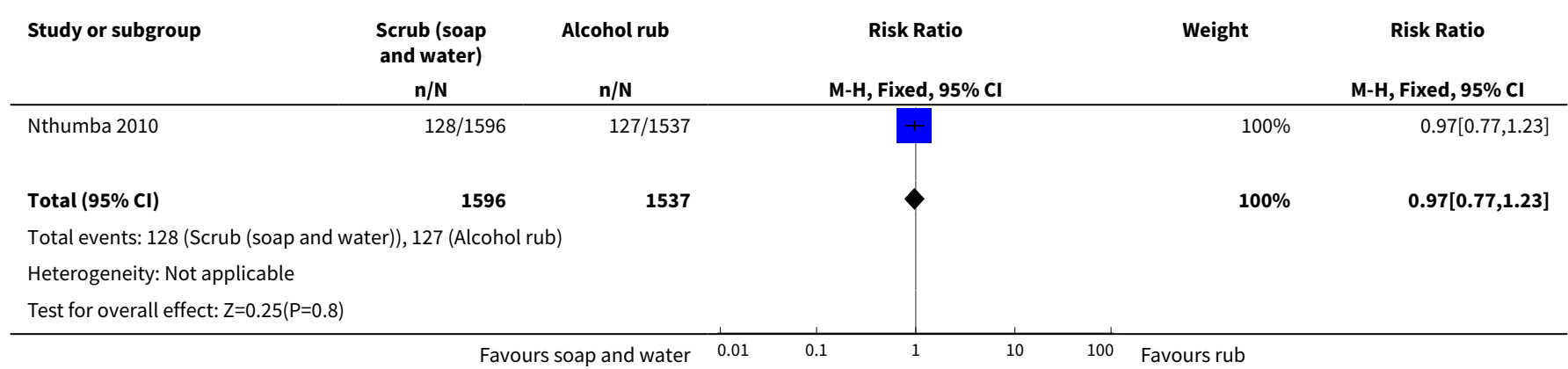

\section{Comparison 2. chlorhexidine versus iodine}

\begin{tabular}{lllll}
\hline Outcome or subgroup title & $\begin{array}{l}\text { No. of } \\
\text { studies }\end{array}$ & $\begin{array}{l}\text { No. of } \\
\text { partici- } \\
\text { pants }\end{array}$ & Statistical method & Effect size \\
\hline 1 CFUs & 3 & & $\begin{array}{l}\text { Mean Difference (IV, Fixed, 95\% } \\
\text { Cl) }\end{array}$ & Totals not selected \\
\hline 1.1 CFUs immediately after antisepsis & 3 & $\begin{array}{l}\text { Mean Difference (IV, Fixed, 95\% } \\
\text { Cl) }\end{array}$ & $0.0[0.0,0.0]$ \\
\hline 1.2 CFUs 2 h after initial antisepsis & 1 & $\begin{array}{l}\text { Mean Difference (IV, Fixed, 95\% } \\
\text { Cl) }\end{array}$ & $0.0[0.0,0.0]$ \\
\hline 1.3 CFUs 2 h after subsequent antisepsis & 1 & $\begin{array}{l}\text { Mean Difference (IV, Fixed, 95\% } \\
\text { Cl) }\end{array}$ & $0.0[0.0,0.0]$ \\
\hline 1.4 CFUs after surgical procedure & 1 & $\begin{array}{l}\text { Mean Difference (IV, Fixed, 95\% } \\
\text { Cl) }\end{array}$ & $0.0[0.0,0.0]$
\end{tabular}

Analysis 2.1. Comparison 2 chlorhexidine versus iodine, Outcome 1 CFUs.

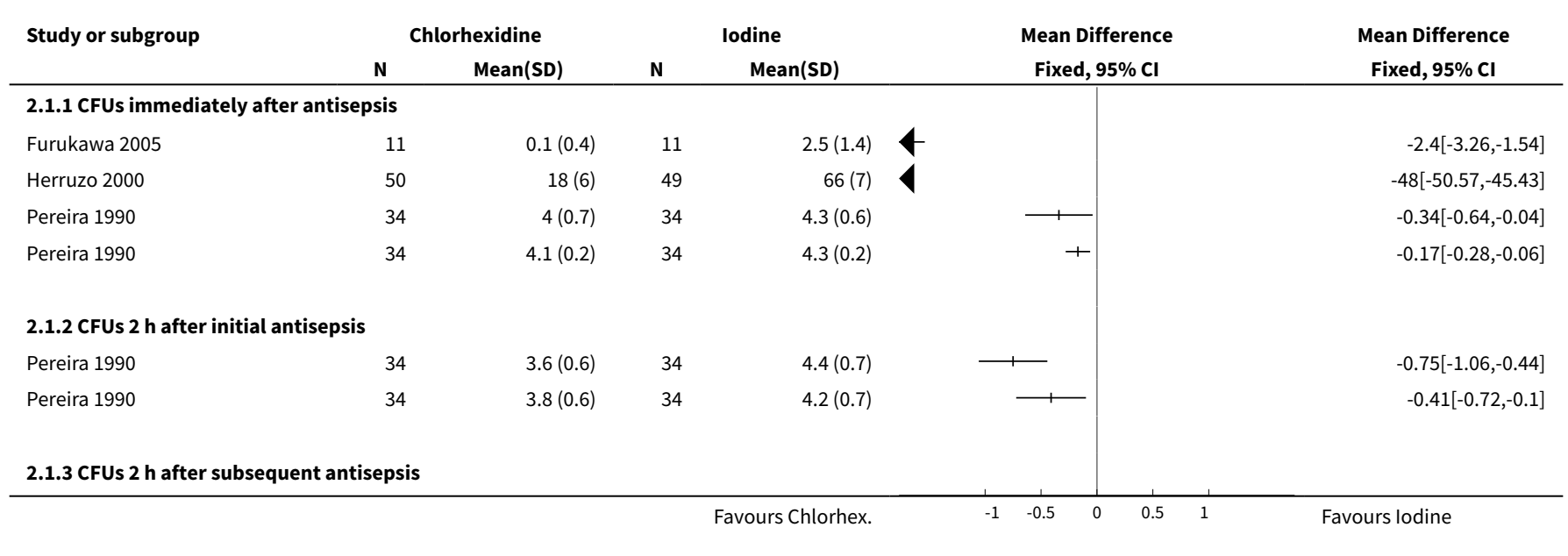




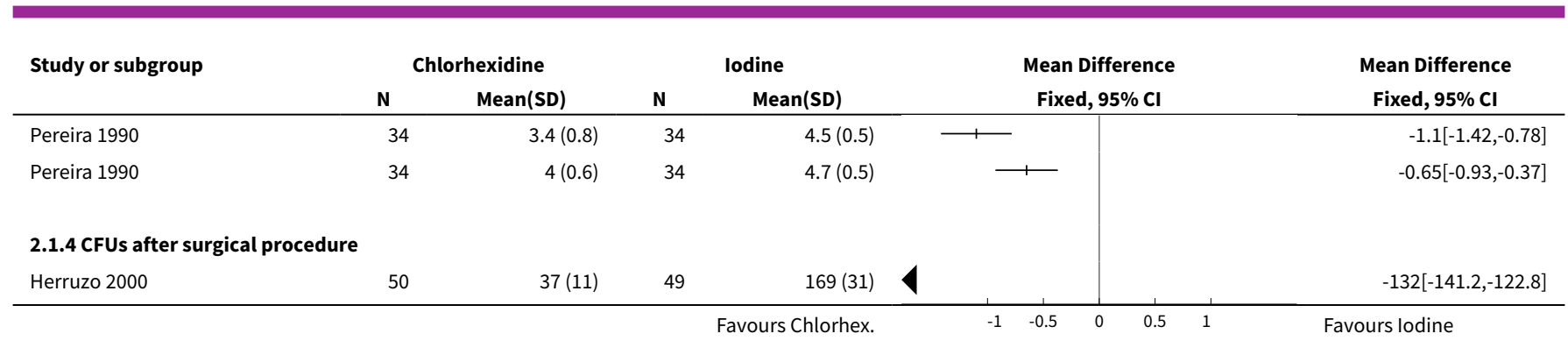

Comparison 3. chlorhexidine versus iodine plus triclosan

\begin{tabular}{lllll}
\hline Outcome or subgroup title & $\begin{array}{l}\text { No. of } \\
\text { studies }\end{array}$ & $\begin{array}{l}\text { No. of } \\
\text { partici- } \\
\text { pants }\end{array}$ & Statistical method & Effect size \\
\hline 1 CFUs & 1 & & $\begin{array}{l}\text { Mean Difference (IV, Fixed, 95\% } \\
\text { Cl) }\end{array}$ & Totals not selected \\
\hline 1.1 CFUs immediately after antisepsis & 1 & $\begin{array}{l}\text { Mean Difference (IV, Fixed, 95\% } \\
\text { Cl) }\end{array}$ & $0.0[0.0,0.0]$ \\
\hline 1.2 CFUs 2 h after initial antisepsis & 1 & Mean Difference (IV, Fixed, 95\% & $0.0[0.0,0.0]$ \\
\hline 1.3 CFUs 2 h after subsequent antisepsis & 1 & Cl) & $\begin{array}{l}\text { Mean Difference (IV, Fixed, 95\% } \\
\text { Cl) }\end{array}$ & $0.0[0.0,0.0]$ \\
\hline
\end{tabular}

Analysis 3.1. Comparison 3 chlorhexidine versus iodine plus triclosan, Outcome 1 CFUs.

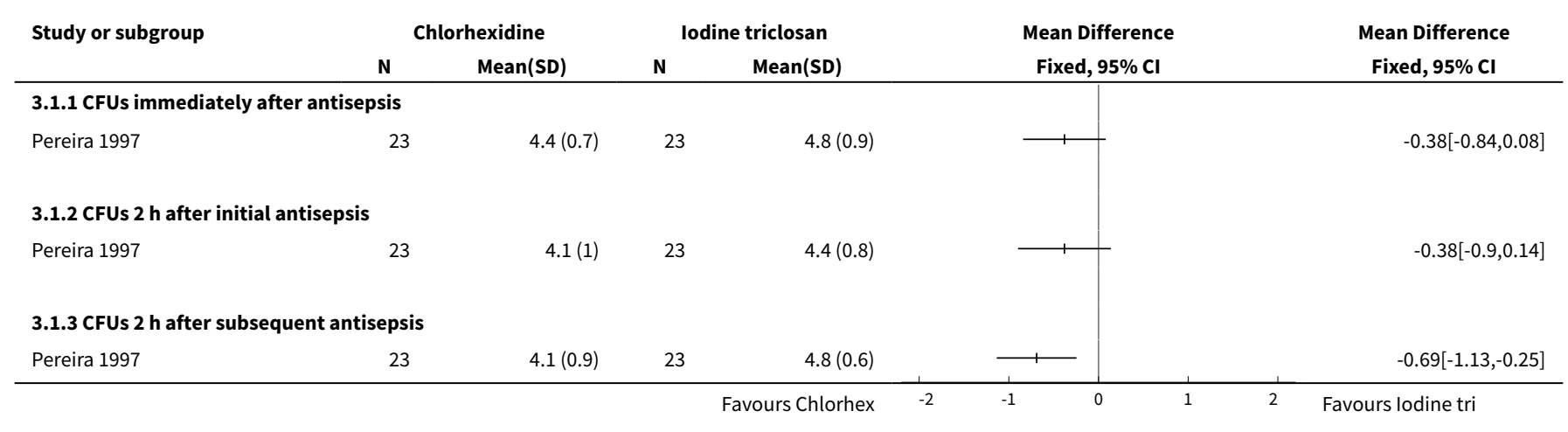

\section{Comparison 4. alcohol rub versus other alcohol rub}

\begin{tabular}{lllll}
\hline Outcome or subgroup title & $\begin{array}{l}\text { No. of } \\
\text { studies }\end{array}$ & $\begin{array}{l}\text { No. of } \\
\text { partici- } \\
\text { pants }\end{array}$ & Statistical method & Effect size \\
\hline 1 CFUs & 1 & Mean Difference (IV, Fixed, 95\% Cl) & Totals not selected \\
\hline
\end{tabular}




\begin{tabular}{lllll}
\hline Outcome or subgroup title & $\begin{array}{l}\text { No. of } \\
\text { studies }\end{array}$ & $\begin{array}{l}\text { No. of } \\
\text { partici- } \\
\text { pants }\end{array}$ & Statistical method & Effect size \\
\hline 1.1 Immediately after antisepsis & 1 & Mean Difference (IV, Fixed, 95\% Cl) & $0.0[0.0,0.0]$ \\
\hline $1.22 \mathrm{~h}$ after initial antisepsis & 1 & Mean Difference (IV, Fixed, 95\% Cl) & $0.0[0.0,0.0]$ \\
\hline $1.32 \mathrm{~h}$ after subsequent antisepsis & 1 & Mean Difference (IV, Fixed, 95\% Cl) & $0.0[0.0,0.0]$ \\
\hline
\end{tabular}

Analysis 4.1. Comparison 4 alcohol rub versus other alcohol rub, Outcome 1 CFUs.

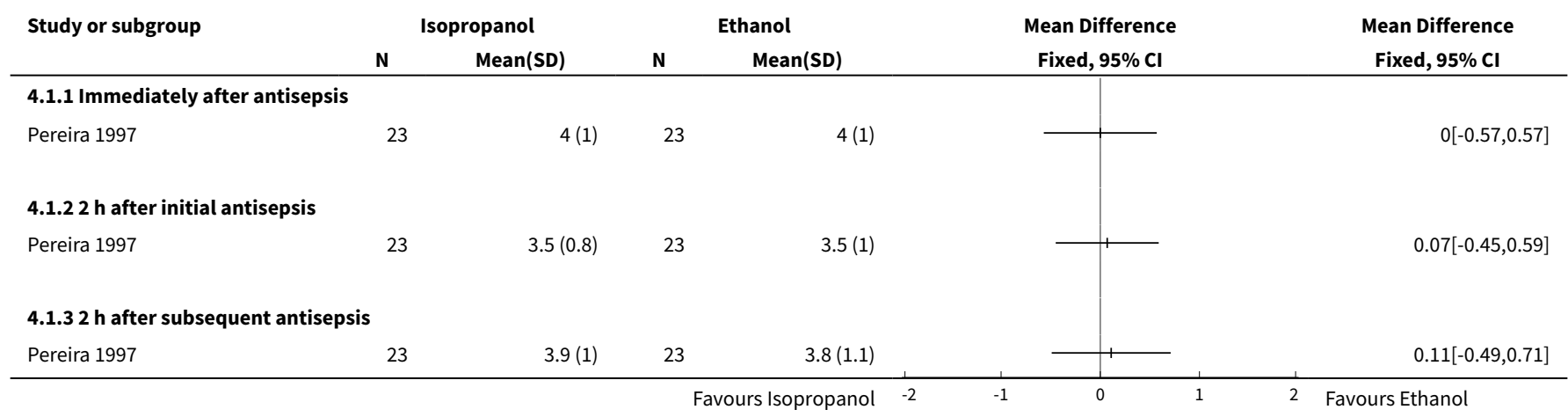

\section{Comparison 5. scrub versus alcohol-only rub}

\begin{tabular}{lllll}
\hline $\begin{array}{l}\text { Outcome or subgroup } \\
\text { title }\end{array}$ & $\begin{array}{l}\text { No. of } \\
\text { studies }\end{array}$ & $\begin{array}{l}\text { No. of partici- } \\
\text { pants }\end{array}$ & Statistical method & Effect size \\
\hline $1 \mathrm{SSI}$ & 1 & 500 & Risk Ratio (M-H, Fixed, 95\% Cl) & $0.56[0.23,1.34]$ \\
\hline
\end{tabular}

Analysis 5.1. Comparison 5 scrub versus alcohol-only rub, Outcome 1 SSI.

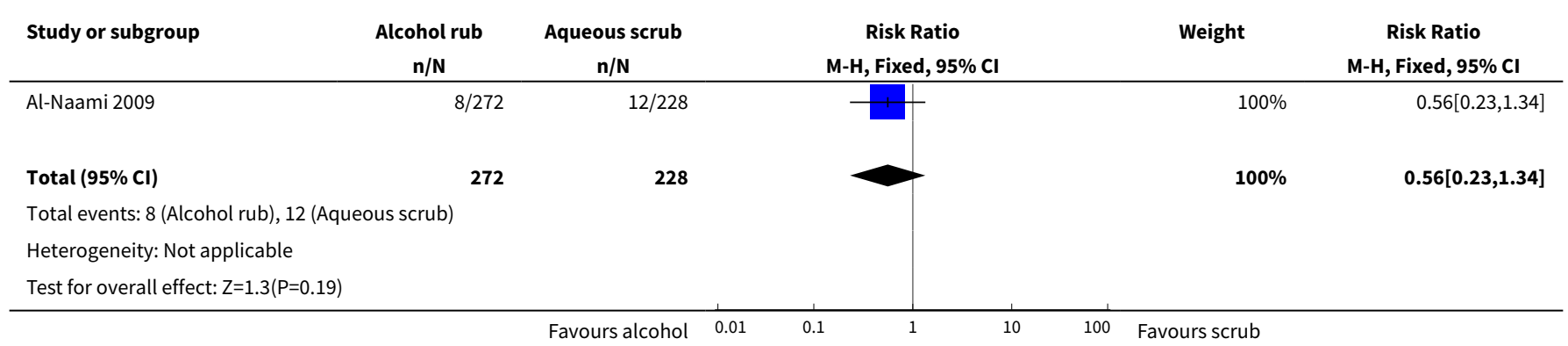


Comparison 6. scrub versus alcohol rub

\begin{tabular}{llll}
\hline $\begin{array}{l}\text { Outcome or subgroup ti- } \\
\text { tle }\end{array}$ & $\begin{array}{l}\text { No. of } \\
\text { studies }\end{array}$ & $\begin{array}{l}\text { No. of partici- } \\
\text { pants }\end{array}$ & Statistical method \\
\hline $1 \mathrm{SSI}$ & 2 & Risk Ratio (M-H, Fixed, 95\% Cl) \\
\hline
\end{tabular}

Analysis 6.1. Comparison 6 scrub versus alcohol rub, Outcome 1 SSI.

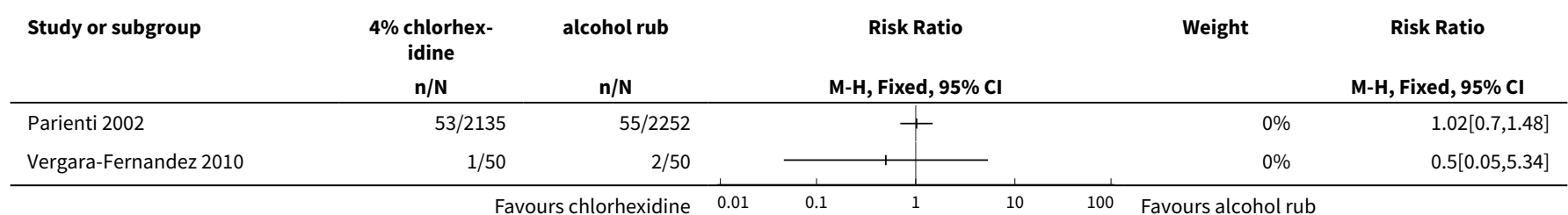

Comparison 7. scrub (chlorhexidine) versus alcohol rub + additional ingredient

\begin{tabular}{llllll}
\hline Outcome or subgroup title & $\begin{array}{l}\text { No. of } \\
\text { studies }\end{array}$ & $\begin{array}{l}\text { No. of } \\
\text { partici- } \\
\text { pants }\end{array}$ & Statistical method & Effect size \\
\hline 1 CFUs & 1 & Mean Difference (IV, Fixed, 95\% Cl) & Totals not selected \\
\hline 1.1 Immediately after antisepsis & 1 & Mean Difference (IV, Fixed, 95\% Cl) & $0.0[0.0,0.0]$ \\
\hline 1.2 After surgical procedure & 1 & Mean Difference (IV, Fixed, $95 \% \mathrm{Cl})$ & $0.0[0.0,0.0]$ \\
\hline
\end{tabular}

Analysis 7.1. Comparison 7 scrub (chlorhexidine) versus alcohol rub + additional ingredient, Outcome 1 CFUs.

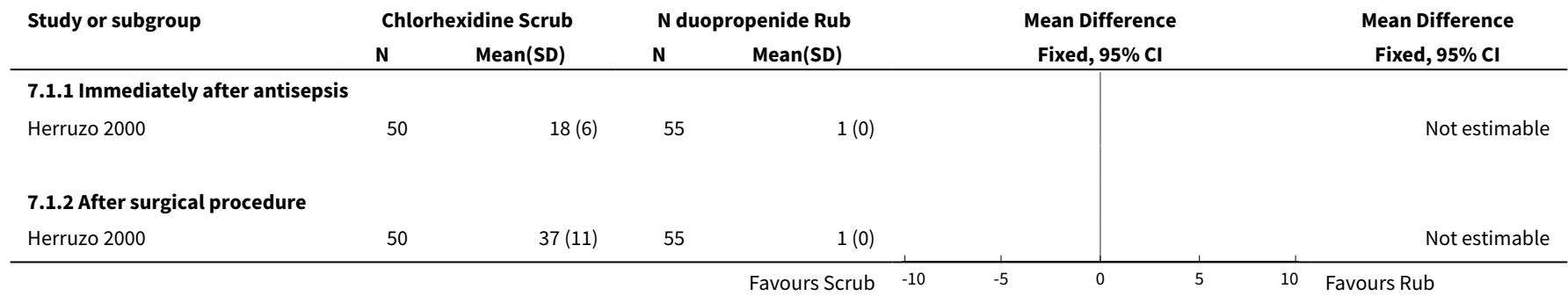

Comparison 8. scrub (povidone iodine) versus alcohol rub + additional ingredient

\begin{tabular}{lllll}
\hline Outcome or subgroup title & $\begin{array}{l}\text { No. of } \\
\text { studies }\end{array}$ & $\begin{array}{l}\text { No. of } \\
\text { partici- } \\
\text { pants }\end{array}$ & Statistical method & Effect size \\
\hline 1 CFUs & 1 & Mean Difference (IV, Fixed, 95\% CI) & Totals not selected \\
\hline
\end{tabular}




\begin{tabular}{lllll}
\hline Outcome or subgroup title & $\begin{array}{l}\text { No. of } \\
\text { studies }\end{array}$ & $\begin{array}{l}\text { No. of } \\
\text { partici- } \\
\text { pants }\end{array}$ & Statistical method & Effect size \\
\hline 1.1 Immediately after antisepsis & 0 & Mean Difference (IV, Fixed, 95\% Cl) & $0.0[0.0,0.0]$ & $0.0[0.0,0.0]$ \\
\hline 1.2 After surgical procedure & 1 & Mean Difference (IV, Fixed, 95\% Cl) & 0.000 \\
\hline
\end{tabular}

Analysis 8.1. Comparison 8 scrub (povidone iodine) versus alcohol rub + additional ingredient, Outcome 1 CFUs.

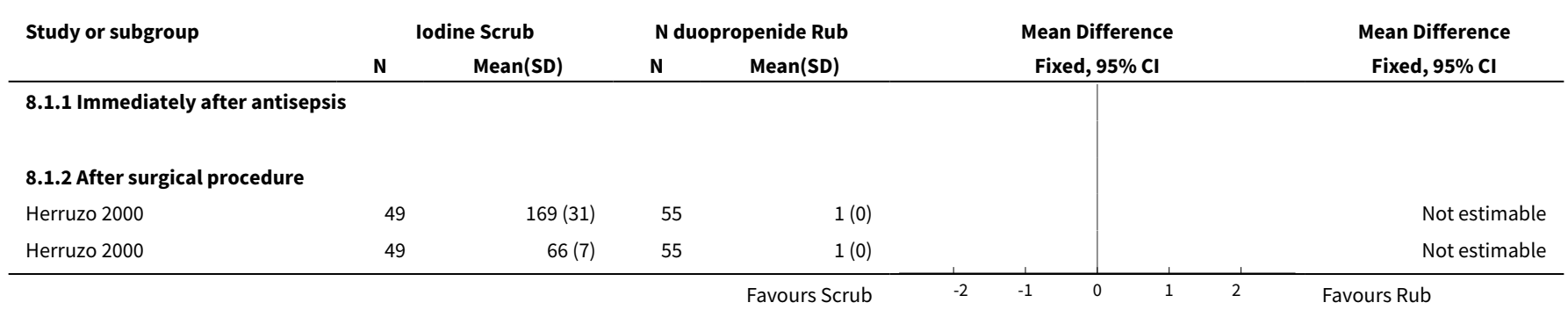

Comparison 9. scrub (chlorhexidine) versus rub + additional ingredient

\begin{tabular}{lllll}
\hline Outcome or subgroup title & $\begin{array}{l}\text { No. of } \\
\text { studies }\end{array}$ & $\begin{array}{l}\text { No. of } \\
\text { partici- } \\
\text { pants }\end{array}$ & Statistical method & Effect size \\
\hline 1 CFUs & 1 & Mean Difference (IV, Fixed, 95\% Cl) & Totals not selected \\
\hline 1.1 Immediately after antisepsis & 1 & Mean Difference (IV, Fixed, 95\% Cl) & $0.0[0.0,0.0]$ \\
\hline 1.2 After surgical procedure & 1 & Mean Difference (IV, Fixed, 95\% Cl) & $0.0[0.0,0.0]$ \\
\hline
\end{tabular}

Analysis 9.1. Comparison 9 scrub (chlorhexidine) versus rub + additional ingredient, Outcome 1 CFUs.

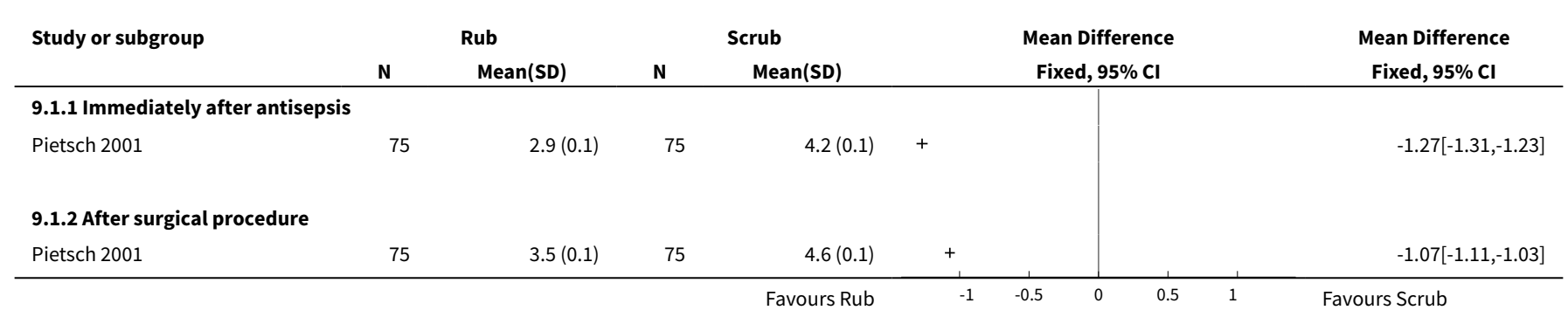


Comparison 10. scrub (chlorhexidine) versus alcohol rub + additional ingredient

\begin{tabular}{lllll}
\hline $\begin{array}{l}\text { Outcome or subgroup } \\
\text { title }\end{array}$ & $\begin{array}{l}\text { No. of } \\
\text { studies }\end{array}$ & $\begin{array}{l}\text { No. of partici- } \\
\text { pants }\end{array}$ & Statistical method & Effect size \\
\hline 1 CFUS & 1 & 53 & Mean Difference (IV, Fixed, 95\% Cl) & $-135.6[-153.39,-117.81]$ \\
\hline
\end{tabular}

Analysis 10.1. Comparison 10 scrub (chlorhexidine) versus alcohol rub + additional ingredient, Outcome 1 CFUs.

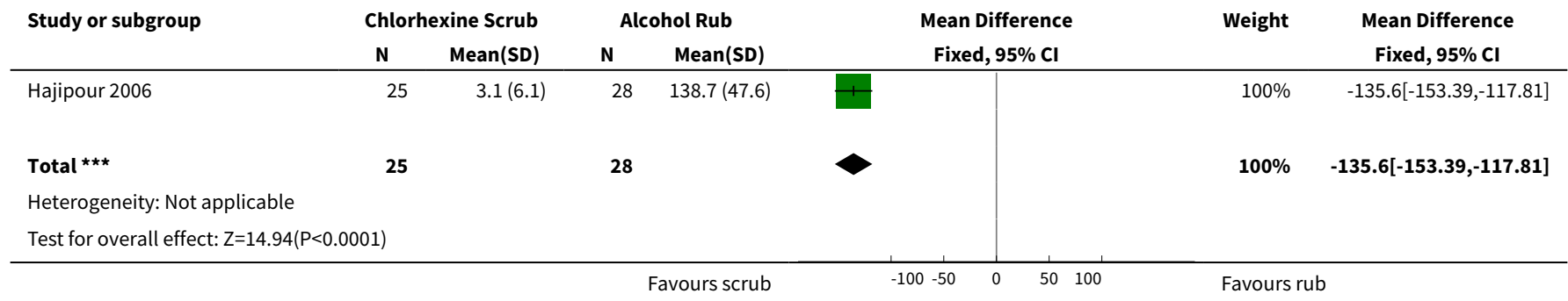

Comparison 11. duration - Kappstein ( 5 minutes versus 3 minutes)

\begin{tabular}{lllll}
\hline Outcome or subgroup title & $\begin{array}{l}\text { No. of } \\
\text { studies }\end{array}$ & $\begin{array}{l}\text { No. of par- } \\
\text { ticipants }\end{array}$ & Statistical method & Effect size \\
\hline 1 CFUs immediately after antisepsis & 1 & 48 & Mean Difference (IV, Fixed, 95\% Cl) & $0.26[0.14,0.38]$ \\
\hline
\end{tabular}

Analysis 11.1. Comparison 11 duration - Kappstein (5 minutes versus 3 minutes), Outcome 1 CFUs immediately after antisepsis.

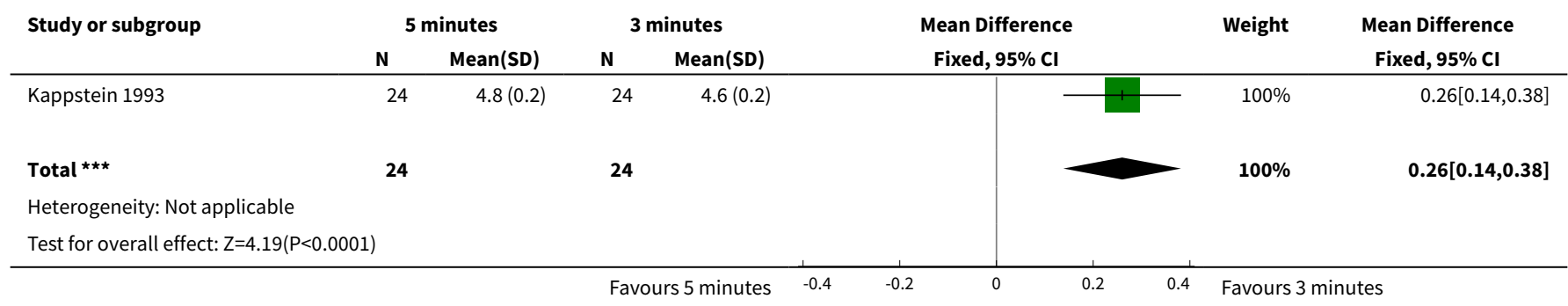

\section{Comparison 12. duration $-5+3$ min versus $3+0.5$ min with chlorhexidine)}

\begin{tabular}{lllll}
\hline Outcome or subgroup title & $\begin{array}{l}\text { No. of } \\
\text { studies }\end{array}$ & $\begin{array}{l}\text { No. of } \\
\text { partici- } \\
\text { pants }\end{array}$ & Statistical method & Effect size \\
\hline 1 CFUs & 1 & Mean Difference (IV, Fixed, 95\% Cl) & Totals not selected \\
\hline 1.1 Immediately after antisepsis & 1 & Mean Difference (IV, Fixed, 95\% Cl) & $0.0[0.0,0.0]$ \\
\hline
\end{tabular}




\begin{tabular}{llllll}
\hline Outcome or subgroup title & $\begin{array}{l}\text { No. of } \\
\text { studies }\end{array}$ & $\begin{array}{l}\text { No. of } \\
\text { partici- } \\
\text { pants }\end{array}$ & Statistical method & Effect size \\
\hline $1.22 \mathrm{~h}$ after initial antisepsis & 1 & Mean Difference (IV, Fixed, 95\% Cl) & $0.0[0.0,0.0]$ & $0.0[0.0,0.0]$ \\
\hline $1.32 \mathrm{~h}$ after subsequent antisepsis & 1 & Mean Difference (IV, Fixed, 95\% Cl) & 0.00 \\
\hline
\end{tabular}

Analysis 12.1. Comparison 12 duration $-5+3$ min versus $3+0.5 \mathrm{~min}$ with chlorhexidine), Outcome 1 CFUs.

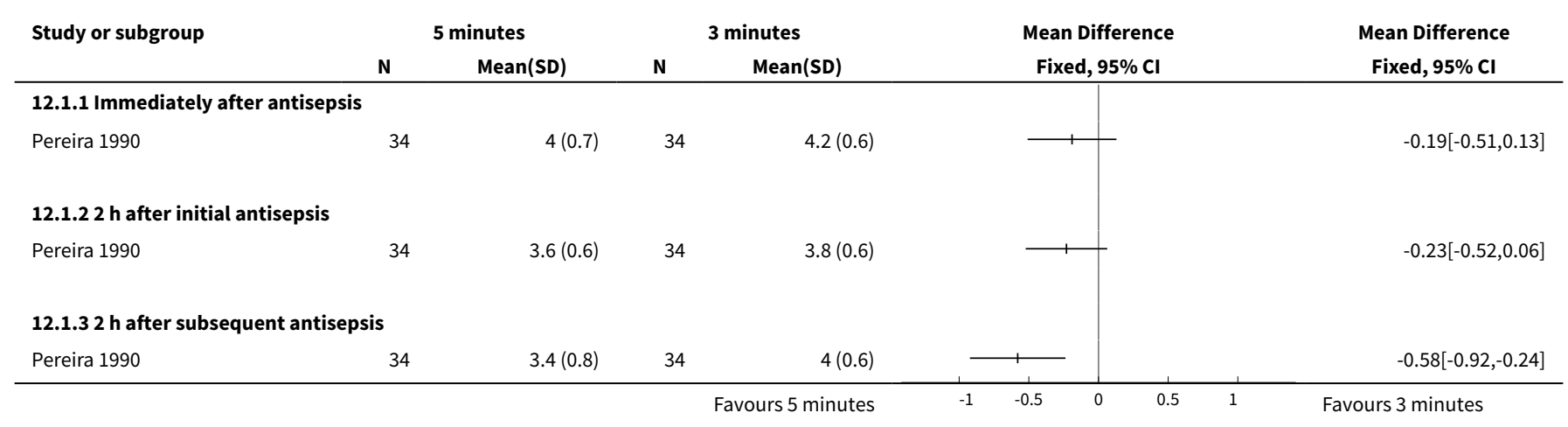

Comparison 13. duration $-5+3$ min versus $3+0.5$ minutes with iodine)

\begin{tabular}{lllll}
\hline Outcome or subgroup title & $\begin{array}{l}\text { No. of } \\
\text { studies }\end{array}$ & $\begin{array}{l}\text { No. of } \\
\text { partici- } \\
\text { pants }\end{array}$ & Statistical method & Effect size \\
\hline 1 CFUs & 1 & Mean Difference (IV, Fixed, 95\% Cl) & Totals not selected \\
\hline 1.1 Immediately after antisepsis & 1 & Mean Difference (IV, Fixed, 95\% Cl) & $0.0[0.0,0.0]$ \\
\hline 1.2 After initial antisepsis & 1 & Mean Difference (IV, Fixed, 95\% Cl) & $0.0[0.0,0.0]$ \\
\hline 1.32 h after subsequent antisepsis & 1 & Mean Difference (IV, Fixed, 95\% Cl) & $0.0[0.0,0.0]$ \\
\hline
\end{tabular}

Analysis 13.1. Comparison 13 duration $-5+3$ min versus $3+0.5$ minutes with iodine), Outcome 1 CFUs.

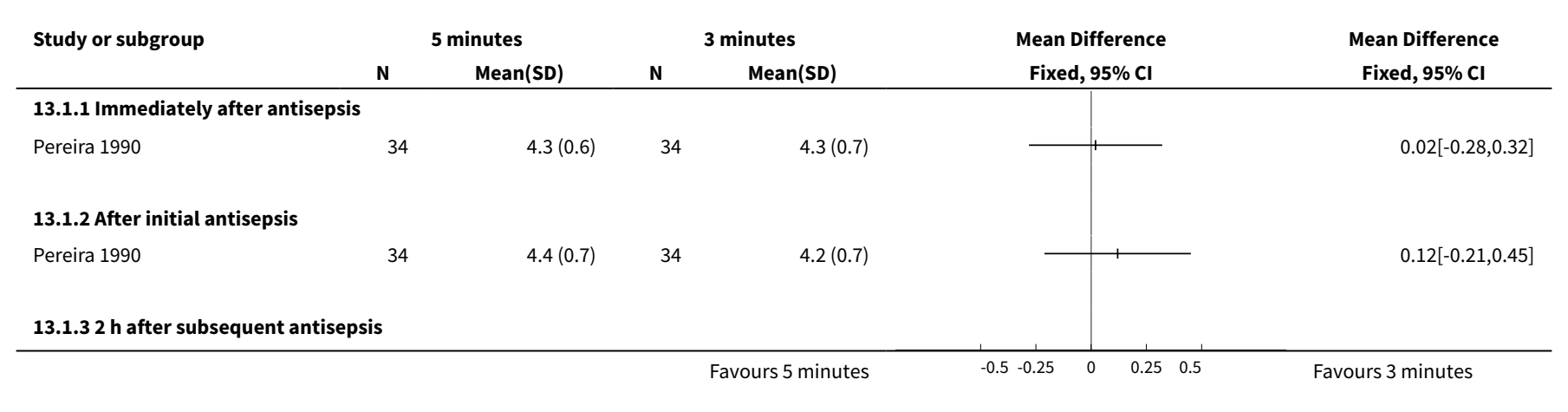




\begin{tabular}{|c|c|c|c|c|c|c|c|}
\hline \multirow{3}{*}{$\begin{array}{l}\text { Study or subgroup } \\
\text { Pereira } 1990\end{array}$} & \multicolumn{2}{|c|}{5 minutes } & \multicolumn{2}{|c|}{3 minutes } & \multirow{2}{*}{\multicolumn{2}{|c|}{$\begin{array}{c}\text { Mean Difference } \\
\text { Fixed, } 95 \% \mathrm{Cl}\end{array}$}} & \multirow{3}{*}{$\begin{array}{c}\begin{array}{c}\text { Mean Difference } \\
\text { Fixed, } 95 \% \text { Cl }\end{array} \\
-0.13[-0.37,0.11]\end{array}$} \\
\hline & \multirow{2}{*}{$\frac{\mathbf{N}}{34}$} & \multirow{2}{*}{$\frac{\text { Mean(SD) }}{4.5(0.5)}$} & \multirow{2}{*}{$\frac{\mathbf{N}}{34}$} & \multirow{2}{*}{$\frac{\text { Mean(SD) }}{4.7(0.5)}$} & & & \\
\hline & & & & & 1 & + & \\
\hline & & & & urs 5 minutes & $-0.5-0.25$ & $0.25 \quad 0.5$ & Favours 3 minutes \\
\hline
\end{tabular}

Comparison 14. duration - $5+3.5$ min versus $3+2.5$ min chlorhexidine)

\begin{tabular}{lllll}
\hline Outcome or subgroup title & $\begin{array}{l}\text { No. of } \\
\text { studies }\end{array}$ & $\begin{array}{l}\text { No. of } \\
\text { partici- } \\
\text { pants }\end{array}$ & Statistical method & Effect size \\
\hline 1 CFUs & 1 & Mean Difference (IV, Fixed, 95\% Cl) & Totals not selected \\
\hline 1.1 Immediately after antisepsis & 1 & Mean Difference (IV, Fixed, 95\% Cl) & $0.0[0.0,0.0]$ \\
\hline 1.22 h after initial antisepsis & 1 & Mean Difference (IV, Fixed, 95\% Cl) & $0.0[0.0,0.0]$ \\
\hline $1.32 \mathrm{~h}$ after subsequent antisepsis & 1 & Mean Difference (IV, Fixed, 95\% Cl) & $0.0[0.0,0.0]$ \\
\hline
\end{tabular}

Analysis 14.1. Comparison 14 duration - $5+3.5$ min versus $3+2.5$ min chlorhexidine), Outcome 1 CFUs.

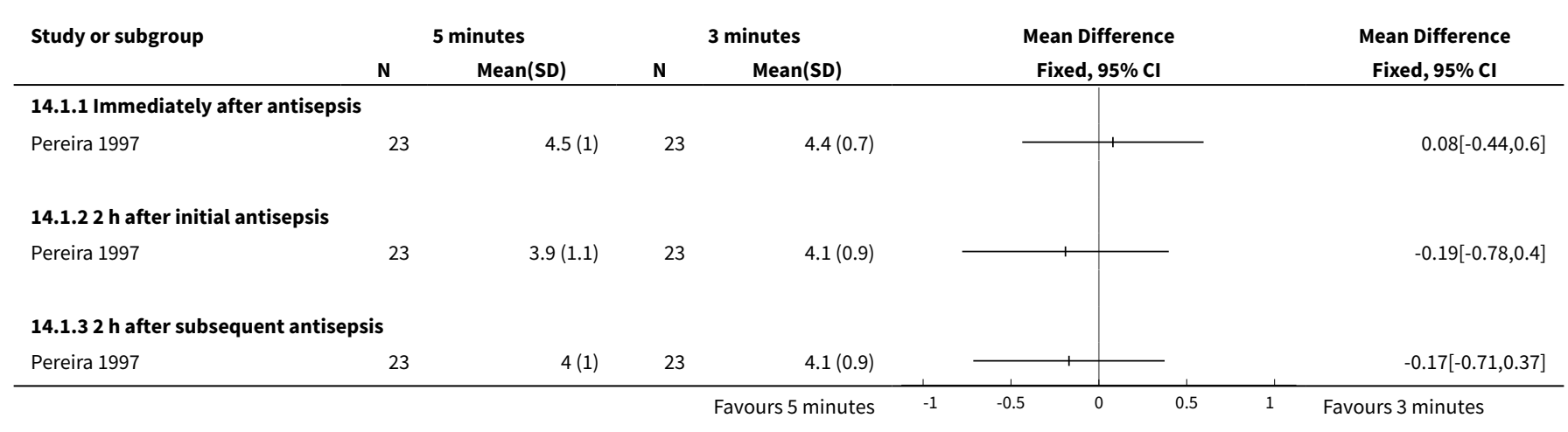

\section{Comparison 15. scrub versus scrub plus brush}

\begin{tabular}{lllll}
\hline $\begin{array}{l}\text { Outcome or subgroup } \\
\text { title }\end{array}$ & $\begin{array}{l}\text { No. of } \\
\text { studies }\end{array}$ & $\begin{array}{l}\text { No. of partici- } \\
\text { pants }\end{array}$ & Statistical method & Effect size \\
\hline 1 CFUS & 1 & 108 & Mean Difference (IV, Fixed, 95\% Cl) & $0.24[-0.03,0.51]$ \\
\hline
\end{tabular}


Analysis 15.1. Comparison 15 scrub versus scrub plus brush, Outcome 1 CFUS.

\begin{tabular}{|c|c|c|c|c|c|c|c|c|}
\hline \multirow[t]{2}{*}{ Study or subgroup } & \multicolumn{2}{|c|}{ Experimental } & \multicolumn{2}{|c|}{ Control } & \multirow{2}{*}{\multicolumn{2}{|c|}{$\begin{array}{c}\text { Mean Difference } \\
\text { Fixed, } 95 \% \mathrm{Cl} \\
\end{array}$}} & \multirow[t]{2}{*}{ Weight } & \multirow{2}{*}{$\begin{array}{c}\text { Mean Difference } \\
\text { Fixed, } 95 \% \mathrm{Cl} \\
\end{array}$} \\
\hline & $\mathbf{N}$ & $\operatorname{Mean}(S D)$ & $\mathbf{N}$ & Mean(SD) & & & & \\
\hline Tanner 2009 & 54 & $3.1(0.7)$ & 54 & $2.9(0.7)$ & & I & $100 \%$ & $0.24[-0.03,0.51]$ \\
\hline 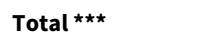 & 54 & & 54 & & & & $100 \%$ & $0.24[-0.03,0.51]$ \\
\hline \multicolumn{9}{|c|}{ Heterogeneity: $\mathrm{Tau}^{2}=0 ; \mathrm{Chi}^{2}=0, \mathrm{df}=0(\mathrm{P}<0.0001) ;\left.\right|^{2}=100 \%$} \\
\hline \multicolumn{9}{|c|}{ Test for overall effect: $\mathrm{Z}=1.77(\mathrm{P}=0.08)$} \\
\hline
\end{tabular}

Comparison 16. scrub versus scrub plus nail pick

\begin{tabular}{lllll}
\hline $\begin{array}{l}\text { Outcome or subgroup } \\
\text { title }\end{array}$ & $\begin{array}{l}\text { No. of } \\
\text { studies }\end{array}$ & $\begin{array}{l}\text { No. of partici- } \\
\text { pants }\end{array}$ & Statistical method & Effect size \\
\hline 1 CFUs & 1 & 108 & Mean Difference (IV, Fixed, 95\% Cl) & $0.13[-0.14,0.40]$ \\
\hline
\end{tabular}

Analysis 16.1. Comparison 16 scrub versus scrub plus nail pick, Outcome 1 CFUs.

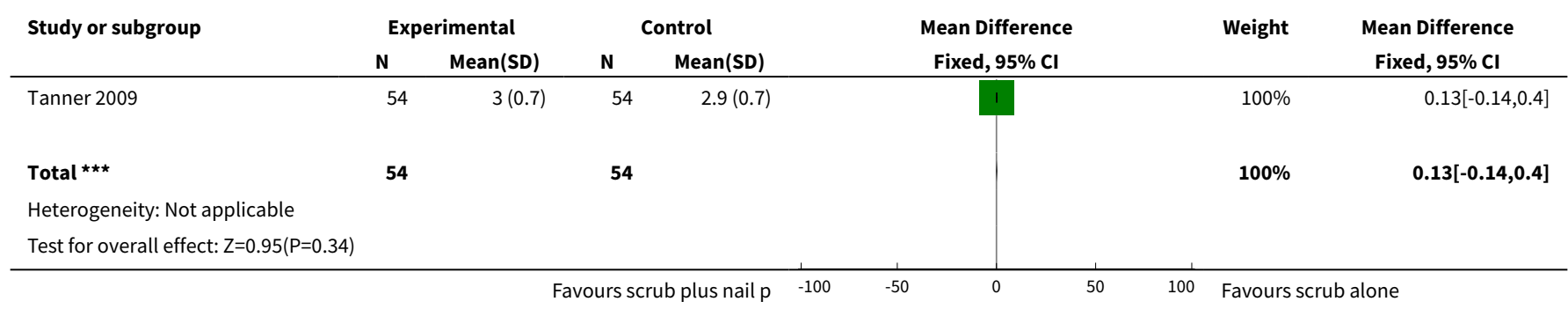

\section{Comparison 17. scrub plus brush versus scrub plus nail pick}

\begin{tabular}{lllll}
\hline $\begin{array}{l}\text { Outcome or subgroup } \\
\text { title }\end{array}$ & $\begin{array}{l}\text { No. of } \\
\text { studies }\end{array}$ & $\begin{array}{l}\text { No. of partici- } \\
\text { pants }\end{array}$ & Statistical method & Effect size \\
\hline 1 CFUS & 1 & 108 & Mean Difference (IV, Fixed, 95\% CI) & $0.11[-0.16,0.38]$ \\
\hline
\end{tabular}

Analysis 17.1. Comparison 17 scrub plus brush versus scrub plus nail pick, Outcome 1 CFUs.

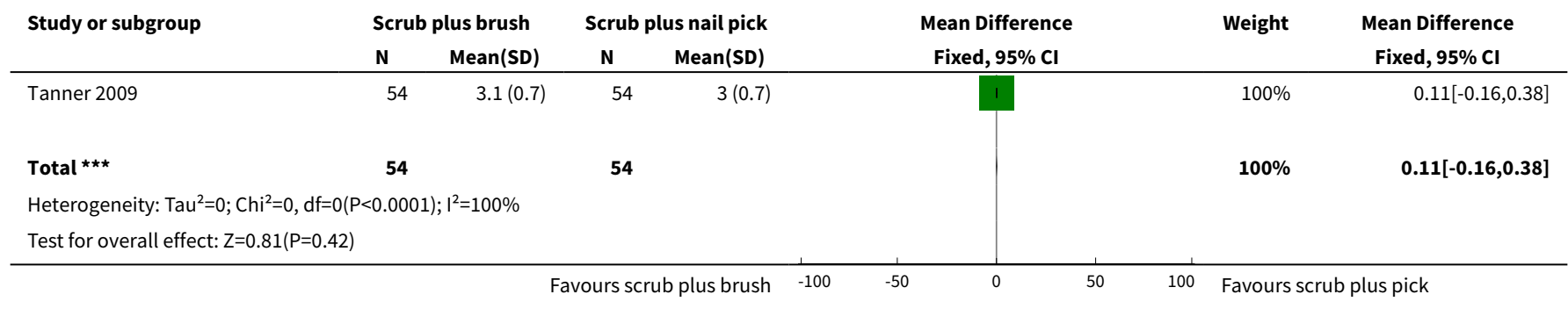


ADDITIONAL TABLES 
Table 1. Overview of included studies

\section{Trial arms}

Study

12

2

34

4

$5 \quad$ Country

Trial involved

SSI

CFU

Al-Naami 2009

Aqueous

Alcohol rub

NA

NA

NA

Saudi

$\mathrm{n}=600$ patients (data on 500 )

scrub

Arabia

Clea

Clean and

clean-contam-

inated opera-

tions. Mainly

abdominal.

\begin{tabular}{lllllllllllllll}
\hline Furukawa 2005 & Aqueous & Aqueous scrub & NA & NA & NA & Japan & $\#$
\end{tabular}

$n=22$ operating nurses

scrub

mmediately after antisepsis;

glove juice method

\begin{tabular}{|c|c|c|c|c|c|c|c|c|c|}
\hline Gupta 2007 & $\begin{array}{l}\text { Aqueous } \\
\text { scrub }\end{array}$ & $\begin{array}{l}\text { Alcohol rub + ac- } \\
\text { tive ingredient }\end{array}$ & NA & NA & NA & USA & $\checkmark$ & $\#$ & $\checkmark$ \\
\hline$n=22$ operating staff & & & & & & & $\begin{array}{l}\text { Ophthalmic, } \\
\text { podiatric and } \\
\text { general surgery }\end{array}$ & & $\begin{array}{l}\text { Before antisepsis } \\
\text { and immediately af- } \\
\text { ter antisepsis on day } \\
1 \text {, after } 6 \text { hours on } \\
\text { days } 2 \text { and 5; }\end{array}$ \\
\hline
\end{tabular}

glove juice method

\begin{tabular}{|c|c|c|c|c|c|c|c|c|c|}
\hline $\begin{array}{l}\text { Hajipour } 2006 \\
n=4 \text { surgeons (randomised } \\
\text { and tested } 53 \text { times) }\end{array}$ & $\begin{array}{l}\text { Aqueous } \\
\text { scrub }\end{array}$ & $\begin{array}{l}\text { Alcohol rub + ac- } \\
\text { tive ingredient }\end{array}$ & $\begin{array}{l}\text { alcohol } \\
\text { rub }+ \text { ac- } \\
\text { tive in- } \\
\text { gredient }\end{array}$ & NA & NA & UK & $\begin{array}{l}\# \\
\text { Trauma }\end{array}$ & $\#$ & $\begin{array}{l}\checkmark \\
\text { At the end of the sur- } \\
\text { gical procedure; }\end{array}$ \\
\hline
\end{tabular}

glove juice method

\begin{tabular}{|c|c|c|c|c|c|c|c|c|c|}
\hline Herruzo 2000 & Aqueous & Aqueous scrub & NA & NA & NA & Spain & $\checkmark$ & $\#$ & $\checkmark$ \\
\hline $\mathrm{n}=154$ surgical staff & & & & & & & $\begin{array}{l}\text { Plastic surgery } \\
\text { and traumatol- } \\
\text { ogy }\end{array}$ & & $\begin{array}{l}\text { Before antisepsis, } \\
\text { immediately after } \\
\text { antisepsis and at the } \\
\text { end of the surgical } \\
\text { procedure; }\end{array}$ \\
\hline
\end{tabular}




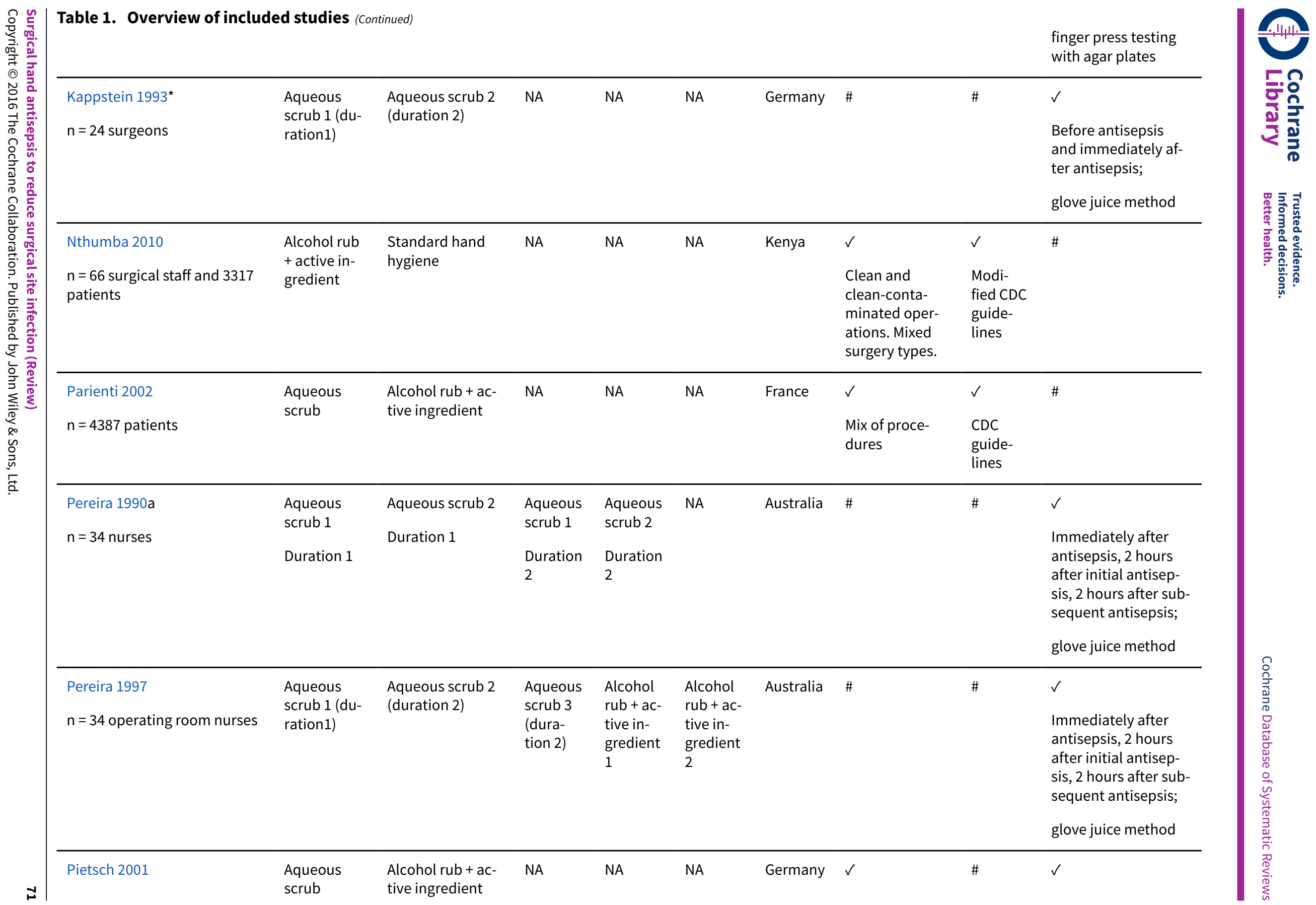




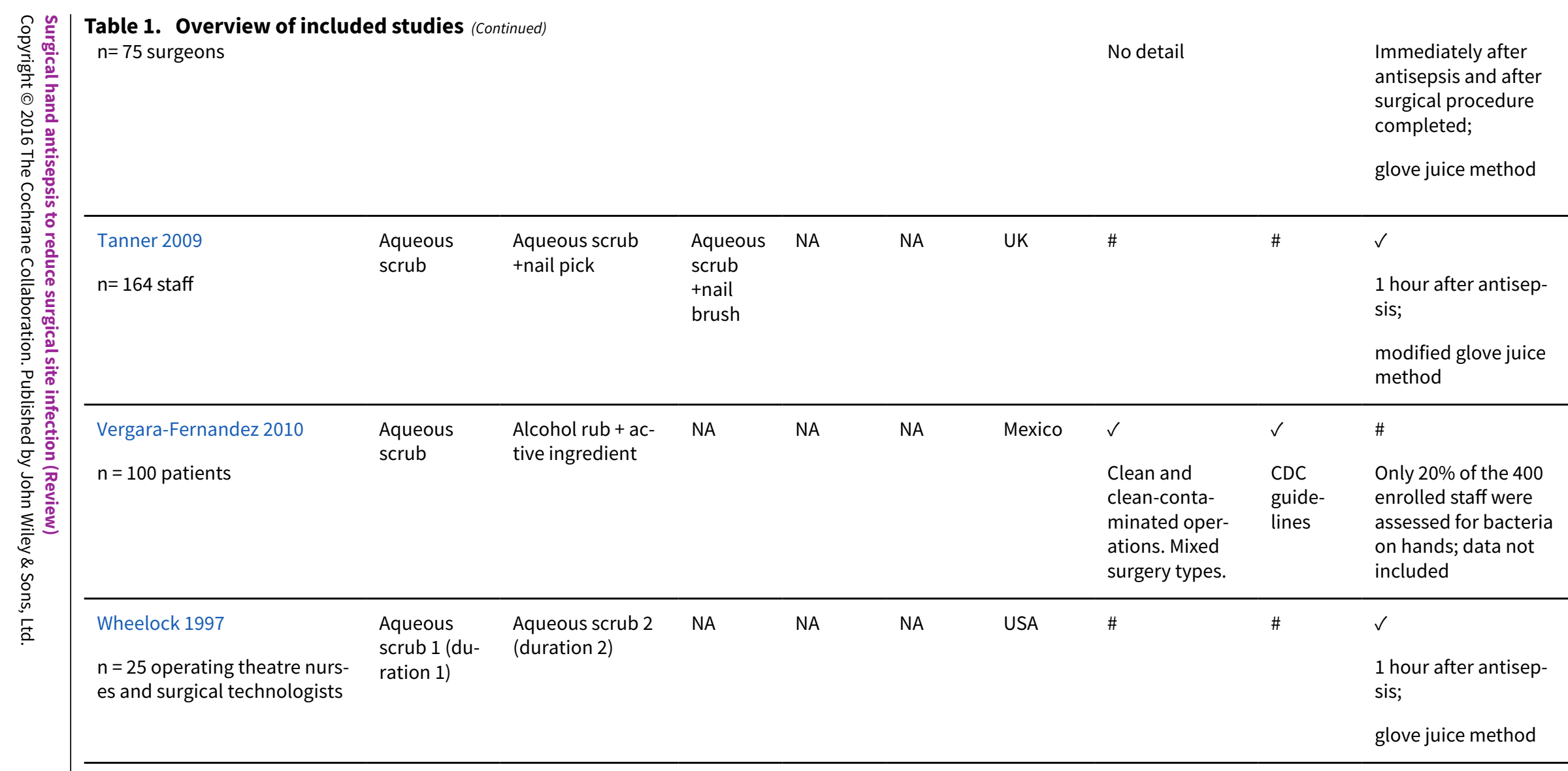

NA: not applicable 


\section{APPENDICES}

\section{Appendix 1. Search methods used in previous versions}

Original review (2007)

- Cochrane Wounds Group Specialised Register (Searched 12 June 2007);

- The Cochrane Central Register of Controlled Trials (CENTRAL) (The Cochrane Library 2007, Issue 2);

- Ovid MEDLINE (2005 to May Week 5 2007);

- Ovid EMBASE (2005 to 2007 Week 23);

- Ovid CINAHL (2005 to June Week 2 2007);

- ZETOC database of conference proceedings was searched from 1993 to 2005.

The following search strategy was used for searching CENTRAL:

$1 \mathrm{MeSH}$ descriptor Surgical Wound Infection explode all trees

2 surgical NEAR infection ${ }^{*}$

3 surgical NEAR wound*

4 (post-operative or postoperative) NEAR (wound NEXT infection*)

$5 \mathrm{MeSH}$ descriptor Preoperative Care explode all trees

$6 \mathrm{MeSH}$ descriptor Perioperative Care explode all trees

7 preoperative or pre-operative

8 (\#1 OR \#2 OR \#3 OR \#4 OR \#5 OR \#6 OR \#7)

$9 \mathrm{MeSH}$ descriptor Skin explode all trees

$10 \mathrm{MeSH}$ descriptor Antisepsis explode all trees

11 (\#9 AND \#10)

12 antisepsis

$13 \mathrm{MeSH}$ descriptor lodine explode all trees

$14 \mathrm{MeSH}$ descriptor lodophors explode all trees

$15 \mathrm{MeSH}$ descriptor Povidone-lodine explode all trees

$16 \mathrm{MeSH}$ descriptor Chlorhexidine explode all trees

$17 \mathrm{MeSH}$ descriptor Alcohols explode all trees

$18 \mathrm{MeSH}$ descriptor Soaps explode all trees

$19 \mathrm{MeSH}$ descriptor Detergents explode all trees

$20 \mathrm{MeSH}$ descriptor Disinfection explode all trees

21 iodophor ${ }^{\star}$ or povidone-iodine or betadine or chlorhexidine or

alcohol or alcohols or antiseptic ${ }^{\star}$ or soap ${ }^{\star}$ or detergent ${ }^{\star}$ or disinfect*

22 (\#11 OR \#12 OR\#13 OR\#14 OR\#15 OR\#16 OR\#17 OR \#18 OR \#19 OR

\#20 OR \#21)

$23 \mathrm{MeSH}$ descriptor Handwashing explode all trees

24 hand or hands or handwash* or surgical scrub*)

25 (\#23 OR \#24)

26 (\#8 AND \#22 AND \#25)

\section{Appendix 2. Ovid MEDLINE search strategy}

1 exp Surgical Wound Infection/

2 exp Surgical Wound Dehiscence/

3 (surg* $^{\star}$ adj5 infect*).tw.

4 ( surg $^{\star}$ adj5 wound $\left.{ }^{\star}\right)$.tw.

5 (surg* adj5 site*).tw.

6 (surg* adj 5 incision $\left.^{\star}\right)$.tw.

7 (surg $^{\star}$ adj5 dehiscen $\left.{ }^{\star}\right)$.tw.

8 ((post-operative or postoperative) adj5 wound infection $\left.{ }^{\star}\right)$.tw.

9 exp Preoperative Care/

10 exp Perioperative Care/

11 ((preoperative or pre-operative) adj care).tw.

12 or/1-11

13 exp Skin/

14 exp Antisepsis/

15 and/13-14 
16 skin antisep*.tw.

17 exp Anti-Infective Agents, Local/

18 exp lodophors/

19 exp Povidone-lodine/

20 exp Chlorhexidine/

21 exp Alcohols/

22 exp Soaps/

23 (iodophor $^{\star}$ or povidone-iodine or betadine or chlorhexidine or triclosan or hexachlorophene or benzalkonium or alcohol or alcohols or antiseptic* or soap ${ }^{\star}$ ).tw.

24 exp Disinfectants/

2513 and 24

26 (skin adj5 disinfect $\left.{ }^{\star}\right)$.tw.

27 exp Detergents/

2813 and 27

29 (skin adj5 detergent $\left.{ }^{\star}\right)$.tw.

30 or/15-23,25-26,28-29

31 exp Handwashing/

32 exp Hand/

33 (hand or hands or handwash* or surgical scrub*).tw.

34 or/31-33

3512 and 30 and 34

\section{Appendix 3. Ovid EMBASE search strategy}

1 exp Surgical Wound Infection/

2 exp Surgical Wound Dehiscence/

3 ( surg $^{\star}$ adj5 infect $\left.{ }^{\star}\right)$.tw.

4 (surg* $^{\star}$ adj5 wound $\left.{ }^{\star}\right)$.tw.

5 (surg $^{\star}$ adj5 site $\left.{ }^{\star}\right)$.tw.

6 ( surg* $^{\star}$ adj5 incision $\left.{ }^{\star}\right)$.tw.

7 (surg* $^{\star}$ adj5 dehiscen $\left.{ }^{\star}\right)$.tw.

8 ((post-operative or postoperative) adj5 wound infection*).tw.

9 exp Preoperative Care/

10 exp Perioperative Care/

11 ((preoperative or pre-operative) adj care).tw.

12 or/1-11

13 exp Skin/

14 exp Antisepsis/

15 and/13-14

16 skin antisep*.tw.

17 exp Anti-Infective Agents, Local/

18 exp lodophors/

19 exp Povidone-lodine/

$20 \exp$ Chlorhexidine/

21 exp Alcohols/

22 exp Soaps/

23 (iodophor* or povidone-iodine or betadine or chlorhexidine or triclosan or hexachlorophene or benzalkonium or alcohol or alcohols or antiseptic* or soap $\left.{ }^{\star}\right)$.tw.

24 exp Disinfectants/

2513 and 24

26 (skin adj5 disinfect*).tw.

27 exp Detergents/

2813 and 27

29 (skin adj5 detergent $\left.{ }^{\star}\right)$.tw.

30 or/15-23,25-26,28-29

31 exp Handwashing/

32 exp Hand/

33 (hand or hands or handwash* or surgical scrub*).tw.

34 or/31-33

3512 and 30 and 34 


\section{Appendix 4. EBSCO CINAHL search strategy}

S32 S12 and S25 and S31

$\mathrm{S} 31 \mathrm{~S} 26$ or $\mathrm{S} 27$ or $\mathrm{S} 28$ or $\mathrm{S} 29$ or S30

S30 TI ( surgical scrub*) or AB ( surgical scrub*)

$\mathrm{S} 29 \mathrm{TI}$ ( hand or hands or handwash ${ }^{\star}$ ) or $\mathrm{AB}$ ( hand or hands or handwash*)

S28 (MH "Surgical Scrubbing")

S27 (MH "Hand+")

S26 (MH "Handwashing+")

$\mathrm{S} 25 \mathrm{~S} 13$ or $\mathrm{S} 14$ or $\mathrm{S} 15$ or $\mathrm{S} 16$ or $\mathrm{S} 17$ or $\mathrm{S} 18$ or $\mathrm{S} 19$ or $\mathrm{S} 20$ or $\mathrm{S} 23$ or $\mathrm{S} 24$

S24 TI skin N5 disinfect* or AB skin N5 disinfect*

S23 S21 and S22

S22 (MH "Skin+")

$\mathrm{S} 21$ (MH "Disinfectants")

S20 TI (iodophor* or povidone-iodine or betadine or chlorhexidine or triclosan or hexachlorophene or benzalkonium or alcohol or alcohols or antiseptic ${ }^{\star}$ or soap ${ }^{\star}$ or detergent ${ }^{\star}$ ) or AB ( iodophor ${ }^{\star}$ or povidone-iodine or betadine or chlorhexidine or triclosan or hexachlorophene or benzalkonium or alcohol or alcohols or antiseptic ${ }^{\star}$ or soap ${ }^{\star}$ or detergent ${ }^{\star}$ )

S19 (MH "Detergents+")

S18 (MH "Soaps")

S17 (MH "Alcohols+")

S16 (MH "Chlorhexidine")

S15 (MH "Povidone-lodine")

S14 (MH "lodine")

S13 $\mathrm{TI}$ antisepsis or AB antisepsis

$\mathrm{S} 12 \mathrm{~S} 1$ or $\mathrm{S} 2$ or S3 or S4 or S5 or S6 or S7 or S8 or S9 or S10 or S11

$\mathrm{S} 11 \mathrm{TI}$ ( preoperative care or pre-operative care) or AB ( preoperative care or pre-operative care)

S10 (MH "Perioperative Care+")

S9 (MH "Preoperative Care+")

S8 $\mathrm{TI}$ ( postoperative* N5 wound infection* OR post-operative* N5 wound infection* ) or AB ( postoperative* N5 wound infection* OR post-

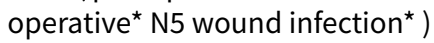

S7 TI surg* N5 dehiscen* or AB surg* N5 dehiscen*

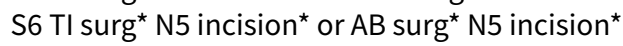

S5 TI surg ${ }^{\star}$ N5 site* or AB surg* N5 site*

S4 TI surg* N5 wound ${ }^{\star}$ or AB surg* N5 wound*

S3 TI surg* N5 infection* or AB surg* N5 infection*

S2 (MH "Surgical Wound Dehiscence")

S1 (MH "Surgical Wound Infection")

\section{Appendix 5. Risk of Bias assessment}

\section{Was the allocation sequence randomly generated?}

\section{Low risk of bias}

The investigators describe a random component in the sequence generation process, such as referring to a random number table; using a computer random number generator; tossing a coin; shuffling cards or envelopes; throwing dice; drawing of lots.

\section{High risk of bias}

The investigators describe a non-random component in the sequence generation process. Usually, the description would involve some systematic, non-random approach, for example, sequence generated by odd or even date of birth; sequence generated by some rule based on date (or day) of admission; sequence generated by some rule based on hospital or clinic record number.

\section{Unclear}

Insufficient information about the sequence generation process available to permit a judgement of low or high risk of bias.

\section{Was the treatment allocation adequately concealed?}

\section{Low risk of bias}

Participants and investigators enrolling participants could not foresee assignment because one of the following, or an equivalent method, was used to conceal allocation: central allocation (including telephone, web-based and pharmacy-controlled randomisation); sequentially numbered drug containers of identical appearance; sequentially numbered, opaque, sealed envelopes. 


\section{High risk of bias}

Participants or investigators enrolling participants could possibly foresee assignments and thus introduce selection bias, such as allocation based on using an open random allocation schedule (e.g. a list of random numbers); assignment envelopes were used without appropriate safeguards (e.g. if envelopes were unsealed or non-opaque or were not sequentially numbered); alternation or rotation; date of birth; case record number; any other explicitly unconcealed procedure.

\section{Unclear}

Insufficient information to permit judgement of low or high risk of bias. This is usually the case if the method of concealment is not described or is not described in sufficient detail to allow a definitive judgement, for example, if the use of assignment envelopes is described, but it remains unclear whether envelopes were sequentially numbered, opaque and sealed.

\section{Blinding (participants, personnel and outcome assessors) - was knowledge of the allocated interventions adequately prevented during the study?}

\section{Low risk of bias}

Any one of the following.

- No blinding, but the review authors judge that the outcome and the outcome measurement are not likely to be influenced by lack of blinding.

- Blinding of participants and key study personnel ensured, and unlikely that the blinding could have been broken.

- Either participants or some key study personnel were not blinded, but outcome assessment was blinded and the non-blinding of others is unlikely to introduce bias.

\section{High risk of bias}

Any one of the following.

- No blinding or incomplete blinding, and the outcome or outcome measurement is likely to be influenced by lack of blinding.

- Blinding of key study participants and personnel attempted, but likely that the blinding could have been broken.

- Either participants or some key study personnel were not blinded, and the non-blinding of others is likely to introduce bias.

\section{Unclear}

Either of the following.

- Insufficient information available to permit a judgement of low or high risk of bias.

- The study did not address this outcome.

\section{Were incomplete outcome data adequately addressed?}

\section{Low risk of bias}

Any one of the following.

- No missing outcome data.

- Reasons for missing outcome data unlikely to be related to true outcome (for survival data, censoring unlikely to be introducing bias).

- Missing outcome data balanced in numbers across intervention groups, with similar reasons for missing data across groups.

- For dichotomous outcome data, the proportion of missing outcomes compared with observed event risk not enough to have a clinically relevant impact on the intervention effect estimate.

- For continuous outcome data, plausible effect size (difference in means or standardised difference in means) among missing outcomes not enough to have a clinically relevant impact on observed effect size.

- Missing data have been imputed using appropriate methods.

\section{High risk of bias}

Any one of the following.

- Reason for missing outcome data likely to be related to true outcome, with imbalance in numbers or reasons for missing data across intervention groups.

- For dichotomous outcome data, the proportion of missing outcomes compared with observed event risk enough to induce clinically relevant bias in intervention effect estimate.

- For continuous outcome data, plausible effect size (difference in means or standardised difference in means) among missing outcomes enough to induce clinically relevant bias in observed effect size. 
- 'As-treated' analysis done with substantial departure of the intervention received from that assigned at randomisation.

- Potentially inappropriate application of simple imputation.

\section{Unclear}

Either of the following.

- Insufficient reporting of attrition/exclusions to permit judgement of low or high risk of bias (e.g. number randomised not stated, no reasons for missing data provided).

- The study did not address this outcome.

\section{Are reports of the study free of the suggestion of selective outcome reporting?}

\section{Low risk of bias}

Either of the following.

- The study protocol is available and all of the study's prespecified (primary and secondary) outcomes that are of interest in the review have been reported in the prespecified way.

- The study protocol is not available but it is clear that the published reports include all expected outcomes, including those that were prespecified (convincing text of this nature may be uncommon).

\section{High risk of bias}

Any one of the following.

- Not all of the study's prespecified primary outcomes have been reported.

- One or more primary outcomes are reported using measurements, analysis methods or subsets of the data (e.g. subscales) that were not prespecified.

- One or more reported primary outcomes were not prespecified (unless clear justification for their reporting is provided, such as an unexpected adverse effect).

- One or more outcomes of interest in the review are reported incompletely so that they cannot be entered in a meta-analysis.

- The study report fails to include results for a key outcome that would be expected to have been reported for such a study.

\section{Unclear}

Insufficient information available to permit judgement of low or high risk of bias. It is likely that the majority of studies will fall into this category.

\section{Other sources of potential bias}

\section{Low risk of bias}

The study appears to be free of other sources of bias.

\section{High risk of bias}

There is at least one important risk of bias. For example, the study:

- had a potential source of bias related to the specific study design used; or

- has been claimed to have been fraudulent; or

- had some other problem.

\section{Unclear}

There may be a risk of bias, but there is either:

- insufficient information to assess whether an important risk of bias exists; or

- insufficient rationale or evidence that an identified problem will introduce bias.

\section{FEE D B A C K}

\section{Enquiry about status of any ongoing trials, 11 August 2008}

\section{Summary}

The Authors conclusions' include suggestions for trials that are needed. Ecolab Ltd would like to know if any of the trials have or are being carried out? 
Submitter has modified conflict of interest statement: I certify that I have affiliations with an organisation or entity with a financial interest in the subject matter of my feedback.

\section{Reply}

Tanner conducted a randomised controlled trial in April to June 2008 comparing nail brushes and nail picks with 164 operating room staff. This study found no difference in the number of colony forming units on the hands of the scrub staff one hour after they had scrubbed with antiseptic solution and a nail pick, antiseptic solution and a nail brush or antiseptic solution alone. The authors of this review have not been informed of other studies in this field.

New searches have been conducted for this review which is currently being updated.

\section{Contributors}

Author of feedback: Alex Haworth Occupation Business Development Manager, Ecolab Ltd.

Review author: Judith Tanner

\section{WHAT'S NEW}

\begin{tabular}{lll}
\hline Date & Event & Description \\
\hline 11 January 2016 & $\begin{array}{l}\text { New citation required but conclusions } \\
\text { have not changed }\end{array}$ & $\begin{array}{l}\text { First update. New search. Four new trials. Conclusions un- } \\
\text { changed. }\end{array}$ \\
\hline 30 June 2015 & New search has been performed & $\begin{array}{l}\text { Risk of bias updated, Grade assessment undertaken. Revision of } \\
\text { Results to streamline text and introduction of new supporting ta- } \\
\text { ble to replace text. }\end{array}$ \\
\hline
\end{tabular}

\section{H I S T O R Y}

Protocol first published: Issue 3, 2003

Review first published: Issue 1, 2008

\begin{tabular}{lll}
\hline Date & Event & Description \\
\hline 26 August 2008 & Feedback has been incorporated & Response to enquiry regarding the status of ongoing trials. \\
\hline 8 August 2008 & Amended & Converted to new review format. \\
\hline 4 October 2007 & $\begin{array}{l}\text { New citation required and conclusions } \\
\text { have changed }\end{array}$ & Substantive amendment \\
\hline
\end{tabular}

\section{CONTRIBUTIONS OF AUTHORS}

Judith Tanner: conceived and designed the review; performed part of the data analysis and interpretation, writing and editing; made an intellectual contribution to and advised on the review; approved the final version before submission; performed previous work that was the foundation for the current review and wrote to study authors/experts/companies.

Jo Dumville: extracted data; analysed and interpreted data and checked quality assessment; performed statistical analysis; completed the first draft of the review, approved the final version prior to submission and is the guarantor of the review.

Gill Norman: checked quality of data extraction and analysed and interpreted data; checked quality assessment; checked quality of statistical analysis; performed part of writing and editing the review; and approved the final version before submission.

Matthew Fortnam: undertook quality assessment and approved the final version before submission. 


\section{Contributions of the editorial base}

For this update:

Joan Webster and Nicky Cullum (Editors) edited the protocol, advised on methodology, interpretation and content; approved the final review update prior to submission.

Sally Bell-Syer: co-ordinated the editorial process; advised on content; Gill Rizzello: edited the review update.

Rocio Rodriguez: designed the search strategy, ran the searches. Reetu Child edited the search methods section.

\section{DECLARATIONS OF INTEREST}

\section{Judith Tanner:}

Judith Tanner gave a lecture at two study days in 2013 for which her employer was paid an honorarium from Molnlycke HealthCare. Judith Tanner had no control of the funds. Molnlycke Healthcare produce a surgical hand antiseptic solution.

Judith Tanner gave a lecture at a study day in 2015 for which she was paid an honorarium from Molnlycke HealthCare. This money was later forwarded to her employer and Judith Tanner has no control of the funds. Molnlycke Healthcare produce a surgical hand antiseptic solution.

Judith Tanner gave a lecture at a study day in 2015 for which she was paid an honorarium from Smith and Nephew. Smith and Nephew do not make any products relevant to this review.

Jo Dumville: none known.

Gill Norman: my employment at the University of Manchester is funded by NIHR Cochrane programme Grant 13/89/08- High Priority Cochrane Reviews in Wound Prevention and Treatment.

Matthew Fortnam: none known.

\section{SOURCES OF SUPPORT}

\section{Internal sources}

- University of Nottingham, UK.

- School of Nursing, Midwifery and Social Work, University of Manchester, UK.

\section{External sources}

- National Institute for Health Research (NIHR), UK, UK.

This project was supported by the National Institute for Health Research, via Cochrane Infrastructure and Cochrane Programme Grant funding (NIHR Cochrane Programme Grant 13/89/08 - High Priority Cochrane Reviews in Wound Prevention and Treatment) to Cochrane Wounds. The views and opinions expressed therein are those of the authors and do not necessarily reflect those of the Systematic Reviews Programme, NIHR, NHS or the Department of Health.

\section{DIFFERENCES BETWEEN PROTOCOL AND REVIEW}

In this update we removed rates of septicaemia from the outcomes.

\section{N DEX TERMS}

\section{Medical Subject Headings (MeSH)}

${ }^{\star}$ General Surgery; Anti-Infective Agents, Local [ ${ }^{\star}$ administration \& dosage]; Antisepsis [ ${ }^{*}$ methods]; Colony Count, Microbial; Hand [ ${ }^{\star}$ microbiology]; Hand Disinfection [ ${ }^{*}$ methods]; Randomized Controlled Trials as Topic; Surgical Wound Infection [epidemiology] [* prevention \& control]

\section{MeSH check words}

Humans 